\title{
Group versus conventional antenatal care for women (Review)
}

\author{
Catling CJ, Medley N, Foureur M, Ryan C, Leap N, Teate A, Homer CSE
}

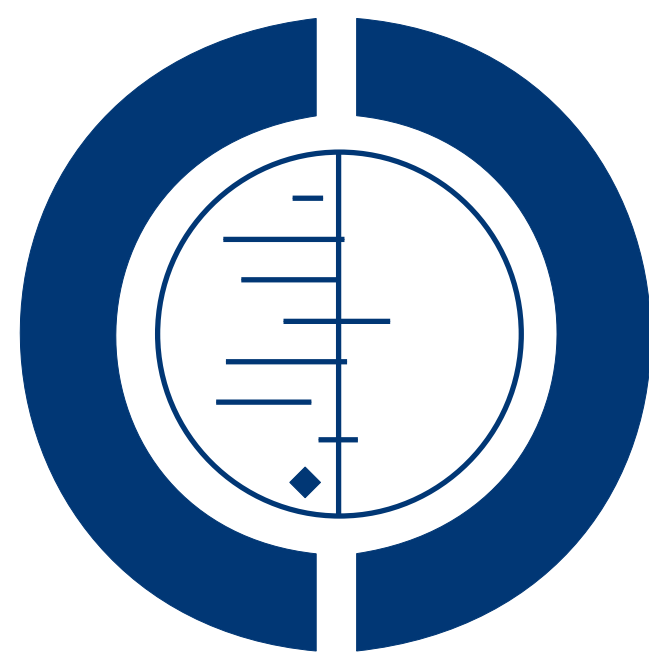

THE COCHRANE COLLABORATION $^{\circledR}$

This is a reprint of a Cochrane review, prepared and maintained by The Cochrane Collaboration and published in The Cochrane Library 2015, Issue 2

http://www.thecochranelibrary.com

\section{WILEY}


TABLE OF CONTENTS

HEADER . . . . . . . . . . . . . . . . . . . . . . . . . . . . . . . . . . . . . . . . . . . . .

ABSTRACT . . . . . . . . . . . . . . . . . . . . . . . . . . . . . . . . . . . . . . . . . . . . . . 1

PLAIN LANGUAGE SUMMARY . . . . . . . . . . . . . . . . . . . . . . . . . . . . . . . . . . . . . . . . . . . . .

SUMMARY OF FINDINGS FOR THE MAIN COMPARISON . . . . . . . . . . . . . . . . . . . . . . . . . . . . .

BACKGROUND . . . . . . . . . . . . . . . . . . . . . . . . . . . . . . . . . . . . . . . . . . . .

OBJECTIVES . . . . . . . . . . . . . . . . . . . . . . . . . . . . . . . . . . . . . . . . . . . . . .

METHODS . . . . . . . . . . . . . . . . . . . . . . . . . . . . . . . . . . . . . .

Figure 1. . . . . . . . . . . . . . . . . . . . . . . . . . . . . . . . . . . . . . . . 10

RESULTS . . . . . . . . . . . . . . . . . . . . . . . . . . . . . . . . . . . . . . . . . . .

DISCUSSION . . . . . . . . . . . . . . . . . . . . . . . . . . . . . . . . . . . . . . . . . . . . . .

AUTHORS' CONCLUSIONS . . . . . . . . . . . . . . . . . . . . . . . . . . . . . . . . . . . . . . . . . 19

ACKNOWLEDGEMENTS . . . . . . . . . . . . . . . . . . . . . . . . . . . . . . . . . . . . . . 19

REFERENCES . . . . . . . . . . . . . . . . . . . . . . . . . . . . . . . . . . . . . . 20

CHARACTERISTICS OF STUDIES . . . . . . . . . . . . . . . . . . . . . . . . . . . . . . . . . . . . . . .

DATA AND ANALYSES . . . . . . . . . . . . . . . . . . . . . . . . . . . . . . . . . . . . . . . . . . . . . . . . . .

Analysis 1.1. Comparison 1 Group antenatal care versus individual antenatal care (adjusted data), Outcome 1 Preterm birth. . . . . . . . . . . . . . . . . . . . . . . . . . . . . . . . 34

Analysis 1.2. Comparison 1 Group antenatal care versus individual antenatal care (adjusted data), Outcome 2 Gestational age. . . . . . . . . . . . . . . . . . . . . . . . . . . . . . . . . . . . . .

Analysis 1.3. Comparison 1 Group antenatal care versus individual antenatal care (adjusted data), Outcome 3 Low birthweight.

Analysis 1.4. Comparison 1 Group antenatal care versus individual antenatal care (adjusted data), Outcome 4 Small-forgestational age.

Analysis 1.5. Comparison 1 Group antenatal care versus individual antenatal care (adjusted data), Outcome 5 Perinatal mortality.

Analysis 1.6. Comparison 1 Group antenatal care versus individual antenatal care (adjusted data), Outcome 6 Birthweight.

Analysis 1.7. Comparison 1 Group antenatal care versus individual antenatal care (adjusted data), Outcome 7 Inadequate antenatal care.

Analysis 1.8. Comparison 1 Group antenatal care versus individual antenatal care (adjusted data), Outcome 8 Neonatal intensive care unit admission (not pre-specified). . . . . . . . . . . . . . . . . . . . . . . . . . .

Analysis 1.9. Comparison 1 Group antenatal care versus individual antenatal care (adjusted data), Outcome 9 Apgar at 5 minutes.

Analysis 1.10. Comparison 1 Group antenatal care versus individual antenatal care (adjusted data), Outcome 10 Breastfeeding initiation.

Analysis 1.11. Comparison 1 Group antenatal care versus individual antenatal care (adjusted data), Outcome 11 Antenatal knowledge.

Analysis 1.12. Comparison 1 Group antenatal care versus individual antenatal care (adjusted data), Outcome 12 Antenatal distress.

Analysis 1.13. Comparison 1 Group antenatal care versus individual antenatal care (adjusted data), Outcome 13 Readiness for labour and birth.

Analysis 1.14. Comparison 1 Group antenatal care versus individual antenatal care (adjusted data), Outcome 14 Readiness for infant care.

Analysis 1.15. Comparison 1 Group antenatal care versus individual antenatal care (adjusted data), Outcome 15 Satisfaction with antenatal care.

Analysis 1.16. Comparison 1 Group antenatal care versus individual antenatal care (adjusted data), Outcome 16 Induction of labour.

Analysis 1.17. Comparison 1 Group antenatal care versus individual antenatal care (adjusted data), Outcome 17 Augmentation using Syntocinon.

Analysis 1.18. Comparison 1 Group antenatal care versus individual antenatal care (adjusted data), Outcome 18 Other pain management. . . . . . . . . . . . . . . . . . . . . . . . . . . . . . . . . . . 47

Analysis 1.19. Comparison 1 Group antenatal care versus individual antenatal care (adjusted data), Outcome 19 Epidural. 
Analysis 1.20. Comparison 1 Group antenatal care versus individual antenatal care (adjusted data), Outcome 20 Episiotomy.

Analysis 1.21. Comparison 1 Group antenatal care versus individual antenatal care (adjusted data), Outcome 21 Spontaneous vaginal birth. . . . . . . . . . . . . . . . . . . . . . . . . . . . . . .

Analysis 1.22. Comparison 1 Group antenatal care versus individual antenatal care (adjusted data), Outcome 22 Caesarean section. . . . . . . . . . . . . . . . . . . . . . . . . . . . . . . . . . . . .

Analysis 1.23. Comparison 1 Group antenatal care versus individual antenatal care (adjusted data), Outcome 23 Operative vaginal birth. . . . . . . . . . . . . . . . . . . . . . . . . . . . . . . . . . . . . .

Analysis 1.24. Comparison 1 Group antenatal care versus individual antenatal care (adjusted data), Outcome 24 Depression using component of CES-D instrument in third trimester. $\quad . \quad$. $\quad . \quad$. $\quad . \quad$. . . . . . . . . . . . . . . . . .

Analysis 1.25. Comparison 1 Group antenatal care versus individual antenatal care (adjusted data), Outcome 25 Depression using component of CES-D instrument 6 months' postpartum. $\quad . \quad$. . . . . . . . . . . . . . . . . . . . .

Analysis 1.26. Comparison 1 Group antenatal care versus individual antenatal care (adjusted data), Outcome 26 Depression using component of CES-D instrument 12 months' postpartum. . . . . . . . . . . . . . . . . . . . .

Analysis 1.27. Comparison 1 Group antenatal care versus individual antenatal care (adjusted data), Outcome 27 Stress using PSS at 6 months' postpartum. . . . . . . . . . . . . . . . . . . . . . . . . . . . . . . .

Analysis 1.28. Comparison 1 Group antenatal care versus individual antenatal care (adjusted data), Outcome 28 Stress using PSS at 12 months' postpartum. . . . . . . . . . . . . . . . . . . . . . . . . . . . . . . . . . . . .

Analysis 1.30. Comparison 1 Group antenatal care versus individual antenatal care (adjusted data), Outcome 30 Attendance at antenatal care (number of sessions). . . . . . . . . . . . . . . . . . . . . . . . . . 54

ADDITIONAL TABLES . . . . . . . . . . . . . . . . . . . . . . . . . . . . . . . . . . . 54

WHAT'S NEW . . . . . . . . . . . . . . . . . . . . . . . . . . . . . . . . . . . . . 55

CONTRIBUTIONS OF AUTHORS . . . . . . . . . . . . . . . . . . . . . . . . . . . . . . . . . . . . . . . 56

DECLARATIONS OF INTEREST . . . . . . . . . . . . . . . . . . . . . . . . . . . . . . . . . . . . . . . $\quad . \quad 56$

SOURCES OF SUPPORT . . . . . . . . . . . . . . . . . . . . . . . . . . . . . . . . . . . . . . 56

DIFFERENCES BETWEEN PROTOCOL AND REVIEW . . . . . . . . . . . . . . . . . . . . . 57

INDEX TERMS . . . . . . . . . . . . . . . . . . . . . . . . . . . . . . . . . . . . 57

Group versus conventional antenatal care for women (Review) 


\title{
[Intervention Review]
}

\section{Group versus conventional antenatal care for women}

\author{
Christine J Catling ${ }^{1}$, Nancy Medley ${ }^{2}$, Maralyn Foureur ${ }^{1}$, Clare Ryan ${ }^{1}$, Nicky Leap ${ }^{1}$, Alison Teate ${ }^{1}$, Caroline SE Homer ${ }^{1}$ \\ ${ }^{1}$ Centre for Midwifery, Child and Family Health, University of Technology Sydney, Broadway, Australia. ${ }^{2}$ Cochrane Pregnancy and \\ Childbirth Group, Department of Women's and Children's Health, The University of Liverpool, Liverpool, UK \\ Contact address: Christine J Catling, Centre for Midwifery, Child and Family Health, University of Technology Sydney, Faculty of \\ Health, Broadway, NSW, 2007, Australia. christine.catling@uts.edu.au.
}

Editorial group: Cochrane Pregnancy and Childbirth Group.

Publication status and date: New search for studies and content updated (no change to conclusions), published in Issue 2, 2015.

Review content assessed as up-to-date: 31 October 2014.

Citation: Catling CJ, Medley N, Foureur M, Ryan C, Leap N, Teate A, Homer CSE. Group versus conventional antenatal care for women. Cochrane Database of Systematic Reviews 2015, Issue 2. Art. No.: CD007622. DOI: 10.1002/14651858.CD007622.pub3.

Copyright (C) 2015 The Cochrane Collaboration. Published by John Wiley \& Sons, Ltd.

\begin{abstract}
A B S T R A C T

\section{Background}

Antenatal care is one of the key preventive health services used around the world. In most Western countries, antenatal care traditionally involves a schedule of one-to-one visits with a care provider. A different way of providing antenatal care involves use of a group model.
\end{abstract}

\section{Objectives}

1. To compare the effects of group antenatal care versus conventional antenatal care on psychosocial, physiological, labour and birth outcomes for women and their babies.

2. To compare the effects of group antenatal care versus conventional antenatal care on care provider satisfaction.

\section{Search methods}

We searched the Cochrane Pregnancy and Childbirth Group's Trials Register (31 October 2014), contacted experts in the field and reviewed the reference lists of retrieved studies.

\section{Selection criteria}

All identified published, unpublished and ongoing randomised and quasi-randomised controlled trials comparing group antenatal care with conventional antenatal care were included. Cluster-randomised trials were eligible, and one has been included. Cross-over trials were not eligible.

\section{Data collection and analysis}

Two review authors independently assessed trials for inclusion and risk of bias and extracted data; all review authors checked data for accuracy.

\section{Main results}

We included four studies (2350 women). The overall risk of bias for the included studies was assessed as acceptable in two studies and good in two studies. No statistically significant differences were observed between women who received group antenatal care and those given standard individual antenatal care for the primary outcome of preterm birth (risk ratio (RR) $0.75,95 \%$ confidence interval (CI) 0.57 to 1.00 ; three trials; $\mathrm{N}=1888$ ). The proportion of low-birthweight (less than $2500 \mathrm{~g}$ ) babies was similar between groups ( $R R$ $0.92,95 \%$ CI 0.68 to 1.23 ; three trials; $\mathrm{N}=1935$ ). No group differences were noted for the primary outcomes small-for-gestational 
age (RR 0.92, 95\% CI 0.68 to 1.24 ; two trials; $\mathrm{N}=1473$ ) and perinatal mortality (RR $0.63,95 \%$ CI 0.32 to 1.25 ; three trials; $\mathrm{N}=$ 1943).

Satisfaction was rated as high among women who were allocated to group antenatal care, but this outcome was measured in only one trial. In this trial, mean satisfaction with care in the group given antenatal care was almost five times greater than that reported by those allocated to standard care (mean difference 4.90, 95\% CI 3.10 to 6.70; one study; $\mathrm{N}=993$ ). No differences in neonatal intensive care admission, initiation of breastfeeding or spontaneous vaginal birth were observed between groups. Several outcomes related to stress and depression were reported in one trial. No differences between groups were observed for any of these outcomes.

No data were available on the effects of group antenatal care on care provider satisfaction.

We used the GRADE (Grades of Recommendation, Assessment, Development and Evaluation) approach to assess evidence for seven prespecified outcomes; results ranged from low quality (perinatal mortality) to moderate quality (preterm birth, low birthweight, neonatal intensive care unit admission, breastfeeding initiation) to high quality (satisfaction with antenatal care, spontaneous vaginal birth).

\section{Authors' conclusions}

Available evidence suggests that group antenatal care is positively viewed by women and is associated with no adverse outcomes for them or for their babies. No differences in the rate of preterm birth were reported when women received group antenatal care. This review is limited because of the small numbers of studies and women, and because one study contributed $42 \%$ of the women. Most of the analyses are based on a single study. Additional research is required to determine whether group antenatal care is associated with significant benefit in terms of preterm birth or birthweight.

\section{PLAIN LANGUAGE SUMMARY}

\section{Group versus conventional antenatal care for pregnant women}

Antenatal care is one of the most important healthcare services provided for pregnant women around the world. In most Western countries, health care during pregnancy traditionally involves a schedule of one-to-one visits with a midwife, an obstetrician or a general practitioner (GP) in a hospital or clinic setting. A different way of providing pregnancy care involves use of a group model rather than a one-to-one approach. Group antenatal or pregnancy care has been developed in the USA in a model known as CenteringPregnancy. Care is provided by a midwife or an obstetrician to groups of eight to 12 women of similar gestational age. Groups meet eight to 10 times during pregnancy at the usual scheduled visits, with sessions running for 90 to 120 minutes. All pregnancy care is provided in this group setting by integrating the usual pregnancy health assessment with information, education and peer support.

We undertook a systematic review of trials that compared the effects of group pregnancy care versus conventional individual pregnancy care on psychosocial, physiological, labour and birth outcomes for women and their babies as well as on care provider satisfaction. Four randomised controlled trials (involving 2350 women) were included: two were undertaken in the USA, one in Sweden and one in Iran. We found no differences between women who received group pregnancy care and those given one-to-one care in terms of important pregnancy outcomes such as preterm birth, infant birthweight or death of the baby. Women who attended group pregnancy care were no more likely to initiate breastfeeding than those receiving standard care. In one of the trials, satisfaction was rated as more high among women who attended group pregnancy care.

Major differences between trials were noted. One trial targeted young women 14 to 25 years of age in a setting with many African American women who had limited financial resources. The main purpose was to reduce human immunodeficiency virus (HIV) risk behaviour and sexually transmitted infections. Another trial was mainly looking at family readiness in a military setting, and another focused on women's satisfaction and emotional aspects of their care.

This review is limited owing to the small numbers of studies and women, with one study contributing $42 \%$ of the women. More research is required to determine whether group pregnancy care is associated with significant benefits.

Group versus conventional antenatal care for women (Review) 


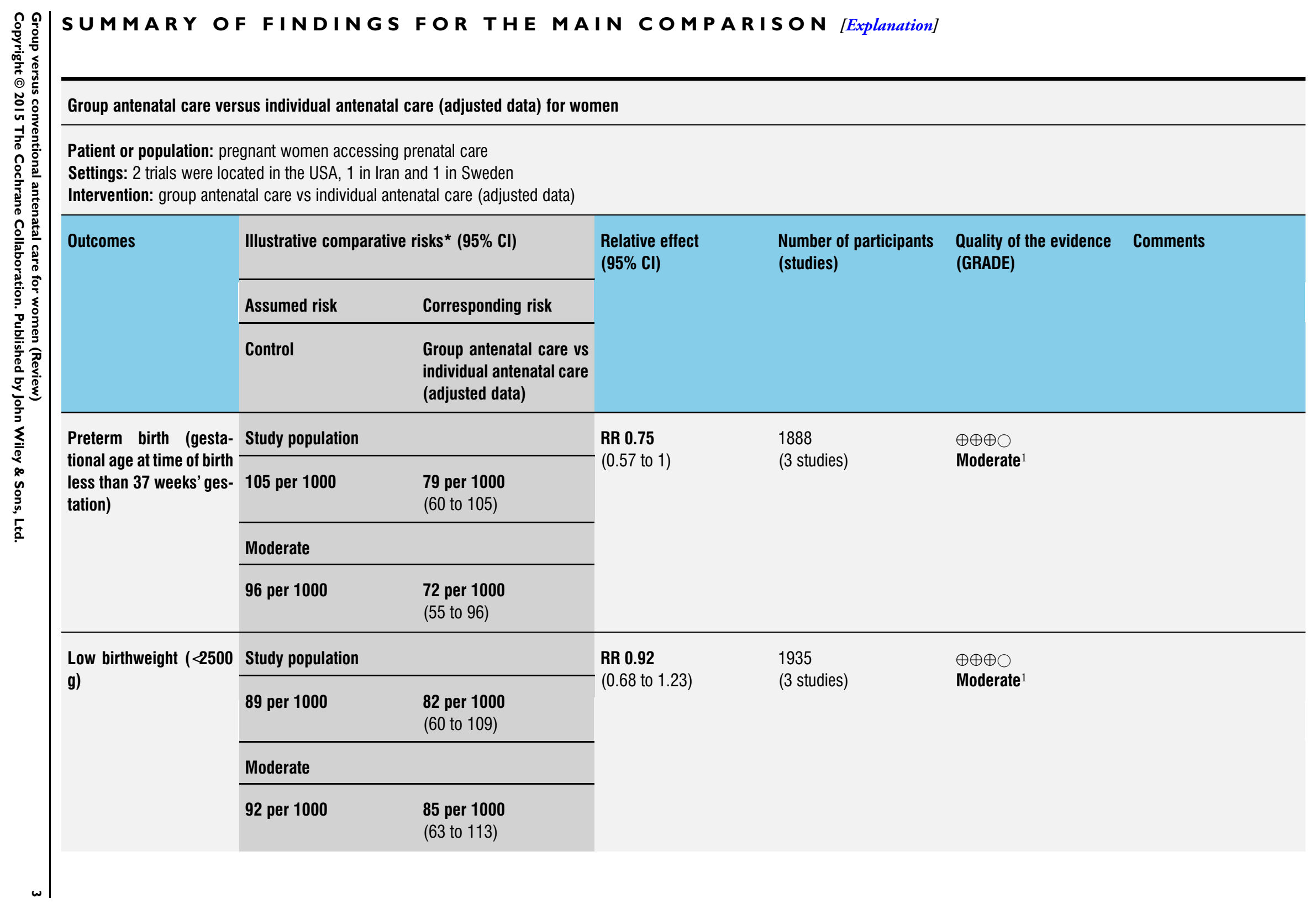




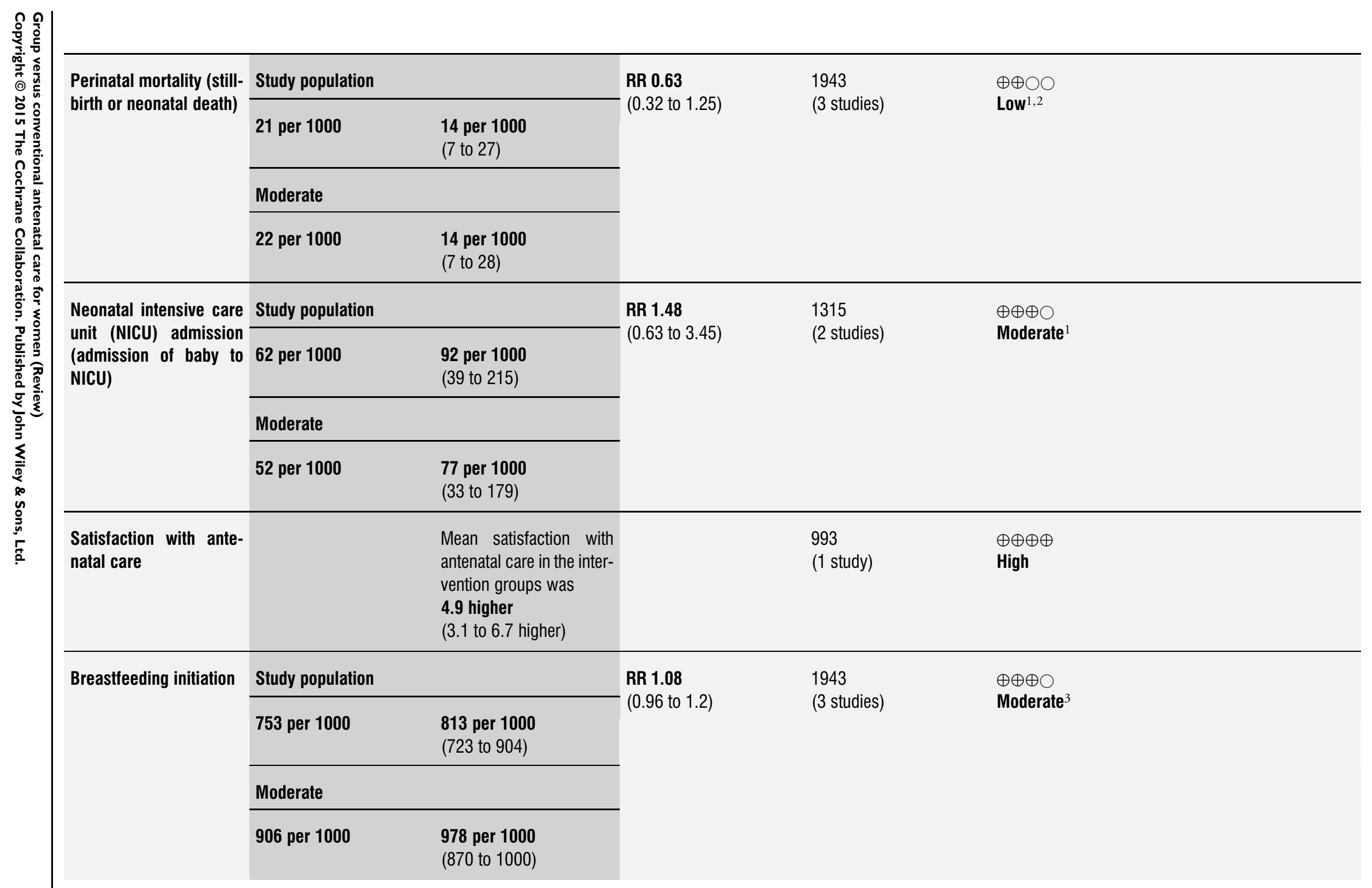




\begin{tabular}{|c|c|c|c|c|c|c|}
\hline \multirow{4}{*}{$\begin{array}{l}\text { Spontaneous } \\
\text { birth }\end{array}$} & \multirow[t]{4}{*}{ vaginal } & \multicolumn{2}{|c|}{ Study population } & \multirow{4}{*}{$\begin{array}{l}\text { RR } 0.96 \\
(0.8 \text { to } 1.15)\end{array}$} & \multirow{4}{*}{$\begin{array}{l}322 \\
\text { (1 study) }\end{array}$} & \multirow{4}{*}{$\begin{array}{l}\oplus \oplus \oplus \oplus \\
\text { High }\end{array}$} \\
\hline & & 606 per 1000 & $\begin{array}{l}582 \text { per } \mathbf{1 0 0 0} \\
\text { (485 to } 697)\end{array}$ & & & \\
\hline & & \multicolumn{2}{|l|}{ Moderate } & & & \\
\hline & & 606 per 1000 & $\begin{array}{l}\mathbf{5 8 2} \text { per } \mathbf{1 0 0 0} \\
\text { (485 to } 697)\end{array}$ & & & \\
\hline
\end{tabular}

*The basis for the assumed risk (e.g. median control group risk across studies) is provided in footnotes. The corresponding risk (and its $95 \%$ confidence interval) is based on the assumed risk in the comparison group and the relative effect of the intervention (and its $95 \% \mathrm{Cl}$ ).

Cl: Confidence interval; RR: Risk ratio.

GRADE Working Group grades of evidence.

High quality: Further research is very unlikely to change our confidence in the estimate of effect.

Moderate quality: Further research is likely to have an important impact on our confidence in the estimate of effect and may change the estimate.

Low quality: Further research is very likely to have an important impact on our confidence in the estimate of effect and is likely to change the estimate.

Very low quality: We are very uncertain about the estimate.

${ }^{1}$ Wide confidence intervals crossing the line of no effect $(-1)$.

${ }^{2}$ Greatest weight from study with design limitations $(-1)$.

${ }^{3}$ Statistical heterogeneity $\left(I^{2}=89 \%\right)(-1)$. 


\section{B A C K G ROU N D}

\section{Description of the condition}

\section{Antenatal care}

Antenatal care is one of the key preventive health services provided around the world (Renfrew 2014). In many Western countries, antenatal care traditionally involves a schedule of one-to-one visits with a care provider (midwife, obstetrician or general practitioner (GP)). Antenatal care in Western countries is usually offered in a hospital or clinic setting, where women may wait for long periods of time to receive fragmented antenatal care from a range of practitioners. In one large cohort study assessing satisfaction with conventional antenatal care, approximately one in five women reported that they were dissatisfied with the care they received (Hildingsson 2005). In this study, lack of consistent care providers throughout pregnancy was associated with decreased satisfaction. A more recent cross-national study shows that factors contributing to low satisfaction with antenatal care include deficiencies in provision of information (Hildingsson 2013). In another study, women with complex needs-young women, those experiencing multiple social health problems, women of non-English-speaking background and women at high risk of complications in pregnancy-were least likely to say that the antenatal care provided met their needs (Brown 2014). More than a decade ago, it was suggested that conventional antenatal care and its scope and practice were based more on tradition and ritual than on evidence (Villar 2001). Despite this belief, one-to-one conventional antenatal care remains the predominant model of antenatal care in many countries.

Innovative models of care during pregnancy and childbirth have the potential to improve outcomes for women and babies and to enhance maternal and care provider satisfaction with antenatal care. In particular, midwife-led continuity of care is associated with significant benefit for mothers and newborn infants, absence of adverse effects (Sandall 2013) and cost benefits for the health system (Devane 2010; Tracy 2013). One-to-one midwife-led continuous care has been established in several countries in response to evidence showing benefit (Homer 2014; Renfrew 2014). Widespread implementation, however, has been challenging, and midwife-led continuity does not constitute mainstream care in all countries (Homer 2006). Group antenatal care has been proposed as an alternative method of providing antenatal care, although usually it does not provide continuity throughout labour and birth and the postpartum period.

\section{Description of the intervention}

\section{Group antenatal care}

A different way of providing antenatal care involves a group model rather than a one-to-one approach (Rising 1998; Rising 2004). Group antenatal care has been developed in the USA in a model known as CenteringPregnancy. Developed by Sharon Schindler Rising (Rising 1998), CenteringPregnancy is an innovative approach to antenatal care by which care is provided to groups of eight to 12 women of similar gestational age. Groups meet eight to 10 times during pregnancy (at the usual scheduled visits for antenatal care), and sessions run for 90 to 120 minutes. Antenatal care is provided by a midwife, an obstetrician or another maternity care provider in this group setting. Physical assessments such as fundal height and fetal heart rate take place in the group room but are undertaken as an individual assessment alongside the group to maintain privacy. Groups integrate the usual antenatal assessment with information, education and peer support. Emphasis is placed on engaging women more fully in their own health assessments. Women with issues of high risk during pregnancy receive concurrent care provided by a specialist obstetrician or physician, in addition to attending CenteringPregnancy group sessions.

The 'Essential Elements of CenteringPregnancy' include the following.

1. Health assessment occurs within the group space.

2. Women are involved in self-care activities.

3. Stability of group leadership is required.

4. A facilitative leadership style is used.

5. Each session has an overall plan.

6. Attention is given to core content; emphasis may vary.

7. Group conduct honours the contribution of each member.

8. The group is conducted in a circle and group size is optimal to promote the process.

9. The composition of the group is stable but is not rigid.

10. Involvement of family support people is optional.

11. Group members are offered time to socialise.

12. Evaluation of outcomes is ongoing.

Group antenatal care or CenteringPregnancy has been adapted for use in several countries including Australia (Teate 2011; Teate 2013), England (Gaudion 2010), Sweden (Andersson 2013), Iran (Jafari 2010), Canada (Benediktsson 2013) and Malawi and Tanzania (Patil 2013).

\section{How the intervention might work}

CenteringPregnancy, as one model of group antenatal care, allows increased time in antenatal care, with women receiving between 12 and 20 hours of care in a group setting compared with an estimated two to three hours (eight to 10 visits of 15 to $20 \mathrm{~min}$ utes' duration) during conventional antenatal care. This would be likely to result in increased education about pregnancy, childbirth and early parenting, which in turn may affect perinatal outcomes. Results from randomised and non-randomised trials have shown 
that CenteringPregnancy is associated with a reduction in hospital emergency department visits during the third trimester (Rising 1998), a decrease in prematurity (Ickovics 2007a), a reduction in risk of preterm birth and low birthweight (Grady 2004; Ickovics 2003), improved pregnancy knowledge (Baldwin 2006) and high rates of satisfaction with care (Klima 2009; Rising 1998; Teate 2011). The additional time provided during group antenatal care means that women are more satisfied with the information they receive regarding labour, birth and breastfeeding and they feel better engaged with their care provider compared with women receiving individual antenatal care (Andersson 2013). Greater attention to the fidelity of the CenteringPregnancy model has been shown to be associated with significantly lower odds of preterm birth and intensive utilisation of care Novick 2013.

Recently, group antenatal care has been implemented in low-resource countries with positive results. It has been suggested that this approach may be suitable in these contexts, where lack of support, restrictive cultural and traditional practices and low-quality healthcare services may mean that standard models of care are less effective or are sought after by women (Jafari 2010). In sub-Saharan Africa, a preliminary trial has shown that group antenatal care is acceptable in low-literacy, high-human immunodeficiency virus (HIV) settings (Patil 2013).

Group antenatal care is likely to provide greater social support by linking women with other pregnant women at similar gestational ages. Conventional models of antenatal care often provide limited opportunities for women to make social contact with other pregnant women. Social support during pregnancy has been associated with seeking antenatal care, intentions to breastfeed, fewer labour complications, increased infant birthweight, higher Apgar scores at birth and a reduction in the risk of postnatal depression (Logsdon 2003). One qualitative study of women showed that group antenatal care and social networking were viewed positively by the women involved (Novick 2011).

\section{Why it is important to do this review}

Antenatal care is a very widely used type of care that impacts the large population of childbearing women (NICE 2008). It is associated with considerable expense. It is important to identify effective models of antenatal care and to understand their impact on different groups of women and newborns and in different settings. Group antenatal care is a relatively recent model of antenatal care that is being implemented in many settings; it is important to assess the evidence base for such an intervention. It is also important to determine the acceptability of new models of care for care providers, if longevity of the model is to be assured. Some qualitative evidence suggests that group antenatal care is a positive experience for care providers (Teate 2013).

This systematic review of randomised controlled trials (RCTs) will test the hypothesis that group antenatal care improves outcomes for women and their babies compared with conventional antena- tal care, and it increases maternal and care provider satisfaction with antenatal care. This review will include models of CenteringPregnancy, as well as other models that provide antenatal care in a group setting. This review would be of interest to women and their families, healthcare professionals, policy makers and administrators.

Group antenatal care is being tested in other groups of high-risk pregnant women such as obese women (Davis 2012) and those considering vaginal birth after caesarean section, despite lack of strong evidence for these groups.

\section{O B JE C T IVES}

1. To compare the effects of group antenatal care versus conventional antenatal care on psychosocial, physiological, labour and birth outcomes for women and their babies.

2. To compare the effects of group antenatal care versus conventional antenatal care on care provider satisfaction.

\section{METHODS}

\section{Criteria for considering studies for this review}

\section{Types of studies}

All identified published, unpublished and ongoing RCTs and quasi-RCTs comparing group antenatal care with conventional antenatal care were included. RCTs using all types of designs (such as parallel groups and cluster randomisation) were considered for inclusion. Cross-over randomised designs are not appropriate for this intervention and were not included in the review.

Studies that address group antenatal education but do not provide antenatal care and assessment (i.e. assessment of fetal well-being, maternal blood pressure, urinalysis) for the group were excluded, as group antenatal education is an adjunct to standard antenatal care.to

\section{Types of participants}

Pregnant women accessing antenatal care.

\section{Types of interventions}

Group model antenatal care, including CenteringPregnancy: In group antenatal care, women receive most of their antenatal care in a group session rather than by a conventional one-to-one approach. Group antenatal care differs from group antenatal education, as all aspects of antenatal care are performed in the group setting, 
including assessment of fetal well-being. The comparison group will consist of women receiving conventional antenatal care on a one-to-one basis with a care provider (midwife/obstetrician/GP). The term 'CenteringPregnancy' has been coined by founders of this model of care and is copyrighted for this use. To be defined as CenteringPregnancy, healthcare services have to abide by a series of guidelines including requirements for training and ongoing development and evaluation and must follow the "10 Essential Elements of CenteringPregnancy Care" as defined by the founder (Rising 1998).

\section{Types of outcome measures}

Primary and secondary outcomes were prespecified. Primary outcomes of preterm birth and low birthweight were selected, as cohort studies had suggested that group antenatal care may affect rates of low birthweight and may be associated with longer pregnancies (Ickovics 2003). In this cohort study, group antenatal care appeared to protect against early preterm birth, although the numbers of these poorer outcomes were small, thus limiting generalisability. It has been hypothesised that additional time with providers results in better understanding of the physiology of a healthy pregnancy, improved knowledge and skills and more health-promoting behaviours and fewer health-damaging behaviours, which in turn may lead to better health outcomes for mother and baby, including improved birthweight and potentially less preterm birth (Massey 2006). It has been suggested that group care may promote changes in social norms to reduce high-risk behaviours during pregnancy (e.g. smoking cessation) that contribute to adverse outcomes, for example, preterm birth (Massey 2006). Another possible mechanism is that women receiving group antenatal care are aware of the need for support and hence are better prepared for labour, thus reducing the stress that can contribute to preterm birth (Dunkel-Schetter 2001).

Perinatal mortality was also selected as a primary outcome, as this is an important consideration when models of antenatal care are assessed. In addition, earlier studies of midwifery models of care, which included antenatal care, highlighted concerns with higher rates of perinatal mortality associated with innovative models of care (Gottvall 2004).

\section{Primary outcomes}

1. Gestational age at birth (preterm birth defined as birth before 37 completed gestational weeks; very preterm birth defined as birth before 34 completed gestational weeks).

2. Low birthweight (defined as less than $2500 \mathrm{~g}$ ).

3. Small-for-gestational age (defined as less than the 10th percentile for gestation and gender).

4. Perinatal mortality.

\section{Secondary outcomes}

1. Maternal satisfaction with antenatal care.

2. Breastfeeding initiation (self-reported).

3. Duration of exclusive breastfeeding (self-reported).

4. Length of maternal hospital stay.

5. Length of infant hospital stay.

6. Infant Apgar scores.

7. Mode of birth (vaginal birth versus caesarean section).

8. Induction of labour.

9. Analgesia/anaesthesia use in labour (epidural analgesia).

10. Attendance at antenatal care (number of sessions/contact hours).

11. Care provider's satisfaction.

12. Cost-effectiveness.

13. Postnatal depression.

14. Social support.

15. Number of admissions to hospital during antenatal period.

16. Smoking.

17. Vaginal birth after previous caesarean section.

18. Maternal knowledge about labour and birth/parenting.

19. Maternal anxiety/stress.

20. Maternal self-efficacy/self-confidence for parenting.

21. Neonatal intensive care unit (NICU) admission (not a prespecified outcome).

\section{Search methods for identification of studies}

The following methods section of this review is based on a standard template used by the Cochrane Pregnancy and Childbirth Group.

\section{Electronic searches}

We searched the Cochrane Pregnancy and Childbirth Group's Trials Register by contacting the Trials Search Co-ordinator (31 October 2014).

The Cochrane Pregnancy and Childbirth Group's Trials Register is maintained by the Trials Search Co-ordinator and contains trials identified through:

1. monthly searches of the Cochrane Central Register of Controlled Trials (CENTRAL);

2. weekly searches of MEDLINE (Ovid);

3. weekly searches of Embase (Ovid);

4. handsearches of 30 journals and the proceedings of major conferences; and

5. weekly current awareness alerts for a further 44 journals plus monthly BioMed Central email alerts.

Details of the search strategies for CENTRAL, MEDLINE and Embase; the list of handsearched journals and conference proceedings; and the list of journals reviewed via the current awareness service can be found in the 'Specialized Register' section within the editorial information provided on the Cochrane Pregnancy and Childbirth Group.

Group versus conventional antenatal care for women (Review)

Copyright $\odot 2015$ The Cochrane Collaboration. Published by John Wiley \& Sons, Ltd. 
Each of the trials identified through the search activities described above is assigned to a review topic (or topics). The Trials Search Co-ordinator searches the register for each review using the topic list rather than keywords.

\section{Searching other resources}

We contacted known investigators in the relevant area to obtain data from any unpublished work and reviewed reference lists of retrieved articles to look for further studies of relevance to the review.

We applied no language or date restrictions.

\section{Data collection and analysis}

For methods used in the previous version of this review, see Homer 2012.

For this update, the following methods were used in assessing the nine reports identified as a result of the updated search.

The following methods section of this review is based on a standard template used by the Cochrane Pregnancy and Childbirth Group.

\section{Selection of studies}

Two review authors independently assessed for inclusion all potential studies identified as a result of the search. We resolved disagreements through discussion, or, if required, we consulted the third review author.

\section{Data extraction and management}

We designed a form for use in extracting data. For eligible studies, two review authors extracted data using the agreed upon form. We resolved discrepancies through discussion, or, if required, we consulted the third review author. Data were entered into Review Manager software (RevMan 2014) and were checked for accuracy. When information regarding any of the above was unclear, we contacted authors of the original reports to request further details.

\section{Assessment of risk of bias in included studies}

Two review authors independently assessed risk of bias for each study using the criteria outlined in the Cochrane Handbook for Systematic Reviews of Interventions (Higgins 2011) (Figure 1). Disagreements were resolved by discussion or by consultation with a third assessor. 
Figure I. Risk of bias summary: review authors' judgements about each risk of bias item for each included study.

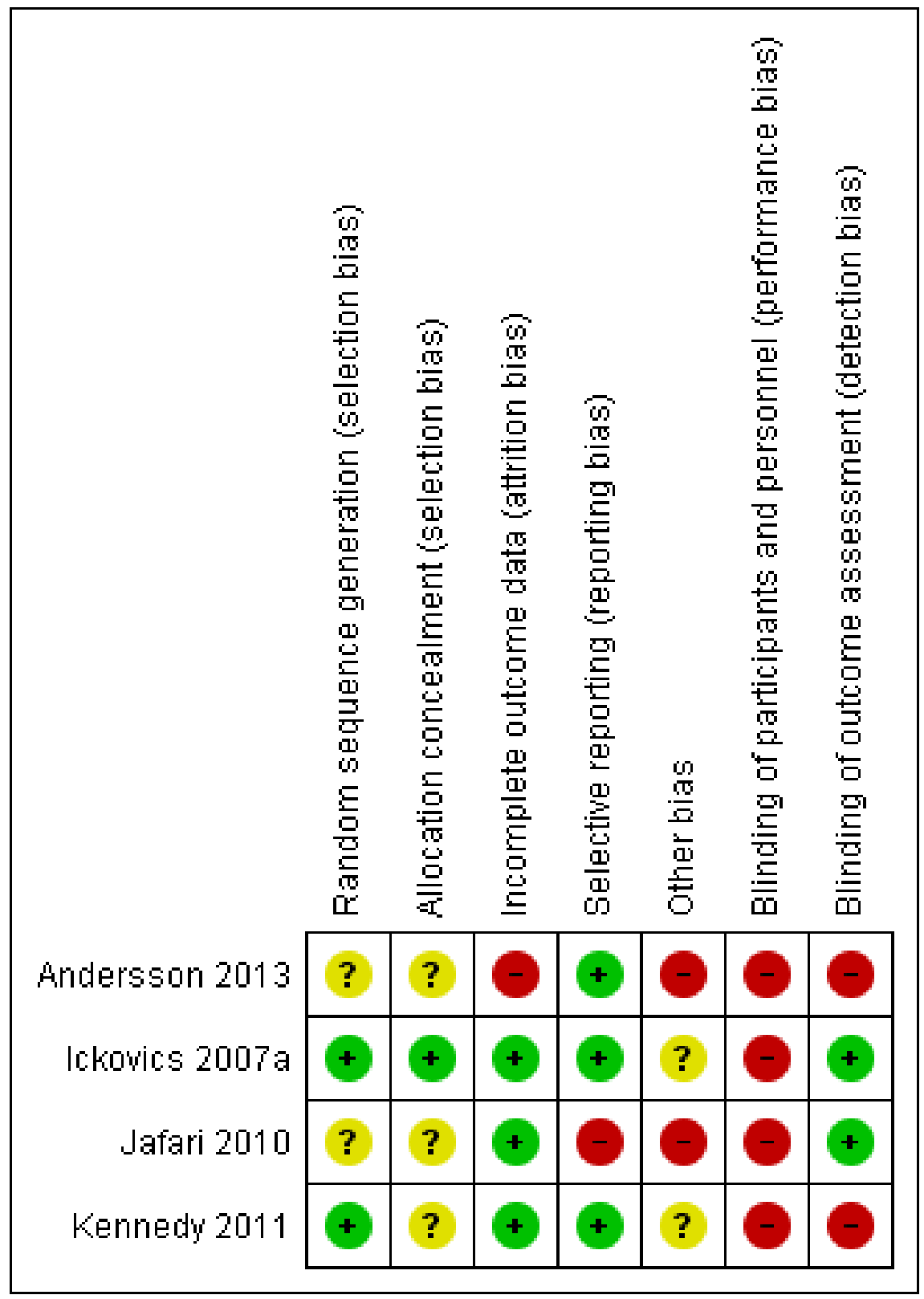


(I) Random sequence generation (checking for possible selection bias)

We described for each included study the method used to generate the allocation sequence in sufficient detail to allow an assessment of whether it should produce comparable groups.

We assessed the method as:

- low risk of bias (any truly random process, e.g. random number table; computer random number generator);

- high risk of bias (any non-random process, e.g. odd or even date of birth; hospital or clinic record number); or

- unclear risk of bias.

\section{(2) Allocation concealment (checking for possible selection} bias)

We described for each included study the method used to conceal allocation to interventions before the time of assignment and assessed whether intervention allocation could have been foreseen in advance of or during recruitment, or could have been changed after assignment.

We assessed the methods as:

- low risk of bias (e.g. telephone or central randomisation; consecutively numbered sealed opaque envelopes);

- high risk of bias (open random allocation; unsealed or nonopaque envelopes; alternation; date of birth); or

- unclear risk of bias.

\section{(3.I) Blinding of participants and personnel (checking for possible performance bias)}

We described for each included study methods used, if any, to blind study participants and personnel from knowledge of which intervention a participant received. We considered that studies were at low risk of bias if they were blinded, or if we judged that lack of blinding was unlikely to affect results. We assessed blinding separately for different outcomes or classes of outcomes.

We assessed the methods as:

- low, high or unclear risk of bias for participants; or

- low, high or unclear risk of bias for personnel.

\section{(3.2) Blinding of outcome assessment (checking for possible detection bias)}

We described for each included study the methods used, if any, to blind outcome assessors from knowledge of which intervention a participant received. We assessed blinding separately for different outcomes or for different classes of outcomes.

We assessed methods used to blind outcome assessment as:

- low, high or unclear risk of bias.
(4) Incomplete outcome data (checking for possible attrition bias due to the quantity, nature and handling of incomplete outcome data)

We described for each included study, and for each outcome or class of outcomes, completeness of data, including attrition and exclusion from analysis. We stated whether attrition and exclusions were reported and the numbers included in the analysis at each stage (compared with the total number of randomly assigned participants), reasons for attrition or exclusion when reported and whether missing data were balanced across groups or were related to outcomes. When sufficient information was reported, or could be supplied by the trial authors, we planned to reinclude missing data in the analyses that we undertook.

We assessed methods as:

- low risk of bias (e.g. no missing outcome data; missing outcome data balanced across groups);

- high risk of bias (e.g. numbers or reasons for missing data not balanced across groups; 'as treated' analysis done with substantial departure of intervention received from that assigned at randomisation); or

- unclear risk of bias.

\section{(5) Selective reporting (checking for reporting bias)}

We described for each included study how we investigated the possibility of selective outcome reporting bias and what we found. We assessed the methods as:

- low risk of bias (when it was clear that all of the study's prespecified outcomes and all expected outcomes of interest to the review had been reported);

- high risk of bias (when not all of the study's prespecified outcomes had been reported; one or more reported primary outcomes were not prespecified; outcomes of interest were reported incompletely and so could not be used; study failed to include results of a key outcome that would have been expected to have been reported); or

- unclear risk of bias.

(6) Other bias (checking for bias due to problems not covered by (I) to (5) above)

We described for each included study important concerns that we had about other possible sources of bias.

\section{(7) Overall risk of bias}

We made explicit judgements about whether studies were at high risk of bias, according to the criteria given in the Cochrane Handbook for Systematic Reviews of Interventions (Higgins 2011). With 
reference to 1 to 6 above, we assessed the likely magnitude and direction of the bias, and whether we considered it likely to impact the findings. In future updates, we will explore the impact of the level of bias by undertaking sensitivity analyses (see Sensitivity analysis).

For this update the quality of the evidence was assessed using the GRADE approach (Schunemann 2009) to assess the quality of the body of evidence related to the following key outcomes for the main comparison group antenatal care versus individual antenatal care.

1. Preterm birth.

2. Low birthweight.

3. Perinatal mortality.

4. Neonatal intensive care unit (NICU) admission.

5. Maternal satisfaction with antenatal care.

6. Mode of birth (spontaneous vaginal birth).

7. Breastfeeding initiation.

GRADEprofiler (GRADE 2014) was used to import data from Review Manager 5.3 (RevMan 2014) to create 'Summary of findings' tables. A summary of the intervention effect and a measure of quality for each of the above outcomes were produced using the GRADE approach. The GRADE approach is based on five considerations (study limitations, consistency of effect, imprecision, indirectness and publication bias) used to assess the quality of the body of evidence for each outcome. Evidence can be downgraded from 'high quality' by one level for serious (or by two levels for very serious) limitations, depending on assessments for risk of bias, indirectness of evidence, serious inconsistency, imprecision of effect estimates or potential publication bias.

\section{Measures of treatment effect}

\section{Dichotomous data}

For dichotomous data we presented results as summary risk ratios with $95 \%$ confidence intervals.

\section{Continuous data}

For continuous data we used mean differences if outcomes were measured in the same way between trials. We used standardised mean differences to combine trials that measured the same outcome but used different methods.

\section{Unit of analysis issues}

\section{Cluster-randomised trials}

We have included one cluster-randomised trial in the review ( Jafari 2010). We have analysed outcome data from that clusterrandomised trial along with those from individually randomised trials; the analyses are presented as subgroups by study design with totals displayed. We considered it reasonable to combine the results into totals if little heterogeneity was observed between study designs, and if the interaction between effects of interventions and choice of randomisation unit was considered unlikely.

We contacted the authors of the cluster-randomised trial to ask about adjustments made in the paper because the intracluster correlation co-efficient (ICC) was not stated outright in the paper, and because study results show that additional adjustments are apparent but were not specified (Jafari 2010). We have received no reply from the study authors.

To include in the review data from the cluster-randomised trial (Jafari 2010), we adjusted the event rate and the sample size for relevant outcomes using the simple adjustment methods described in the Cochrane Handbook for Systematic Reviews of Interventions (Section 16.3.4 or 16.3.6). We took estimates of the ICC published in Piaggio 2001 for relevant outcomes. When a specific review outcome had no corresponding published ICC, we used the nearest approximation. Specifically, for the continuous variable gestational age, we used the published ICC for small-for-gestational age and adjusted the sample size only. For the continuous variable birthweight, we used the ICC for low birthweight and adjusted the sample size only. For Apgar at five minutes, we used the ICC for Apgar at one minute and adjusted the sample size only. For caesarean section, we used the published ICC for elective caesarean section. We have not adjusted the outcome data for 'breastfeeding initiation' because no corresponding or related ICC was provided. Details of adjustments carried out along with the original data can be found in the additional table 'Adjustment of outcome data' (Table 1).

\section{Dealing with missing data}

For included studies, levels of attrition were noted. In future updates, if more eligible studies are included, the impact of including studies with high levels of missing data in the overall assessment of treatment effect will be explored by performing sensitivity analysis.

For all outcomes, analyses were carried out, as far as possible, on an intention-to-treat basis (i.e. we attempted to include in the analyses all participants randomly assigned to each group). The denominator for each outcome in each trial was the number randomly assigned minus any participants whose outcomes were known to be missing.

\section{Assessment of heterogeneity}

We assessed statistical heterogeneity in each meta-analysis by using $\mathrm{Tau}^{2}, \mathrm{I}^{2}$ and $\mathrm{Chi}^{2}$ statistics. We regarded heterogeneity as substantial if $\mathrm{I}^{2}$ was greater than $30 \%$ and either $\mathrm{Tau}^{2}$ was greater than zero, or if the $\mathrm{P}$ value was low $(<0.10)$ in the $\mathrm{Chi}^{2}$ test for heterogeneity. 


\section{Assessment of reporting biases}

In future updates, if 10 or more studies are included in the metaanalysis, we will investigate reporting biases (such as publication bias) by using funnel plots. We will assess funnel plot asymmetry visually. If asymmetry is suggested by visual assessment, we will perform exploratory analyses to investigate this.

\section{Data synthesis}

We carried out statistical analysis using Review Manager software (RevMan 2014). We used a fixed-effect meta-analysis for combining data when it was reasonable to assume that studies were estimating the same underlying treatment effect, that is, when trials were examining the same intervention and their populations and methods were judged sufficiently similar.

If clinical heterogeneity was sufficient to suggest that underlying treatment effects differed between trials, or if substantial statistical heterogeneity was detected, we used random-effects meta-analysis to produce an overall summary when an average treatment effect across trials was considered clinically meaningful. The randomeffects summary was treated as the average range of possible treatment effects, and we discussed the clinical implications of differing treatment effects between trials. If the average treatment effect was not clinically meaningful, we did not combine trials. If we used random-effects analyses, results were presented as the average treatment effect with $95 \%$ confidence intervals, along with estimates of $\mathrm{Tau}^{2}$ and $\mathrm{I}^{2}$.

\section{Subgroup analysis and investigation of heterogeneity}

No subgroup analysis was performed, apart from presentation of outcome data from the single cluster-randomised trial (Jafari 2010), as mentioned above. In future updates, we plan to undertake a subgroup analysis based on:

1. the number of group sessions attended by those in the antenatal care groups (four or fewer sessions vs five or more sessions);

2. membership of the groups (e.g. with and without the woman's support personnel including partners, spouses and sisters);

3. CenteringPregnancy qualified or registered programmes versus other group care programmes; and

4. broader socioeconomic settings of high-, middle- and lowincome countries.

When substantial heterogeneity was identified in pooled outcome data, we conducted random-effects analysis and reported $\mathrm{Tau}^{2}$ and $I^{2}$ along with the effect estimate. Studies were too few for review authors to conduct meaningful sensitivity analyses. Instead, we have discussed potential reasons for heterogeneity in the Results section of the text.

In future updates, if we identify substantial heterogeneity, we will investigate this by performing subgroup analyses and sensitivity analyses. We will consider whether an overall summary is meaningful, and if it is, we will use a random-effects analysis to produce it.

\section{Sensitivity analysis}

Three studies (Andersson 2013; Jafari 2010; Kennedy 2011) had unclear allocation concealment. Hence, we undertook a sensitivity analysis to explore the effects of the quality of trials in this review on the four primary outcomes. When all studies that reported 'preterm birth' were included, no statistically significant differences were observed between women who received group antenatal care and those given standard individual antenatal care (risk ratio (RR) $0.75,95 \%$ confidence interval (CI) 0.57 to 1.00 ; three trials; $\mathrm{N}=1943)$. When studies with unclear allocation concealment were excluded, the results changed very little (RR 0.71 , 95\% CI 0.50 to 1.01 ), although only one trial (Ickovics 2007a) was included. In relation to the primary outcome of 'low birthweight,' the same sensitivity analysis was performed and the overall effect was unchanged. For the 'low birthweight' outcome, removal of studies with an unclear allocation concealment moved the effect size to the null (RR $0.92,95 \%$ CI 0.68 to 1.23 changed to RR $1.04,95 \%$ CI 0.72 to 1.50 ). For the other two primary outcomes, 'small-for-gestational age' and 'perinatal mortality,' removal of studies with unclear allocation concealment made no difference.

\section{R E S U L T S}

\section{Description of studies}

\section{Results of the search}

Our original search strategy identified six potentially eligible trials (19 reports). The updated search identified 10 further reports. From these searches, four trials involving 2350 women were included (Andersson 2013) ( $\mathrm{n}=407)$; Ickovics 2007a ( $\mathrm{n}=993)$; Jafari $2010(\mathrm{n}=628)$; Kennedy $2011(\mathrm{n}=322)$ ). Seven trials were excluded from the updated search (Bhutta 2008; Ford 2001; Koushede 2013; Leung 2012; Manandhar 2004; Olenick 2011; Salmela-Aro 2012).

For additional information, see Characteristics of included studies, Characteristics of excluded studies and Characteristics of ongoing studies.

\section{Included studies}

Four trials involving a total of 2350 women were included in the review (Andersson 2013; Ickovics 2007a; Jafari 2010; Kennedy 2011). 
The Ickovics 2007a study was a multi-site, three-arm RCT conducted at two university-affiliated hospital antenatal clinics. The primary objective of the trial was to evaluate whether group antenatal care would result in decreased HIV risk behaviours and sexually transmitted diseases (STDs). The secondary objective of the trial was to determine whether group antenatal care would lead to better reproductive health outcomes, such as reductions in numbers of preterm births and low-birthweight infants, as well as improved psychological outcomes, participant satisfaction and healthcare costs. Between September 2001 and December 2004, women attending their first or second antenatal care visit were referred to a provider or were approached directly by research staff. Inclusion criteria were as follows: (1) less than 24 weeks of pregnancy; (2) age 25 years or younger; (3) no medical problems requiring individualised care as high-risk pregnancy care (e.g. diabetes, HIV); (4) English or Spanish speaking participants; and (5) willingness to be randomly assigned. A total of 1047 pregnant women without medical problems were randomly assigned to standard or group antenatal care.

The intervention in the Ickovics trial (Ickovics 2007a) consisted of antenatal care provided within a group space in a community or conference room. Two group antenatal care arms were included: usual group antenatal care (CenteringPregnancy) and integrated group antenatal care (CenteringPregnancy plus specific skill building in the areas of HIV/STD prevention including assertiveness and negotiation skills). The two intervention arms were combined in this review, as the principles of group antenatal care applied equally to both. Group antenatal care (in both arms) was provided through the partnership of a credentialed provider and a pregnant woman when continuity of care providers was maintained throughout pregnancy. All care, education and support were provided within the two-hour time period allocated to the group, and no waiting was required. Women participated in their own physical assessment (e.g. blood pressure, weight) and documented this in their own records. Fundal height and fetal heart rate measurements were performed in the group space. If required, health concerns that required private consultation and intimate examinations were addressed during ancillary visits in a private examination room. A total of 10 group sessions used structured educational materials including self-assessment sheets. The schedule of group visits was made available at the first session, which occurred at approximately 16 weeks. Total provider/participant time throughout pregnancy was approximately 20 hours.

The traditional model of antenatal care (Ickovics 2007a) involved one-to-one examination room visits. Care was provided by a credentialed antenatal provider, and variable continuity of providers was maintained throughout pregnancy. Care was focused primarily on medical outcomes, and recommended testing and waiting times for visits varied. Education was often provider-dependent and was based on time available for education, response to participant-initiated queries or both. Physical assessment was performed inside an examination room by a provider who completed the an- tenatal care records. These records were not shared with participants unless requested. Traditional care provided few opportunities for women to interact socially with other pregnant women. Data were collected from both groups at baseline, during the third trimester of pregnancy (mean of 35 weeks of pregnancy), at birth and at six months' and 12 months' postpartum.

Kennedy 2011 was a multi-site RCT conducted in antenatal clinics at two military settings in the USA. One site was a US Naval Hospital in the Pacific Northwest that provides care to 60,000 eligible military families, and the other was a US Air Force Medical Group on the Atlantic Coast serving two Fighter Wings. The primary purpose of the trial was to compare the effects of group antenatal care versus individual care on outcomes of family healthcare readiness in a military setting. Military family readiness or force readiness is not clearly defined in the trial; however, it is acknowledged that poor pregnancy outcomes directly affect force readiness, and that an ill mother or child compromises family readiness. If a service member is distracted about his or her family's quality of life, then efficiency, productivity and safety are compromised, and family readiness is reduced.

The military sites were known to include transient military populations; therefore the trial was sampled to account for an attrition rate of $10 \%$ for each data collection time point. This resulted in a final baseline sample of 322 women. Inclusion criteria were similar to those of the Ickovics trial (Ickovics 2007a), although gestation was earlier and the age group did not target young women. Criteria included the following: (1) pregnancy with a gestational age of less than 16 weeks; (2) age 18 years or older at last birthday; (3) absence of severe medical problems requiring individualised assessment and tracking as 'high-risk' pregnancy (e.g. diabetes, hypertension); (4) ability to understand English; and (5) willingness to be randomly assigned to group versus individual antenatal care. Women were randomly assigned at between 12 and 16 weeks' gestation to group or individual antenatal care.

The intervention consisted of group antenatal care using the CenteringPregnancy model, which provides antenatal care, education and support in a small group environment. As in the Ickovics trial (Ickovics 2007a), group antenatal care consisted of nine group antenatal care visits and one postpartum reunion. Groups consisted of a minimum of six women and a maximum of 12 women. An antenatal care provider and an assistant facilitated the group sessions. Individualised antenatal care was not described.

Data were collected from both groups at four time points: baseline, 32 to 36 weeks' gestation, birth and three months' postpartum.

Jafari 2010 studied maternal and neonatal outcomes of group versus individual antenatal care in Iran. This was a cluster RCT for which the health centre was the unit of randomisation. Participating health centres had to be able to provide at least 12 new women over a period not longer than one month, and both intervention and control health centres had to be located in the same geographical area and had to serve similar populations. Fourteen health centres participated and were randomly assigned to group 
prenatal care or individual prenatal care (seven in each group). Midwives from the intervention health centres were trained to facilitate group antenatal care. A total of 678 women were enrolled in the study: 344 in group care and 334 in individual antenatal care groups. Each group consisted of eight to 10 women who met 10 times during their pregnancies to receive group antenatal care. Inclusion criteria for women included the following: (1) pregnancy less than 24 weeks' gestation; (2) absence of severe medical issues; and (3) willingness to participate in the trial.

Jafari 2010 described the group antenatal care intervention sessions, which were consistent with the CenteringPregnancy model. Participant data were collected at three points-34 to 36 weeks' gestation, 24 hours' post birth and two months' postpartum-through both medical record documentation and individual structured interviews. This was the only trial that used a cluster-randomised design. The trial report describes adjustments that were made to account for the effects of cluster randomisation, as well as unspecified additional adjustments. We attempted to contact the study authors to clarify these adjustments but have received no reply. To include this trial in the analysis, we adjusted events and sample sizes using ICCs for each relevant outcome published in Piaggio 2001. These adjustments are described in the Methods section above.

The study by Andersson 2013 randomly assigned a minimum of two midwives working at the same antenatal clinic to provide group-based antenatal care or standard care. A total of 31 midwives from 12 antenatal clinics in Sweden accepted the invitation to participate. Group-based care, which was consistent with the CenteringPregnancy model, was provided beginning at 20 weeks' gestation. In this study, data were collected by two questionnaires: the first during the first trimester before the antenatal programme began, and the second, six months after birth. The first questionnaire consisted of demographics such as age, parity, civil status, country of birth, financial situation, tobacco use and chronic disease, and whether the pregnancy was planned. The second questionnaire included questions about opinions on the number of antenatal visits, caregivers and content of care. Detailed questions were asked about the approach of the midwives, as well as medical and emotional aspects of their care. These questions were assessed on a four-point Likert scale. This trial reported only an evaluation of the model of care, including number of visits, level of satisfaction and other activities engaged in by participants. Data related to only one secondary outcome for this review were reported.

Heterogeneity amongst trials was noted. The two American trials by Ickovics 2007a and Kennedy 2011 had major differences in age groups included and in the focus of educational strategies applied. The Ickovics trial (Ickovics 2007a) targeted young women from 14 to 25 years of age in a setting that was over-represented by African American women with limited financial resources; its primary purpose was reduction in HIV risk behaviours and sexually transmitted infections (STIs). Secondary outcomes included broader perinatal outcomes such as preterm birth. The primary focus of the second trial (Kennedy 2011) was family readiness in a military setting. Both Jafari 2010 and Andersson 2013 randomly assigned caregivers. Jafari 2010 randomly assigned the health centre to provide group-based antenatal care or individual care, and Andersson 2013 randomly assigned midwives within the same health centre to provide different types of care as well as the women who attended the health centre.

\section{Excluded studies}

See Characteristics of excluded studies.

Seven studies were excluded. Two of these studies examined the effectiveness of community-based groups that essentially provided education in rural Pakistan and Nepal (Bhutta 2008; Manandhar 2004). These interventions consisted predominantly of participatory women's groups, but investigators did not test models of care that included both care and education. These models of care were very different from the group antenatal care model and did not perform comparisons with conventional antenatal care. Trials by Koushede 2013, Leung 2012, Olenick 2011 and Salmela-Aro 2012 did not study group models of antenatal care. The trial by Olenick 2011 tested a two-hour class on the basis of the breastfeeding self-efficacy theory. Leung 2012 studied groups that focused on strategies to deal with intergenerational conflict, and Salmela-Aro 2012 studied a programme designed to reduce fear of childbirth. The trial by Koushede 2013 focused only on a birth and parenting preparation class. Ford 2001 was excluded because little information was provided on how group sessions were facilitated, so we could not be sure that this study met the inclusion criteria.

\section{Risk of bias in included studies}

See Figure 1 for a summary of risk of bias assessments.

\section{Allocation}

Ickovics 2007a stated a randomised allocation and concealment process whereby allocation was concealed from participants and research staff members until eligibility screening was completed and the study condition was assigned. This was done by a passwordprotected computer-generated randomisation sequence. Kennedy 2011 used the Statistical Package for Social Sciences Version 14 (SPSS) to assign women to either group but did not describe allocation concealment. The studies by Jafari 2010 and Andersson 2013 did not state their method of concealment.

\section{Blinding}

Although blinding to group or conventional antenatal care is not possible, Ickovics $2007 \mathrm{a}$ stated that all measurements and data collection were performed in a blinded fashion. No information 
was given about blinding in the Kennedy 2011 study. Similarly, blinding to the intervention was not possible or was stated in the studies by Jafari 2010 and Andersson 2013.

\section{Incomplete outcome data}

As most of the data were collected by questionnaire, an attrition rate was reported. In the Ickovics $2007 \mathrm{a}$ trial, all participants completed the baseline interview. Eighty-nine completed the third trimester interview, 75\% completed six-month follow-up and $80 \%$ completed 12-month follow-up. Medical record data were collected for $95 \%$ of randomly assigned women. In the Kennedy 2011 trial, $10 \%$ of women were lost to follow-up. It is possible that participants who were lost to follow-up in both studies were those with more negative views or experiences. Similarly, in the Andersson 2013 trial, attrition bias was possible, given that the second questionnaire at six months' postpartum was completed by $53.5 \%$ of women $(228 / 426)$ in the group-based care group, and by $49.7 \%$ of women $(179 / 360)$ in the individual care group. The Jafari 2010 trial reported small attrition rates of $2 \%$ in the group care group and $3.6 \%$ in the individual care group.

\section{Selective reporting}

The largest trial (Ickovics 2007a) reported all primary outcomes. The trial by Andersson 2013 aimed to examine only satisfaction, and measures of this are included. In Kennedy 2011, some data were not provided in tabular form (e.g. social support), although narrative information is presented. Nonetheless, this does not provide evidence of selective reporting.

It is possible that selective reporting occurred in Jafari 2010, as no published protocol was provided, so it is not clear whether all prespecified outcomes were included. A clear primary outcome was not provided. In addition, fetal deaths were excluded without explanation of why or at what stage these deaths occurred.

\section{Other potential sources of bias}

As in most trials of a model of care, blinding of participants and providers was not possible in these trials. This could have created a form of bias, especially if women randomly assigned to standard care groups were unhappy with their allocation. In addition, as providers knew that the trials were being undertaken, they may have changed their behaviours to ensure that intervention groups reported positive satisfaction ratings. Details on these potential forms of bias are not included, so this is not possible to assess.

\section{Effects of interventions}

See: Summary of findings for the main comparison Group antenatal care versus individual antenatal care (adjusted data) for women

\section{Primary outcomes}

No statistically significant differences were reported between women who received group antenatal care and those given standard individual antenatal care on the primary outcome of 'preterm birth' (RR 0.75, 95\% CI 0.57 to 1.00; three trials; $\mathrm{N}=1888$; evidence of moderate quality; Analysis 1.1). No other statistically significant differences were found in any other primary outcomes. Mean gestational age at birth was similar between groups (mean difference (MD) $0.24,95 \%$ CI 0.01 to 0.46 ; Analysis 1.2 ). The proportion of low-birthweight (less than $2500 \mathrm{~g}$ ) babies was similar between the two groups (RR $0.92,95 \%$ CI 0.68 to 1.23 ; three trials; $\mathrm{N}=1935$; evidence of moderate quality; Analysis 1.3), as was the mean birthweight (MD 34.46, 95\% CI -44.32 to 113.24; three trials; $\mathrm{N}=1935$; heterogeneity: $\mathrm{Tau}^{2}=2501.35 ; \mathrm{P}=0.13$; $\mathrm{I}^{2}=52 \%$; Analysis 1.6). Methodological differences and settings could account for the heterogeneity observed for this outcome, although birthweight is a reasonably standard measurement.

The proportion of small-for-gestational age babies was not statistically significantly different between groups (RR 0.92, 95\% CI 0.68 to 1.24 ; two trials; $\mathrm{N}=1473$; Analysis 1.4 ). The perinatal mortality rate was the same between groups (RR 0.63, 95\% CI 0.32 to 1.25 ; three trials; $\mathrm{N}=1943$; evidence of low quality; Analysis 1.5). A total of 15 perinatal deaths were reported in group antenatal care and 18 perinatal deaths in standard care groups.

\section{Secondary outcomes}

Maternal knowledge was examined using antenatal knowledge and readiness for labour and birth and parenting/infant care. The mean level of antenatal knowledge among women allocated to group care was 2.6 times higher (MD 2.60, 95 CI\% 1.7 higher to 3.5 higher) than among those given standard care (one trial; $\mathrm{N}=993$; Analysis 1.11). Mean readiness for labour and birth in group care was 7.6 times higher (MD 7.60, 95\% CI 3.45 higher to 11.75 higher) than among women who received standard care (one trial; $\mathrm{N}=993$; Analysis 1.13). Mean readiness for infant care was similar between groups (MD 3.10, 95\% CI -0.06 to 6.26; one trial; $\mathrm{N}=$ 993; Analysis 1.14).

Satisfaction with antenatal care was rated as high by women who were allocated to group care. Mean satisfaction among those given antenatal group care was 4.9 times higher (MD 4.90, 95\% CI 3.1 higher to 6.7 higher) than among those allocated to standard care (one trial; $\mathrm{N}=993$; evidence of high quality; Analysis 1.15) (unit of measurement not provided). One trial assessed the adequacy of antenatal care and showed that group antenatal care reduced reports of inadequate care (RR 0.81, 95\% CI 0.66 to 0.98 ; Analysis $1.7)$.

No difference in initiation of breastfeeding was observed between groups (average RR $1.10,95 \%$ CI 0.83 to 1.46 ; heterogeneity: $\mathrm{Tau}^{2}=0.01 ; \mathrm{P}=0.0005 ; \mathrm{I}^{2}=87 \%$; three trials; $\mathrm{N}=1733$; evidence of moderate quality). It is possible that methodological differences between trials could account for the heterogeneity. In 
addition, two trials took place in the USA and one in Iran, with one US study specifically recruiting young women (aged 14 to 25 years). Differences in background rates of breastfeeding may have contributed to heterogeneity. The small number of trials also means that heterogeneity is both possible and difficult to explore (Analysis 1.10). Data were insufficient to permit assessment of the duration of exclusive breastfeeding (Analysis 1.29).

Mean Apgar scores (MD 0.03, 95\% CI -0.08 to 0.14; three trials; $\mathrm{N}=1935$; Analysis 1.9) were similar between groups. A higher proportion of babies whose mothers were allocated to group antenatal care were admitted to the neonatal intensive care unit, but again this finding was not statistically significant (average RR 1.48 , 95\% CI 0.63 to 3.45 ; heterogeneity: $\mathrm{Tau}^{2}=0.23$; $\mathrm{P}=0.13$; $\mathrm{I}^{2}=$ $55 \%$; two trials; $\mathrm{N}=1315$; evidence of moderate quality). The criteria for admission to a neonatal intensive care unit may vary across hospitals in these two trials, which could account for this heterogeneity (Analysis 1.8).

Several secondary clinical outcomes were measured but only in one trial (Kennedy 2011; N = 322). These outcomes included induction of labour (RR 0.86, 95\% CI 0.53 to 1.38; Analysis 1.16), augmentation using Syntocinon (RR 1.31, 95\% CI 0.92 to 1.85 ; Analysis 1.17), epidural anaesthesia in labour (RR 1.26, 95\% CI 1.00 to 1.57 ; Analysis 1.19), other pain management (RR 0.85 , 95\% CI 0.58 to 1.24; Analysis 1.18), episiotomy (RR 0.74, 95\% CI 0.26 to 2.09; Analysis 1.20), spontaneous vaginal birth (RR $0.96,95 \%$ CI 0.80 to 1.15 ; evidence of high quality; Analysis 1.21 ) and operative vaginal birth (RR $1.83,95 \%$ CI 0.75 to 4.48 ; Analysis 1.23). No significant differences between groups were noted for any of these outcomes, although the trial was underpowered to show a difference in these outcomes even if it existed. Two trials reported caesarean section rates (Jafari 2010; Kennedy 2011). Data show that women who received group antenatal care were less likely to have a caesarean section, but this finding was not statistically significant (RR $0.83,95 \%$ CI 0.68 to $1.02 ; \mathrm{N}=$ 842; Analysis 1.22).

One trial reported attendance at antenatal care sessions and noted no differences between groups (MD 1.15, 95\% CI 0.52 to 1.78 ; $\mathrm{N}=407$; Analysis 1.30).

Several outcomes related to stress, distress and depression were reported but only in the Ickovics trial (Ickovics 2007a). No differences between groups were reported for the following outcomes: depression during the third trimester (MD -0.20, 95\% CI - 1.97 to 1.57; Analysis 1.24); antenatal distress (MD -0.50, 95\% CI 1.41 to 0.41 ; Analysis 1.12 ); stress at six months' postpartum (MD $-0.40,95 \%$ CI -1.97 to 1.17 ; Analysis 1.27 ) or at 12 months' postpartum (MD 0.24, 95\% CI -2.81 to 3.29; Analysis 1.28); and depression at six months (MD $-0.07,95 \% \mathrm{CI}-1.86$ to 1.72 ; Analysis 1.25 ) and at 12 months (MD $0.10,95 \%$ CI -3.50 to 3.70; Analysis 1.26).

Several secondary outcomes were not reported in either trial and could not be included in this analysis. These included length of hospital stay (maternal and infant), numbers of antenatal sessions/ contact hours, maternal smoking, vaginal birth after caesarean section, maternal self-efficacy or self-confidence for parenting, costeffectiveness and care provider satisfaction.

\section{Non-prespecified outcomes}

Several behavioural outcomes were measured in the Ickovics 2007a trial. These were related to sexual behaviours and STIs and were not included in this review, as they did not address our primary or secondary outcomes.

\section{DISCUSSION}

\section{Summary of main results}

This review included four trials (involving 2350 women) that took place in the USA, Iran and Sweden. All trials followed the CenteringPregnancy (Rising 1998) principles in terms of implementation of intervention arms, and a high level of consistency in the intervention is evident across the trials.

The four trials had different primary outcomes, and all except Andersson 2013 reported perinatal outcomes. The primary outcome in the Ickovics 2007a trial was HIV risk behaviours and STDs, whereas the primary outcome in the Kennedy 2011 trial was family healthcare readiness in military settings. The Jafari 2010 trial included perinatal outcomes as primary outcomes, and the Andersson 2013 trial assessed content of care and women's opinions. The focus of this review is perinatal outcomes.

No statistically significant differences were noted between women who received group antenatal care and those given standard individual antenatal care for the primary outcome of 'preterm birth' (RR 0.75, 95\% CI 0.57 to 1.00 ; three trials; $\mathrm{N}=1943$ ). Reductions in preterm birth have been recently linked to midwifery-led continuity of care models in a systematic review by Sandall 2013. Among trials that reported preterm birth, women attended eight to 10 antenatal care and education sessions throughout pregnancy, which were facilitated by midwives or other healthcare professionals (e.g. obstetricians, registered nurses). This represents significantly more time with a healthcare professional during pregnancy compared with women given standard individual care. Additional trials of group antenatal care might result in statistically significant findings for this outcome because the Sandall 2013 review included seven trials $(\mathrm{N}=11,500)$ and this (current) review includes only three trials that reported preterm birth.

All other outcomes showed no statistically significant differences between groups. However, some benefits in behavioural outcomes were reported, although it should be noted that some of these outcomes were measured in only one trial. 
Benefits in relation to women's satisfaction with care were reported. It is possible that time spent in group antenatal care provided additional opportunities for sharing of information and development of relationships between pregnant women. Women valued the additional time and the environment in which care was provided. The experiences of midwives have also been studied, and this research provides suggestions for the implementation and sustainability of the CenteringPregnancy model of care that will be useful for future studies (Baldwin 2011).

Cost-effectiveness analyses were not reported in any trial; this is a significant limitation. In addition, no data on care provider outcomes were provided.

This review is limited by the small numbers of included studies/ women and by the fact that most of the analyses are based on a single study. Continued research is required to determine whether group antenatal care is associated with significant benefits.

\section{Overall completeness and applicability of evidence}

Four trials comparing group antenatal care and standard antenatal care are included in this review. All compared the effects of both types of antenatal care on women and their babies. However, studies were undertaken in very different countries: two in the USA, and one in both Sweden and Iran. Although many facets of antenatal care in the USA are similar to those in other countries, it must be noted that funding models and health workforce are different in the USA from those seen in many other countries. Also, the few studies identified are not sufficient to fully address all of the objectives of this review. The rate of outcomes such as 'preterm birth' is higher in these trials than in trials in some other countries, which potentially reduces the applicability of the evidence.

\section{Quality of the evidence}

The overall risk of bias for the included studies was assessed as acceptable (Andersson 2013; Jafari 2010) and good (Ickovics 2007a; Kennedy 2011). The main limitations were lack of description of allocation concealment (Kennedy 2011) and 'unclear' allocation concealment (Andersson 2013; Jafari 2010). In addition, the Andersson 2013 trial paper did not state which data collection tools were used that were within the linked clinical trial site. This may have indicated some reporting bias. No included trial described blinding of participants and personnel; two trials described blinding of outcome assessment (Jafari 2010; Kennedy 2011). We used GRADE to assess the evidence for seven prespecified outcomes, and results ranged from low quality (perinatal mortality) to moderate quality (preterm birth, low birthweight, neonatal intensive care unit admission, breastfeeding initiation) to high quality (satisfaction with antenatal care, spontaneous vaginal birth). Please see Summary of findings for the main comparison.

\section{Potential biases in the review process}

The review authors have undertaken a pilot study of group antenatal care using CenteringPregnancy principles (Teate 2011). This was done in collaboration with Professor Schindler-Rising, the founder of CenteringPregnancy in the USA, and a co-author and advisor for both trials in this review. Professor Schindler-Rising was not involved in this review and her assistance did not bias methodology or findings.

\section{Agreements and disagreements with other studies or reviews}

Other non-randomised studies of CenteringPregnancy have similarly demonstrated improvement in rates of social isolation, prematurity and babies with low birthweight, as well as in social and emotional outcomes including social support and satisfaction with care (Grady 2004; Teate 2011). However, one feasibility study in the UK did not show improved health-promoting behaviours (Shakespear 2010). This study used a non-randomised cross-sectional design and showed that women in the CenteringPregnancy programme had significantly lower index health behaviour scores compared with those in the traditional care group (Shakespear 2010). The feasibility study showed that CenteringPregnancy group antenatal care could be implemented in a UK setting (Gaudion 2010; Gaudion 2011). Qualitative studies in the USA have shown that CenteringPregnancy was well received by urban, low-income women during their pregnancy and may offer value to select populations (Herrman 2012). Group antenatal care has also been implemented in Sweden in a non-randomised twogroup pilot study. Differences between outcomes among groups were few, although at six months' postpartum, women who attended group antenatal care still met with others from the group more regularly than women who attended traditional antenatal care (Wedin 2010).

CenteringPregnancy builds on other studies of health care provided in groups as a means of sharing information, giving support and bringing about behavioural change. Group models of health care have begun to emerge and are showing improved clinical outcomes and patient satisfaction among chronically ill, older people (Beck 1997; Scott 2004). In another example, one RCT of group care for participants with type 1 diabetes showed improvement in quality of life, knowledge and health behaviours (Trento 2005). This improvement in quality of life was independent of the increase in knowledge and behaviours. In another study of chronically ill participants, group care was associated with higher satisfaction scores, particularly with reference to the quality of care received and time spent with care providers, as well as higher quality of life at two-year follow-up (Scott 2004).

Designing health care that is provided for groups instead of individuals is a relatively new idea that is attracting increasing attention. Traditionally, the experience of group activities for women 
during the childbearing years has predominantly consisted of antenatal education programmes or new mothers' groups. More recently, the importance of antenatal groups that promote social support and sharing of information has been highlighted, citing as an example the groups provided by the Albany Midwifery Practice in London (UK) (Leap 2007).

Group antenatal care was implemented in these trials according to the principles of CenteringPregnancy, which serve as clear guidelines for maintaining model fidelity. This includes a defined process of training for group facilitators, certification of sites once they have adhered to the guidelines and a commitment to contributing data for ongoing evaluation. Becoming a certified CenteringPregnancy site requires payment of registration fees and release of staff for initial and ongoing training. It is not clear whether adherence to guidelines for training and registration is possible in all settings, especially in countries other than the USA.

\section{AUTHORS' CONCLUSIONS}

\section{Implications for practice}

We found only four RCTs on group antenatal care; this limits the evidence base for this intervention. Group antenatal care was not associated with a lower rate of preterm birth, although additional studies are needed to confirm this finding. No adverse outcomes for women and their babies were reported, and women reported high levels of satisfaction with group antenatal care.

An inadequate literature base limits the ability to make practice recommendations; however, evidence suggests maternal satisfaction and adequacy of antenatal care, which could be considered in the future design of antenatal care programmes. Continued research into this intervention is required.

\section{Implications for research}

Only four RCTs have been conducted in this important area. Additional research is needed on outcomes for women who choose group antenatal care and for their babies. Further work is necessary to understand the trend towards women in group antenatal care experiencing less preterm birth. One integrative literature review undertaken to describe (1) conceptual components of the CenteringPregnancy practice model, (2) characteristics of the CenteringPregnancy literature and (3) research methods and outcomes across the CenteringPregnancy research literature has also highlighted the need for further research in this area (Novick 2011). In particular, further research will lead to greater knowledge about the factors inherent in this model that promote participant behavioural changes, resulting in better perinatal outcomes and circumstances that maximise the effectiveness of this model (Manant 2012).
Future researchers need to consider whether benefits are derived for specific groups of women, for example, those who are obese. Evidence suggests that group programmes can be more effective than individual or self-help approaches to weight management (Heshka 2003). A new model of group antenatal care for women with obesity has been implemented in New South Wales, Australia (Davis 2012). This group-based antenatal care consists of basic antenatal care and assessment (blood pressure, urinalysis, fundal height measurement, fetal heart rate, etc.), education on healthy eating and physical activity during pregnancy, setting of weight management goals, peer support, encouragement and motivational techniques. Further research is required to evaluate the success of this model in terms of assisting women to manage their weight during pregnancy and ultimately improving maternity outcomes for mothers and babies at risk of complications owing to obesity. These trials must include a comprehensive cost analysis if economic ramifications are to be determined.

As the relationship between women and their care providers throughout pregnancy, labour and birth is fundamental to their experience of childbirth (Hunter 2008), it is important to examine the impact of group antenatal care without ongoing care during labour from the same care providers. It would be useful to explore whether benefits are associated with group antenatal care plus continuity of care provider into labour and birth and the postpartum period. In addition, it is important to examine whether group care contributes to women's activation and empowerment, and whether women receiving this type of care have access to the same level of information from care providers as those receiving standard one-to-one care.

Future researchers should seek to determine the best model for group antenatal care. For example, should partners be encouraged to attend? Or are women-only groups more beneficial? Other areas that need further exploration include the potential needs of some women for greater privacy and more individualised care.

The experience of care providers was an area of interest of this review, although no data were found to address this component of the planned review. Future researchers need to consider the experiences of care providers, including costs of training and ongoing support mechanisms and experiences. Research into these factors will provide evidence as to the sustainability of group antenatal care and the systems and approaches that need to be put in place for this model to be successful.

\section{ACKNOW LEDGEMENTS}

As part of the prepublication editorial process, the first version of this review (Homer 2012) was commented on by three peers (an editor and two referees who are external to the editorial team), a member of the Pregnancy and Childbirth Group's international 
panel of consumers and the Group's Statistical Adviser. We thank the reviewers of the initial submission for their very helpful comments and suggestions.

For the 2014 update, Nancy Medley's work was financially supported by the UNDP/UNFPA/UNICEF/WHO/World Bank Special Programme of Research, Development and Research Training in Human Reproduction (HRP), Department of Reproductive Health and Research (RHR), World Health Organization. The named review authors alone are responsible for the views expressed in this publication.

\section{R E F E R E N C E S}

\section{References to studies included in this review}

\section{Andersson 2013 \{published data only\}}

Andersson E. Group based care versus individual care effects on parents satisfaction and health. ClinicalTrials.gov (http://clinicaltrials.gov/) [accessed 3 October 2013].

* Andersson E, Christensson K, Hildingsson I. Mothers' satisfaction with group antenatal care versus individual antenatal care - a clinical trial. Sexual and Reproductive Healthcare 2013;4(3):113-20.

Ickovics 2007a \{published data only\}

* Ickovics JR, Kershaw TS, Westdahl C, Magriples U, Massey Z, Reynolds H, et al.Group prenatal care and perinatal outcomes: a randomized controlled trial. Obstetrics \& Gynecology 2007;110(2 Pt 1):330-9. Ickovics JR, Reed E, Magriples U, Westdahl C, Schindler Rising S, Kershaw TS. Effects of group prenatal care on psychosocial risk in pregnancy: results from a randomised controlled trial. Psychology \& Health 2011;26(2):235-50. Kershaw TS, Magriples U, Westdahl C, Schindler Rising S, Ickovics J. Pregnancy as a window of opportunity for HIV prevention: effects of an HIV intervention delivered within prenatal care. American Journal of Public Health 2009;99 (11):2079-86.

Magriples U, Kershaw TS, Rising SS, Massey Z, Ickovics JR. Prenatal health care beyond the obstetrics service: utilization and predictors of unscheduled care. American Journal of Obstetrics and Gynecology 2008;198(1):75.e1-75.e7. Magriples U, Kershaw TS, Rising SS, Westdahl C, Ickovics JR. The effects of obesity and weight gain in young women on obstetric outcomes. American Journal of Perinatology 2009;26(5):365-71.

Novick G, Reid E, Lewis J, Kershaw S, Rising SS, Ickovics R. Group prenatal care: model fidelity and outcomes. American Journal of Obstetrics \& Gynecology 2013;209(2): 112.e1-112.e6.

Novick G, Reid E, Lewis J, Kershaw T, Rising S, Ickovics R. Group prenatal care: model fidelity and outcomes. Journal of Midwifery \& Women's Health 2013;58(5):586-7.

Westdahl CM, Kershaw T, Schindler-Rising S, Ickovics J. Group prenatal care improves breastfeeding initiation and duration: results from a two-site randomized controlled trial. Journal of Human Lactation 2008;24(1):96-7.

Jafari 2010 \{published data only\}

Jafari F, Eftekhar H, Fotouhi A, Mohammad K, Hantoushzadeh S. Comparison of maternal and neonatal outcomes of group versus individual prenatal care: a new experience in Iran. Health Care for Women International 2010;31(7):571-84.

Kennedy 2011 \{published data only\}

Kennedy HP. Enhancing family readiness through group prenatal care. 2009. 131.158.7.207/cgi-bin/tsnrp/ search studies. cgi?id=236. (accessed 19 September 2012). Kennedy HP, Farrell T, Paden R, Hill S, Jolivet R, Rising SS. A randomized clinical trial of group prenatal care in the military. Journal of Midwifery and Women's Health 2007;52 (5):532.

Kennedy HP, Farrell T, Paden R, Hill S, Jolivet R, Willetts J, et al."I wasn't alone" - a study of group prenatal care in the military. Journal of Midwifery \& Women's Health 2009; 54(3):176-83.

* Kennedy HP, Farrell T, Paden R, Hill S, Jolivet RR, Cooper BA, et al.A randomized clinical trial of group prenatal care in two military settings. Military Medicine 2011;176(10):1169-77.

\section{References to studies excluded from this review}

\section{Bhutta 2008 \{published data only\}}

Bhutta ZA, Memon ZA, Soofi S, Salat MS, Cousens S, Martines J. Implementing community-based perinatal care: results from a pilot study in rural Pakistan. Bulletin of the World Health Organization 2008;86(6):452-9.

Ford 2001 \{published data only\}

Ford K, Hoyer P, Weglicki L, Kershaw T, Schram C, Jacobson M. Effects of a prenatal care intervention on the self-concept and self-efficacy of adolescent mothers. Journal of Perinatal Education 2001;10(2):15-22.

Ford K, Weglicki L, Kershaw T, Schram C, Hoyer PJ, Jacobson ML. Effects of a prenatal care intervention for adolescent mothers on birth weight, repeat pregnancy, and 
educational outcomes at one year postpartum. Journal of Perinatal Education 2002;11(1):35-8.

Koushede 2013 \{published data only\}

Koushede V, Brixval CS, Axelsen SF, Lindschou J, Winkel P, Maimburg RD, et al.Group-based antenatal birth and parent preparation for improving birth outcomes and parenting resources: study protocol for a randomised trial. Sexual and Reproductive Healthcare 2013;4(3):121-6.

Leung 2012 \{published data only\}

Leung SSK, Lam TH. Group antenatal intervention to reduce perinatal stress and depressive symptoms related to intergenerational conflicts: a randomized controlled trial. International Journal of Nursing Studies 2012;49(11): 1391-402.

Manandhar 2004 \{published data only\}

Borghi J, Thapa B, Osrin D, Jan S, Morrison J, Tamang S, et al.Economic assessment of a women's group intervention to improve birth outcomes in rural Nepal. Lancet 2005;366 (9500):1882-4.

* Manandhar DS, Osrin D, Shrestha BP, Mesko N, Morrison J, Tumbahangphe KM, et al.Effect of a participatory intervention with women's groups on birth outcomes in Nepal: cluster-randomised controlled trial.

Lancet 2004;364:970-9.

Osrin D, Mesko N, Shrestha BP, Shrestha D, Tamang

$S$, Thapa $S$, et al.Implementing a community-based participatory intervention to improve essential newborn care in rural Nepal. Transactions of the Royal Society of Tropical Medicine \& Hygiene 2003;97:18-21.

Wade A, Osrin D, Shrestha BP, Sen A, Morrison J, Tumbahangphe KM, et al.Behaviour change in perinatal care practices among rural women exposed to a women's group intervention in Nepal [ISRCTN31137309]. BMC Pregnancy and Childbirth 2006;6:20.

Olenick 2011 \{published data only\}

Olenick P, Berens P. The effect of structured group prenatal education on breastfeeding confidence, duration, and exclusivity to 12 weeks postpartum. Breastfeeding Medicine 2010;5(6):334.

* Olenick PL. The effect of structured group prenatal education on breastfeeding confidence, duration, and exclusivity to 12 weeks postpartum. Journal of Human Lactation 2011;27(1):71-2.

Olenick PL. The effect of structured group prenatal education on breastfeeding confidence, duration, and exclusivity to 12 weeks postpartum. Journal of Obstetric Gynecologic \& Neonatal Nursing 2010;39:S104-S105.

Salmela-Aro 2012 \{published data only\}

Salmela-Aro K, Read S, Rouhe H, Halmesmaki E, Toivanen RM, Tokola MI, et al.Promoting positive motherhood among nulliparous pregnant women with an intense fear of childbirth: RCT intervention. Journal of Health Psychology 2012;17(4):520-34.

\section{References to ongoing studies}

Ickovics 2009 \{published data only\}

Ickovics JR. Effectiveness of integrating prenatal care in reducing HIV/STDs among young pregnant women. ClinicalTrials.gov (http://clinicaltrials.gov/) (accessed 9 April 2008).

\section{Additional references}

\section{Baldwin 2006}

Baldwin KA. Comparison of selected outcomes of CenteringPregnancy versus traditional prenatal care. Journal of Midwifery and Women's Health 2006;51(4):266-72.

\section{Baldwin 2011}

Baldwin K, Phillips G. Voices along the journey: midwives' perceptions of Implementing the CenteringPregnancy model of prenatal care. Journal of Perinatal Education 2012; 20(4):210-7.

Beck 1997

Beck A, Scott J, Williams P, Robertson B, Jackson D, Gade $\mathrm{G}$, et al.A randomized trial of group outpatient visits for chronically ill older HMO members: the Cooperative Health Care Clinic. Journal of the American Geriatric Society 1997;45(5):543-9.

Benediktsson 2013

Benediktsson I, McDonald SW, Vekved M, McNeil DA, Dolan SM, Tough SC. Comparing CenteringPregnancy ${ }^{\circledR}$ to standard prenatal care plus prenatal education. $B M C$ Pregnancy and Childbirth 2013;13(Suppl 1):S5.

Brown 2014

Brown SJ, Sutherland GA, Gunn JM, Yelland JS. Changing models of public antenatal care in Australia: is current practice meeting the needs of vulnerable populations?. Midwifery 2014;30(3):303-9.

\section{Cohen 1983}

Cohen S, Kamarck T, Mermelstein R. A global measure of perceived stress. Journal of Health and Social Behavior 1983; 24:385-96.

\section{Davis 2012}

Davis D, Raymond J, Clements V, Adams C, Mollart L, Teate A, Foureur M. Addressing obesity in pregnancy: the design and feasibility of an innovative intervention in NSW, Australia. Women and Birth 2012;25(4):174-80.

Devane 2010

Devane D, Begley C, Clarke M, Walsh D, Sandall J, Ryan P, et al.Socioeconomic Value of the Midwife: A Systematic Review, Meta-Analysis, Meta-Synthesis and Economic Analysis of Midwife-Led Models of Care. London: Royal College of Midwives, 2010.

Dunkel-Schetter 2001

Dunkel-Schetter C, Gurung RAR, Lobel M, Wadhwa PD. Stress processes in pregnancy and birth: psychological, biologic, and sociocultural influences. In: Baum A, Revenson TA, Singer JE editor(s). Handbook of Health Psychology. Mahwah NJ: Lawrence Erlbaum, 2001: 495-518. 


\section{Gaudion 2010}

Gaudion A, Bick D, Menka Y, Demilew J, Walton C, Yiannouzis $\mathrm{K}$, et al.Adapting the CenteringPregnancy model for a UK feasibility study. British Journal of Midwifery 2010; 19(7):433-8.

\section{Gaudion 2011}

Gaudion A, Menka Y. 'No decision about me without me': Centering Pregnancy. Practising Midwife 2011;13(10): $15-8$.

\section{Gottvall 2004}

Gottvall K, Grunewald C, Waldenström U. Safety of birth centre care: perinatal mortality over a 10 -year period. BJOG: an international journal of obstetrics and gynaecology 2004;111(1):71-8.

GRADE 2014

McMaster University. GRADEpro. [Computer program on www.gradepro.org]. Version [2014]. McMaster University, 2014.

Grady 2004

Grady MA, Bloom KC. Pregnancy outcomes of adolescents enrolled in a CenteringPregnancy program. Journal of Midwifery and Women's Health 2004;49(5):412-20.

Herrman 2012

Herrman JW, Rogers S, Ehrenthal DB. Women's perceptions of CenteringPregnancy: a focus group study. $M C N$ : American Journal of Maternal Child Nursing 2012;37(1): $19-26$.

\section{Heshka 2003}

Heshka S, Anderson J, Atkinson R, Greenway F, Hill J. Weight loss with self-help compared with a structured commercial program. A randomized trial. JAMA 2003;289 (14):1792-8.

Higgins 2011

Higgins JPT, Green S (editors). Cochrane Handbook for Systematic Reviews of Interventions Version 5.1.0 [updated March 2011]. The Cochrane Collaboration, 2011. www.cochrane-handbook.org.

Hildingsson 2005

Hildingsson I, Radestad I. Swedish women's satisfaction with medical and emotional aspects of antenatal care. Journal of Advanced Nursing 2005;52(3):239-49.

Hildingsson 2013

Hildingsson I, Haines H, Cross M, Pallant JF, Rubertsson C. Women's satisfaction with antenatal care: comparing women in Sweden and Australia. Women and Birth 2013; 26(1):e9-e14.

\section{Homer 2006}

Homer C. Challenging midwifery care, challenging midwives and challenging the system. Women and Birth 2006;19:79-83.

\section{Homer 2014}

Homer CS, Friberg IK, Dias MA, ten Hoope-Bender P, Sandall J, Speciale AM, et al.The projected effect of scaling up midwifery. Lancet 2014;384(9948):1146-57.

\section{Hunter 2008}

Hunter B, Berg M, Lundgren I, Olafsdottir OA, Kirkham M. Relationships: the hidden threads in the tapestry of maternity care. Midwifery 2008;24:132-7.

\section{Ickovics 2003}

Ickovics JR, Kershaw TS, Westdahl C, Rising SS, Klima C, Reynolds $\mathrm{H}$, et al.Group prenatal care and preterm birth weight: results from a matched cohort study at public clinics. Obstetrics \& Gynecology 2003;102(5):1051-7.

\section{Klima 2009}

Klima C, Norr K, Vonderheid S, Handler A. Introduction of CenteringPregnancy in a public health clinic. Journal of Midwifery \& Women's Health 2009;54(1):27-34. [PUBMED: 19114236]

\section{Kotelchuck 1994}

Kotelchuck M. The Adequacy of Prenatal Care Utilization Index: its US distribution and association with low birthweight. American Journal of Public Health 1994;84(9): 1486-9.

Leap 2007

Leap N, Edwards N. The politics of involving women in decisions about their care. In: Page L, McCandlish R editor (s). The New Midwifery: Science and Sensitivity in Practice. Second Edition. Edinburgh: Churchill Livingstone, 2007.

\section{Littlefield 1987}

Littlefield VM, Adams BN. Patient participation in alternative perinatal care: impact on satisfaction and health locus of control. Research in Nursing \& Health 1987;10(3): $139-48$.

Lobel 1992

Lobel M, Dunkel-Schetter C, Scrimshaw SC. Prenatal maternal stress and prematurity: a prospective study of socioeconomically disadvantaged women. Health Psychology 1992;11:32-40.

Lobel 1996

Lobel M. The Revised Pregnancy Distress Questionnaire (NUPDQ). Stony Brook (NJ): State University of New York, 1996.

\section{Logsdon 2003}

Logsdon MC, Davis DW. Social and professional support for pregnant and parenting women. MCN: American Journal of Maternal and Child Nursing 2003;28(6):371-6.

Manant 2012

Manant A, Dodgson JE. CenteringPregnancy: an integrative literature review. Journal of Midwifery and Women's Health 2012;56:94-102.

\section{Massey 2006}

Massey Z, Rising S, Ickovics J. CenteringPregnancy group prenatal care: promoting relationship-centered care. Journal of Obstetric, Gynecologic, and Neonatal Nursing 2006;35(2): 286-94.

NICE 2008

NICE. Antenatal Care: Routine Care for the Healthy Pregnant Woman. London: National Collaborating Centre for Women's and Children's Health, 2008. 


\section{Norbeck 1983}

Norbeck JS, Lindsey AM, Carrieri VL. Further development of the Norbeck Social Support Questionnaire: normative data and validity testing. Nursing Research 1983;32(1):4-9.

\section{Novick 2011}

Novick G, Sadler L, Kennedy H, Cohen S, Groce N, Knafl $\mathrm{K}$. Women's experience of group prenatal care. Qualitative Health Research 2011;21:97-116.

\section{Novick 2013}

Novick Gina, Reid Allecia E, Lewis Jessica, Kershaw Trace S, Rising Sharon Schindler, Ickovics Jeannette R. Group prenatal care: model fidelity and outcomes. American Journal of Obstetrics \& Gynecology 2013;209(2):112.e1-6.

\section{Patil 2013}

Patil C, Abrams E, Klima C, Kaponda C, Leshabari, S, Vonderheid S, et al.CenteringPregnancy-Africa: a pilot of group antenatal care to address Millennium Development Goals. Midwifery 2013;29(10):1190-8.

\section{Piaggio 2001}

Piaggio G, Carroli G, Villar J, Pinol A, Bakketeig L, Lumbiganon $\mathrm{P}$, et al.Methodological considerations on the design and analysis of an equivalence stratified cluster randomization trial. Statistics in Medicine 2001; Vol. 20, issue 3:401-16. [: CN-00455986]

\section{Renfrew 2014}

Renfrew M, McFadden A, Bastos H, Campbell J, Channon A, Cheung $\mathrm{N}$, et al.Midwifery and quality care: findings from a new evidence informed framework for maternal and newborn care. Lancet 2014;384:1129-45.

\section{RevMan 2014}

The Nordic Cochrane Centre, The Cochrane Collaboration. Review Manager (RevMan). 5.3. Copenhagen: The Nordic Cochrane Centre, The Cochrane Collaboration, 2014.

\section{Rising 1998}

Rising SS. Centering Pregnancy: an interdisciplinary model of empowerment. Journal of Nurse-Midwifery 1998;43(1): $46-54$.

\section{Rising 2004}

Rising S, Powell Kennedy H, Klima C. Redesigning prenatal care through CenteringPregnancy. Journal of Midwifery and Women's Health 2004;49(5):398-404.

\section{Sandall 2013}

Sandall J, Soltani H, Gates S, Shennan A, Devane D. Midwife-led continuity models versus other models of care for childbearing women. Cochrane Database of Systematic Reviews. John Wiley \& Sons, Ltd, 2013, issue 8. [DOI: 10.1002/14651858.CD004667.pub3; : CD004667]

Schunemann 2009

Schunemann HJ. GRADE: from grading the evidence to developing recommendations. A description of the system and a proposal regarding the transferability of the results of clinical research to clinical practice [GRADE: Von der Evidenz zur Empfehlung. Beschreibung des Systems und Losungsbeitrag zur Ubertragbarkeit von Studienergebnissen]. Zeitschrift fur Evidenz, Fortbildung und Qualitat im Gesundheitswesen 2009;103(6):391-400. [PUBMED: 19839216]

\section{Scott 2004}

Scott JC, Conner DA, Venohr I, Gade G, McKenzie M, Kramer AM, et al.Effectiveness of a group outpatient visit model for chronically ill older Health Maintenance Organization members: a 2-year randomized trial of the Cooperative Health Care Clinic. Journal of the American Geriatric Society 2004;52:1463-70.

Shakespear 2010

Shakespear K, Waite PJ, Gast J. A comparison of health behaviors of women in centering pregnancy and traditional prenatal care. Maternal and Child Health Journal 2010;14 (2):202-8.

Sinclair 1999 Sinclair M, O'Boyle C. The childbirth self-efficacy inventory: a replication study. Journal of Advanced Nursing 1999;30(6):1416-23.

Teate 2011

Teate A, Leap N, Schindler-Rising S, Homer CSE. Women's experiences of group antenatal care in Australia - the CenteringPregnancy Pilot Study. Midwifery 2011;27:13845.

Teate 2013

Teate A, Leap N, Homer CS. Midwives' experiences of becoming CenteringPregnancy facilitators: a pilot study in Sydney, Australia. Women and Birth 2013;26(1):e31-6. [PUBMED: 22926224]

\section{Tracy 2013}

Tracy K, Hartz L, Tracy B, Allen J, Forti Amanda, Hall B, et al.Caseload midwifery care versus standard maternity care for women of any risk: M@NGO, a randomised controlled trial. Lancet 2013;382:1723-32.

Trento 2005

Trento M, Passera P, Borgo E, Tomalino M, Bajardi M, Brescianini $\mathrm{A}$, et al.A 3-year prospective randomized controlled clinical trial of group care in type 1 diabetes. Nutrition, Metabolism and Cardiovascular Disease 2005;15 (4):293-301.

Villar 2001

Villar J, Carroli G, Khan-Neelofur D, Piaggio G, Gülmezoglu M. Patterns of routine antenatal care for lowrisk pregnancy. Cochrane Database of Systematic Reviews 2001, Issue 4. [DOI: 10.1002/14651858.CD000934]

Wedin 2010

Wedin K, Molin J, Svalenius ELC. Group antenatal care: new pedagogic method for antenatal care - a pilot study. Midwifery 2010;26(4):389-93.

\section{References to other published versions of this review}

\section{Homer 2012}

Homer CSE, Ryan C, Leap N, Foureur M, Teate A, Catling-Paull CJ. Group versus conventional antenatal care for women. Cochrane Database of Systematic Reviews 2012, Issue 11. [DOI: 10.1002/14651858.CD007622.pub2] 
* Indicates the major publication for the study

\section{CHARACTERISTICS OF STUDIES}

\section{Characteristics of included studies [ordered by study ID]}

\section{Andersson 2013}

Methods

This study randomly assigned a minimum of 2 midwives working in the same antenatal clinic to provide group-based antenatal care or standard care

Participants

A total of 31 midwives from 12 antenatal clinics in Sweden accepted the invitation to participate. These midwives were given information about the study and the 2 models of care before they consented to participate

Interventions

Group-based care took place beginning at 20 weeks' gestation. Visits lasted 2 hours and incorporated an antenatal check for each woman. 8 structured sessions were planned

Outcomes

Data were collected by 2 questionnaires: the first completed during the first trimester before the antenatal programme began, and the second 6 months after birth. Data in the first questionnaire consisted of demographics including age, parity, civil status, country of birth, financial situation, tobacco use, chronic disease and whether the pregnancy was planned. The second questionnaire included questions on opinions about the number of antenatal visits, caregivers and content of care. Detailed questions were asked about the approach of the midwives and about medical and emotional aspects of care. These questions were assessed on a 4-point Likert scale

Notes

Dates the study was conducted: Women were recruited between September 2008 and December 2010

Funding source: Karolinska Institutet.

Declarations of interest: none.

\section{Risk of bias}

\begin{tabular}{|c|c|c|}
\hline Bias & Authors' judgement & Support for judgement \\
\hline $\begin{array}{l}\text { Random sequence generation (selection } \\
\text { bias) }\end{array}$ & Unclear risk & $\begin{array}{l}\text { No information on random sequence gen- } \\
\text { eration was provided. }\end{array}$ \\
\hline Allocation concealment (selection bias) & Unclear risk & Method of concealment was not described. \\
\hline $\begin{array}{l}\text { Incomplete outcome data (attrition bias) } \\
\text { All outcomes }\end{array}$ & High risk & $\begin{array}{l}\text { In the intervention group, } 24 \text { midwives } \\
\text { were randomly assigned to provide care } \\
\text { for } 426 \text { women. Of these women, } 171 \\
\text { ( } 40 \% \text { ) were lost to follow-up. In the con- } \\
\text { trol group, } 24 \text { midwives were randomly as- } \\
\text { signed to provide care for } 360 \text { women. Of } \\
\text { these women, } 122(34 \%) \text { were lost to fol- }\end{array}$ \\
\hline
\end{tabular}


Andersson 2013 (Continued)

\begin{tabular}{|c|c|c|}
\hline & & $\begin{array}{l}\text { low-up. It is possible that women who were } \\
\text { lost to follow-up might have been those } \\
\text { who reported more frequent negative (or } \\
\text { positive) views or experiences }\end{array}$ \\
\hline Selective reporting (reporting bias) & Low risk & $\begin{array}{l}\text { This study aimed to assess only satisfaction, } \\
\text { and several measures of this are included }\end{array}$ \\
\hline Other bias & High risk & $\begin{array}{l}\text { This study randomly assigned providers of } \\
\text { care rather than recipients of care. Providers } \\
\text { then provided care according to their allo- } \\
\text { cation. At the first antenatal visit, women } \\
\text { were informed of the study and were ran- } \\
\text { domly assigned to intervention or control } \\
\text { group care on the basis of day of the month } \\
\text { that their baby was due or on an alternative } \\
\text { basis. It was possible that this approach in- } \\
\text { troduced bias. Attrition bias was also pos- } \\
\text { sible, given that the second questionnaire } \\
\text { at } 6 \text { months' postpartum was completed by } \\
53.5 \% \text { of women ( } 228 / 426) \text { in the group- } \\
\text { based care group, and by } 49.7 \% \text { of women } \\
\text { (179/360) in the individual care group }\end{array}$ \\
\hline $\begin{array}{l}\text { Blinding of participants and personnel } \\
\text { (performance bias) } \\
\text { All outcomes }\end{array}$ & High risk & $\begin{array}{l}\text { No blinding was undertaken. Midwives } \\
\text { who were randomly assigned to provide in- } \\
\text { tervention or control were aware of their } \\
\text { allocation }\end{array}$ \\
\hline $\begin{array}{l}\text { Blinding of outcome assessment (detection } \\
\text { bias) } \\
\text { All outcomes }\end{array}$ & High risk & $\begin{array}{l}\text { No information on blinding of outcomes } \\
\text { assessment was provided }\end{array}$ \\
\hline
\end{tabular}

Ickovics 2007a

Methods

Randomised controlled trial of young pregnant women receiving antenatal care at 2 public clinics in the USA from December 2001 to December 2004. Women were randomly assigned to 1 of 3 groups. Baseline interviews during the second trimester and follow-up interviews were conducted in the third trimester and at 6 and 12 months' postpartum. Birth outcome data were collected at time of birth. The study was originally powered statistically to detect differences in STI. Secondary power analyses were conducted using preterm birth as the outcome

Participants

Young women ( 14 to 25 years of age; $\mathrm{N}=1047$ ) entering antenatal care at 2 publicly funded clinics in Atlanta, Georgia, and New Haven, Connecticut

Interventions

Participants were randomly assigned to 1 of 3 groups: (1) standard individual care, (2) CenteringPregnancy care, (3) integrated CenteringPregnancy plus group care that included specific skill building in the areas of HIV STD prevention, including assertiveness

Group versus conventional antenatal care for women (Review)

Copyright () 2015 The Cochrane Collaboration. Published by John Wiley \& Sons, Ltd. 
Ickovics 2007a (Continued)

and negotiation skills

Outcomes

Notes
Primary outcomes for the study included differences in the incidence of STI. Specific outcomes included bacterial STI acquisition (chlamydia and gonorrhoea) at 6 and 12 months' postpartum, repeat pregnancy, condom use, number of unprotected sex occasions, safe sex communication and HIV and STI risk knowledge

Secondary outcomes included gestational age at birth and infant birthweight (smallfor-gestational age, preterm birth, gestational age, low birthweight). Neonatal outcomes such as fetal demise, neonatal intensive care unit admission and Apgar at 5 minutes were included. Maternal outcomes included hypertension, diabetes, pre-eclampsia, multiple gestations, fetal abnormalities, weight gain during pregnancy and breastfeeding initiation and duration. Clinical outcomes were collected from medical records by trained medical abstractors, who were independent of care and were blinded to study assignment

Psychosocial outcomes measured during the third trimester included stress (using the Perceived Stress Scale), self-esteem (using a self-reported Likert-type scale), social support and social conflict (using a subscale of the Social Relationship Scale), depression (using the Center for Epidemiologic Studies Depression Scale scale) and demographic and behavioural characteristics. Antenatal knowledge, readiness for labour and birth and satisfaction with antenatal care were also measured

Adequacy of antenatal care was measured using the Kotelchuck Index (Kotelchuck 1994); antenatal knowledge was measured using a continuous measure from a non-validated tool devised by study authors; details of the unit of measurement were not provided. Readiness for labour and birth and readiness for infant care were measured using a continuous variable, although the units of measurement were not stated. Antenatal distress was measured by the established Pregnancy Distress Questionnaire (Lobel 1996), although the unit of measurement was not provided. Satisfaction was measured using an adaptation of an existing tool (Patient Participation and Satisfaction Questionnaire) (Littlefield 1987), although the process of adaptation and the eventual unit of measurement were not described

The updated search identified an additional secondary analysis Novick 2013. This paper focused on process and content fidelity of the intervention using ratings from independent researchers who were not involved in delivery of the intervention

\section{Risk of bias}

Bias

Authors' judgement

Random sequence generation (selection Low risk bias)
Support for judgement

Participants were randomly assigned by using a blocked randomised controlled design stratified on the basis of site and expected month of birth. A computer-generated randomisation sequence, password protected for recruitment staff and participants, was used to assign participants

Allocation concealment (selection bias) Low risk
Allocation was concealed from participants and research staff until eligibility screening was completed and study condition was 


\begin{tabular}{|c|c|c|}
\hline & & $\begin{array}{l}\text { assigned. These tasks were completed by } \\
\text { trained research team members who were } \\
\text { independent of antenatal care }\end{array}$ \\
\hline $\begin{array}{l}\text { Incomplete outcome data (attrition bias) } \\
\text { All outcomes }\end{array}$ & Low risk & $\begin{array}{l}\text { All participants }(\mathrm{N}=1047) \text { completed the } \\
\text { baseline interview. } 89 \%(\mathrm{~N}=934) \text { com- } \\
\text { pleted the trimester } 3 \text { interview. } 75 \% \text { (N } \\
=787) \text { completed 6-month follow-up, and } \\
80 \%(\mathrm{~N}=840) \text { completed } 12 \text {-month fol- } \\
\text { low-up. It is possible that women who did } \\
\text { not complete the interviews were those who } \\
\text { had more negative (or positive) views or ex- } \\
\text { periences } \\
\text { Medical record data were collected for } 95 \% \\
\text { of randomly assigned women ( } \mathrm{N}=993 \text { ). } \\
\text { Outcome data were reported only in per- } \\
\text { centages; therefore extrapolation to obtain } \\
\text { the numbers was necessary }\end{array}$ \\
\hline Selective reporting (reporting bias) & Low risk & $\begin{array}{l}\text { The original study was powered to report } \\
\text { STI rates. } 4 \text { other papers examining a range } \\
\text { of outcomes have been produced, the most } \\
\text { of important of which describes preterm } \\
\text { birth. It is unlikely that selective reporting } \\
\text { has occurred in these studies }\end{array}$ \\
\hline Other bias & Unclear risk & $\begin{array}{l}\text { Women receiving the intervention may } \\
\text { have discussed this with women in the con- } \\
\text { trol group, and this could have influenced } \\
\text { group-seeking behaviours in the control } \\
\text { group. In addition, it is possible that staff } \\
\text { members in the intervention group encour- } \\
\text { aged women in the control group to form } \\
\text { informal groups if they believed that this } \\
\text { was beneficial. It is not known whether ei- } \\
\text { ther of these events occurred }\end{array}$ \\
\hline $\begin{array}{l}\text { Blinding of participants and personnel } \\
\text { (performance bias) } \\
\text { All outcomes }\end{array}$ & High risk & It was not possible to blind treatment. \\
\hline $\begin{array}{l}\text { Blinding of outcome assessment (detection } \\
\text { bias) } \\
\text { All outcomes }\end{array}$ & Low risk & $\begin{array}{l}\text { All measurements and data collection were } \\
\text { conducted in blinded fashion independent } \\
\text { of the care setting. Medical record ab- } \\
\text { stracters were independent of clinical care }\end{array}$ \\
\hline
\end{tabular}


Jafari 2010

Methods

This was a cluster-randomised controlled trial in which the healthcare centre was the unit of randomisation. Healthcare centres were located in the Zanjan area of northwest Iran

Participants

Participating healthcare centres had to be able to provide at least 12 new patients over a period not longer than 1 month. Both intervention and control group healthcare centres had to be located in the same geographical area and had to serve similar populations. 14 healthcare centres participated and were randomly assigned to group prenatal care or to individual prenatal care (7 in each group). Women attending centres that implemented the group model were informed about the study, and all formally consented to be part of the study. 678 women were enrolled in the study: 344 in group care and 334 in individual antenatal care

Interventions

The intervention was group-based antenatal care. 1 or 2 groups were started per month at each healthcare centre. Each group consisted of 8 to 10 women who met 10 times during their pregnancies for 90 to 120 minutes. Sessions focused on antenatal education, and all women received their antenatal checks within the group setting

Outcomes

Data were collected at 3 points: 34 to 36 weeks' gestation, 24 hours after birth and 2 months after birth. Data were collected during structured interviews and by examination of medical records. Primary outcomes included low birthweight, preterm birth, Intrauterine growth restriction and perinatal death. Secondary outcomes were urinary tract infection, vaginal infection, premature rupture of membranes, pregnancy-induced hypertension, caesarean delivery, taking iron and multivitamin supplements, infant admission to hospital and postpartum use of contraception

It was reported that infants of group care women were less likely to have low birthweight or preterm birth or IUGR, or to die, but these differences were not significant. Infants had greater birthweight among group care women and higher rates of breastfeeding and of exclusive breastfeeding at 2 months. No difference in Apgar scores at 5 minutes was reported

No significant differences between the 2 groups were noted in the prevalence of maternal outcomes

Notes

Dates the study was conducted: May 2007 to July 2008.

Funding source: Institutional Review Board of the Tehran University of Medical Sciences

Declarations of interest: none.

Risk of bias

\begin{tabular}{l|l|l}
\hline Bias & Authors' judgement & Support for judgement \\
\hline $\begin{array}{l}\text { Random sequence generation (selection } \\
\text { bias) }\end{array}$ & Unclear risk & $\begin{array}{l}\text { No process of randomisation was de- } \\
\text { scribed. Study authors stated that alloca- } \\
\text { tion was done by simple randomisation but } \\
\text { did not state how this was undertaken }\end{array}$ \\
\hline Allocation concealment (selection bias) & Unclear risk & Method of concealment was not described.
\end{tabular}

Group versus conventional antenatal care for women (Review) 
Jafari 2010 (Continued)

\begin{tabular}{|c|c|c|}
\hline $\begin{array}{l}\text { Incomplete outcome data (attrition bias) } \\
\text { All outcomes }\end{array}$ & Low risk & $\begin{array}{l}2 \% \text { of women enrolled in group care and } \\
3.6 \% \text { of those in individual care were lost } \\
\text { to follow-up. It is possible that women who } \\
\text { were lost to follow-up were those who had } \\
\text { more negative (or positive) views or expe- } \\
\text { riences, although these numbers were very } \\
\text { small }\end{array}$ \\
\hline Selective reporting (reporting bias) & High risk & $\begin{array}{l}\text { No published protocol was provided, so it is } \\
\text { not clear whether all prespecified outcomes } \\
\text { were included. In addition, fetal deaths } \\
\text { were excluded without explanation of why } \\
\text { or at what stage these deaths occurred }\end{array}$ \\
\hline Other bias & High risk & $\begin{array}{l}\text { The main concern was exclusion of fetal } \\
\text { deaths. }\end{array}$ \\
\hline $\begin{array}{l}\text { Blinding of participants and personnel } \\
\text { (performance bias) } \\
\text { All outcomes }\end{array}$ & High risk & $\begin{array}{l}\text { Participants and facilitators of groups or } \\
\text { providers of care were aware of group allo- } \\
\text { cation. This is usual in studies of this na- } \\
\text { ture }\end{array}$ \\
\hline $\begin{array}{l}\text { Blinding of outcome assessment (detection } \\
\text { bias) } \\
\text { All outcomes }\end{array}$ & Low risk & $\begin{array}{l}\text { Reviews of medical records and structured } \\
\text { interviews were performed by trained mid- } \\
\text { wives who were independent of care and } \\
\text { blinded to study assignment }\end{array}$ \\
\hline
\end{tabular}

Kennedy 2011

Methods

A 3-year randomised controlled trial was conducted at 2 military settings using mixed methods over 13 months between 2005 and 2007. Clinics were located in northern California, USA. A simple technique using the random function in the Statistical Package for Social Sciences was applied to randomly assign women to group antenatal care (intervention) or individual antenatal care (standard care). Data were collected at baseline, at 32 to 36 weeks' gestation, by hospital record at birth and at 3 months' postpartum

Participants

Women were eligible to participate in the trial if they were $>16$ weeks' gestation, were 18 years of age or older, were at low obstetrical risk, were able to comprehend English and were willing to be randomly assigned to either antenatal care option $(\mathrm{N}=322)$

Interventions

Group antenatal care vs individual antenatal care

Outcomes

Primary outcome of the trial was family healthcare readiness in a military setting Other outcomes included adequacy of antenatal care, antenatal health behaviours, childbirth self-efficacy inventory, social support, emotional stress, emotional distress, postpartum depression and women's and provider's level of satisfaction

The Kotelchuck Index of Adequate Prenatal Care (Kotelchuck 1994) was used to assess whether women received an adequate number of antenatal visits. This is a gross measure 
Kennedy 2011 (Continued)

of whether women in either the intervention group or the individual antenatal care group had more or less than 9 antenatal visits

Antenatal health behaviours were measured by the Prenatal Health Behavior Scale (Lobel 1992). This scale examines health behaviours such as nutrition, sleep, exercise, taking vitamins and drinking fluids as part of 16 items. The Childbirth Self-Efficacy Inventory (Sinclair 1999) was used, although study authors reported that data collectors noted that women disliked this instrument, and this may have affected study findings

The Norbeck Social Support Scale assessed women's perceptions of multiple dimensions of social support at baseline, at third trimester and at 3 months' postpartum (Norbeck 1983). This scale measures affect, affirmation and aid and has been widely used in the general population and during pregnancy. General perceived stress was evaluated using the 10-item version of the Perceived Stress Scale (Cohen 1983). Pregnancy-related stress was measured by the 17-item Revised Prenatal Distress Questionnaire (Lobel 1996).

Antenatal outcomes included preterm birth, augmentation of labour, type of birth, Apgar scores, neonatal intensive care admissions and breastfeeding initiation/continuation. These data were collected from medical records through a chart review performed by a research assistant; $5 \%$ of charts were checked to verify accuracy and consistency each site and of low-risk category

\section{Risk of bias}

\section{Bias}

Random sequence generation (selection Low risk bias)
Authors' judgement

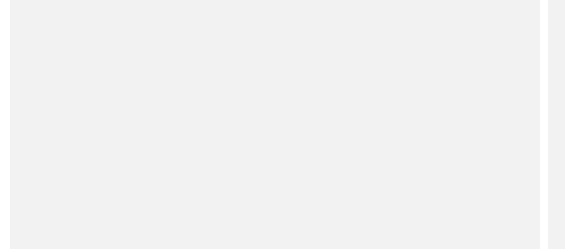

\begin{tabular}{|c|c|c|}
\hline Allocation concealment (selection bias) & Unclear risk & Allocation concealment was not described. \\
\hline $\begin{array}{l}\text { Incomplete outcome data (attrition bias) } \\
\text { All outcomes }\end{array}$ & Low risk & $\begin{array}{l}\text { Missing data were controlled for. } 32 \\
\text { women were lost to follow-up. It is possi- } \\
\text { ble that women who had missing data were } \\
\text { those who had more negative (or positive) } \\
\text { views or experiences }\end{array}$ \\
\hline Selective reporting (reporting bias) & Low risk & $\begin{array}{l}\text { It is unlikely that selective reporting oc- } \\
\text { curred. However, some data were not avail- } \\
\text { able in tabular form }\end{array}$ \\
\hline
\end{tabular}

Simple randomisation technique using the random function in the Statistical Package for Social Sciences. Randomisation was balanced in blocks of 4 assignments. Interim analyses were performed to assess whether the randomisation process needed modification and to ensure that recruitment and follow-up goals were met. No modifications were required

Allocation concealment was not described.

Missing data were controlled for. 32 women were lost to follow-up. It is possible that women who had missing data were those who had more negative (or positive) curred. However, some data were not available in tabular form 


\section{Kennedy 2011 (Continued)}

\begin{tabular}{|l|l|l}
\hline & Unclear risk & $\begin{array}{l}\text { It is possible that women receiving the in- } \\
\text { tervention discussed this with women in } \\
\text { the control group; this may have influ- } \\
\text { enced group-seeking behaviours in the con- } \\
\text { trol group. In addition, it is possible that } \\
\text { staff in the intervention group encouraged } \\
\text { women in the control group to form infor- } \\
\text { mal groups if they believed this was benefi- } \\
\text { cial. It is not known whether either of these } \\
\text { events occurred }\end{array}$ \\
\hline $\begin{array}{l}\text { Blinding of participants and personnel } \\
\text { (performance bias) } \\
\text { All outcomes }\end{array}$ & High risk & Blinding was not described. \\
\hline $\begin{array}{l}\text { Blinding of outcome assessment (detection } \\
\text { bias) } \\
\text { All outcomes }\end{array}$ & High risk & \begin{tabular}{l} 
Blinding was not described. \\
\hline
\end{tabular}
\end{tabular}

HIV: human immunodeficiency virus; IUGR: intrauterine growth restriction; STI: sexually transmitted infection.

\section{Characteristics of excluded studies [ordered by study ID]}

\begin{tabular}{l|l}
\hline Study & Reason for exclusion \\
\hline Bhutta 2008 & The intervention was not group antenatal care, but home antenatal visits (1-to-1) and group education classes \\
\hline Ford 2001 & $\begin{array}{l}\text { No information was provided about setting, schedule or appointments, or how groups were facilitated, by how } \\
\text { many and how information/education was provided }\end{array}$ \\
\hline Koushede 2013 & $\begin{array}{l}\text { This study does not meet the inclusion criteria for this review. The study protocol is focused on group-based } \\
\text { antenatal birth and parent preparation only }\end{array}$ \\
\hline Leung 2012 & $\begin{array}{l}\text { This study does not meet the eligibility criteria for this review. Type of intervention was not a group model of } \\
\text { antenatal care. It was an additional 4-week programme provided during pregnancy and focused on intergenera- } \\
\text { tional conflict }\end{array}$ \\
\hline Manandhar 2004 & $\begin{array}{l}\text { The intervention was not antenatal care, but an educational group for women of reproductive age regarding } \\
\text { health behaviours for the next pregnancy. Participants were women of reproductive age, not specifically pregnant } \\
\text { women }\end{array}$ \\
\hline Olenick 2011 & $\begin{array}{l}\text { The intervention was not antenatal care, but brief antenatal education, that is, a single 2-hour class based on } \\
\text { breastfeeding self-efficacy theory }\end{array}$
\end{tabular}


Salmela-Aro 2012 The intervention in this study does not meet the eligibility criteria for this review. The type of intervention was not a group model of antenatal care. The group intervention consisted of 6 meetings of 2 hours' duration, each led by a psychologist and focused on decreasing fear of childbirth

\section{Characteristics of ongoing studies [ordered by study ID]}

\section{Ickovics 2009}

\begin{tabular}{ll} 
Trial name or title & Integrating prenatal care to reduce HIV/STDs among teens: a translational study \\
\hline Methods & $\begin{array}{l}\text { This study will involve participants receiving antenatal care at } 14 \text { participating CHCs that predominantly } \\
\text { serve black and Latina communities in the New York metropolitan area. The CHCs are assigned randomly to } \\
\text { deliver immediate CenteringPregnancy Plus or waiting list CenteringPregnancy Plus to women seeking care } \\
\text { at the clinics }\end{array}$ \\
\hline Participants & $\begin{array}{l}\text { Inclusion criteria were as follows: pregnant women } 14 \text { to } 21 \text { years of age; ability to attend group treatment } \\
\text { sessions conducted in English or Spanish. Women will be excluded if they have positive HIV infection or } \\
\text { have any severe medical problems requiring individualised assessment and tracking as high-risk pregnancy }\end{array}$ \\
\hline Interventions & $\begin{array}{l}\text { A group antenatal care treatment programme that incorporates HIV/STI prevention education, called Cen- } \\
\text { teringPregnancy Plus, has shown success in reducing sexual risk behaviours in an academic setting, but its } \\
\text { effectiveness at CHCs serving women at high risk for these behaviours is unknown. This study will evaluate } \\
\text { the effectiveness of CenteringPregnancy Plus in reducing transmission of STDs and rapid repeat pregnancies } \\
\text { in pregnant teens seeking care at participating CHCs. The CenteringPregnancy model of group antenatal } \\
\text { care involves skill building in the areas of efficacy, risk assessment, negotiation and prevention. Centering- } \\
\text { Pregnancy Plus integrates HIV prevention into antenatal care, builds on motivation for healthy pregnancy } \\
\text { and creates a sustainable model via reimbursement mechanisms for antenatal care. 10 antenatal group sessions } \\
\text { are provided, each lasting } 2 \text { hours }\end{array}$ \\
\hline
\end{tabular}

Outcomes Primary outcomes:

1. Sexual behaviour risk

2. Laboratory-tested STDs (STIs)

3. Rapid repeat pregnancy

4. Low birthweight

5. Preterm labour

6. Breastfeeding

Starting date

Commenced in January 2007 and extended to time of final data collection in July 2011

Contact information Jeannette R. Ickovics, PhD (jeannette.ickovics@yale.edu).

Notes

Refer to this study by its ClinicalTrials.gov identifier: NCT00628771

CHC: Community Health Centre; HIV: human immunodeficiency virus; STD: sexually transmitted disease; STI: sexually transmitted infection. 
DATA ANDANALYSES

Comparison 1. Group antenatal care versus individual antenatal care (adjusted data)

\begin{tabular}{|c|c|c|c|c|}
\hline Outcome or subgroup title & $\begin{array}{l}\text { No. of } \\
\text { studies }\end{array}$ & $\begin{array}{c}\text { No. of } \\
\text { participants }\end{array}$ & Statistical method & Effect size \\
\hline 1 Preterm birth & 3 & 1888 & Risk Ratio (M-H, Fixed, 95\% CI) & $0.75[0.57,1.00]$ \\
\hline 1.1 Individual-randomised & 2 & 1315 & Risk Ratio (M-H, Fixed, 95\% CI) & $0.78[0.56,1.08]$ \\
\hline 1.2 Cluster-randomised & 1 & 573 & Risk Ratio (M-H, Fixed, 95\% CI) & $0.68[0.39,1.19]$ \\
\hline 2 Gestational age & 3 & 1795 & Mean Difference (IV, Fixed, 95\% CI) & $0.24[0.01,0.46]$ \\
\hline 2.1 Individual-randomised & 2 & 1315 & Mean Difference (IV, Fixed, 95\% CI) & $0.17[-0.11,0.44]$ \\
\hline 2.2 Cluster-randomised & 1 & 480 & Mean Difference (IV, Fixed, 95\% CI) & $0.40[-0.01,0.81]$ \\
\hline 3 Low birthweight & 3 & 1935 & Risk Ratio (M-H, Fixed, 95\% CI) & $0.92[0.68,1.23]$ \\
\hline 3.1 Individual-randomised & 2 & 1315 & Risk Ratio (M-H, Fixed, 95\% CI) & $1.03[0.73,1.46]$ \\
\hline 3.2 Cluster-randomised & 1 & 620 & Risk Ratio (M-H, Fixed, 95\% CI) & $0.69[0.40,1.19]$ \\
\hline 4 Small-for-gestational age & 2 & 1473 & Risk Ratio (M-H, Fixed, 95\% CI) & $0.92[0.68,1.24]$ \\
\hline 4.1 Individual-randomised & 1 & 993 & Risk Ratio (M-H, Fixed, 95\% CI) & $0.94[0.69,1.29]$ \\
\hline 4.2 Cluster-randomised & 1 & 480 & Risk Ratio (M-H, Fixed, 95\% CI) & $0.69[0.22,2.13]$ \\
\hline 5 Perinatal mortality & 3 & 1943 & Risk Ratio (M-H, Fixed, 95\% CI) & $0.63[0.32,1.25]$ \\
\hline 5.1 Individual-randomised & 2 & 1315 & Risk Ratio (M-H, Fixed, 95\% CI) & $0.59[0.22,1.57]$ \\
\hline 5.2 Cluster-randomised & 1 & 628 & Risk Ratio (M-H, Fixed, 95\% CI) & $0.67[0.26,1.75]$ \\
\hline 6 Birthweight & 3 & 1935 & Mean Difference (IV, Random, 95\% CI) & $\begin{array}{l}34.46[-44.32,113 . \\
24]\end{array}$ \\
\hline 6.1 Individual-randomised & 2 & 1315 & Mean Difference (IV, Random, 95\% CI) & $\begin{array}{l}0.33[-112.78,113 . \\
44]\end{array}$ \\
\hline 6.2 Cluster-randomised & 1 & 620 & Mean Difference (IV, Random, 95\% CI) & $87.80[3.36,172.24]$ \\
\hline 7 Inadequate antenatal care & 1 & 993 & Risk Ratio (M-H, Fixed, 95\% CI) & $0.81[0.66,0.98]$ \\
\hline $\begin{array}{l}8 \text { Neonatal intensive care unit } \\
\text { admission (not pre-specified) }\end{array}$ & 2 & 1315 & Risk Ratio (M-H, Random, 95\% CI) & $1.48[0.63,3.45]$ \\
\hline 9 Apgar at 5 minutes & 3 & 1935 & Mean Difference (IV, Fixed, 95\% CI) & $0.03[-0.08,0.14]$ \\
\hline 9.1 Individual-randomised & 2 & 1315 & Mean Difference (IV, Fixed, 95\% CI) & $0.0[-0.13,0.13]$ \\
\hline 9.2 Cluster-randomised & 1 & 620 & Mean Difference (IV, Fixed, 95\% CI) & $0.10[-0.09,0.29]$ \\
\hline 10 Breastfeeding initiation & 3 & 1943 & Risk Ratio (M-H, Random, 95\% CI) & $1.08[0.96,1.20]$ \\
\hline 10.1 Individual-randomised & 2 & 1315 & Risk Ratio (M-H, Random, 95\% CI) & $1.10[0.83,1.46]$ \\
\hline 10.2 Cluster-randomised & 1 & 628 & Risk Ratio (M-H, Random, 95\% CI) & $1.05[1.00,1.10]$ \\
\hline 11 Antenatal knowledge & 1 & 993 & Mean Difference (IV, Fixed, 95\% CI) & $2.60[1.70,3.50]$ \\
\hline 12 Antenatal distress & 1 & 993 & Mean Difference (IV, Fixed, 95\% CI) & $-0.5[-1.41,0.41]$ \\
\hline 13 Readiness for labour and birth & 1 & 993 & Mean Difference (IV, Fixed, 95\% CI) & $7.60[3.45,11.75]$ \\
\hline 14 Readiness for infant care & 1 & 993 & Mean Difference (IV, Fixed, 95\% CI) & $3.10[-0.06,6.26]$ \\
\hline 15 Satisfaction with antenatal care & 1 & 993 & Mean Difference (IV, Fixed, 95\% CI) & $4.90[3.10,6.70]$ \\
\hline 16 Induction of labour & 1 & 322 & Risk Ratio (M-H, Fixed, 95\% CI) & $0.86[0.53,1.38]$ \\
\hline $\begin{array}{l}17 \text { Augmentation using } \\
\text { Syntocinon }\end{array}$ & 1 & 322 & Risk Ratio (M-H, Fixed, 95\% CI) & $1.31[0.92,1.85]$ \\
\hline 18 Other pain management & 1 & 322 & Risk Ratio (M-H, Fixed, 95\% CI) & $0.85[0.58,1.24]$ \\
\hline 19 Epidural & 1 & 322 & Risk Ratio (M-H, Fixed, 95\% CI) & $1.26[1.00,1.57]$ \\
\hline 20 Episiotomy & 1 & 322 & Risk Ratio (M-H, Fixed, 95\% CI) & $0.74[0.26,2.09]$ \\
\hline 21 Spontaneous vaginal birth & 1 & 322 & Risk Ratio (M-H, Fixed, 95\% CI) & $0.96[0.80,1.15]$ \\
\hline
\end{tabular}

Group versus conventional antenatal care for women (Review)

Copyright () 2015 The Cochrane Collaboration. Published by John Wiley \& Sons, Ltd. 
22 Caesarean section 22.1 Individual-randomised 22.2 Cluster-randomised

23 Operative vaginal birth

24 Depression using component of CES-D instrument in third trimester

25 Depression using component of CES-D instrument 6 months' postpartum

26 Depression using component of CES-D instrument 12 months' postpartum

27 Stress using PSS at 6 months' postpartum

28 Stress using PSS at 12 months' postpartum

29 Duration of exclusive breastfeeding

30 Attendance at antenatal care (number of sessions)
842 Risk Ratio (M-H, Fixed, 95\% CI)

$0.83[0.68,1.02]$

$0.93[0.60,1.44]$

$0.80[0.64,1.01]$

$1.83[0.75,4.48]$

$-0.20[-1.97,1.57]$

Risk Ratio (M-H, Fixed, 95\% CI)

Mean Difference (IV, Fixed, 95\% CI)

$-0.07[-1.86,1.72]$

Mean Difference (IV, Fixed, 95\% CI)

840 Mean Difference (IV, Fixed, 95\% CI)

$0.10[-3.50,3.70]$

1

787 Mean Difference (IV, Fixed, 95\% CI)

$-0.40[-1.97,1.17]$

$1840 \quad$ Mean Difference (IV, Fixed, 95\% CI)

$0.24[-2.81,3.29]$

0

0

Mean Difference (IV, Fixed, 95\% CI)

$0.0[0.0,0.0]$

407

\title{
Analysis I.I. Comparison I Group antenatal care versus individual antenatal care (adjusted data), Outcome I Preterm birth.
}

\author{
Review: Group versus conventional antenatal care for women \\ Comparison: I Group antenatal care versus individual antenatal care (adjusted data) \\ Outcome: I Preterm birth
}

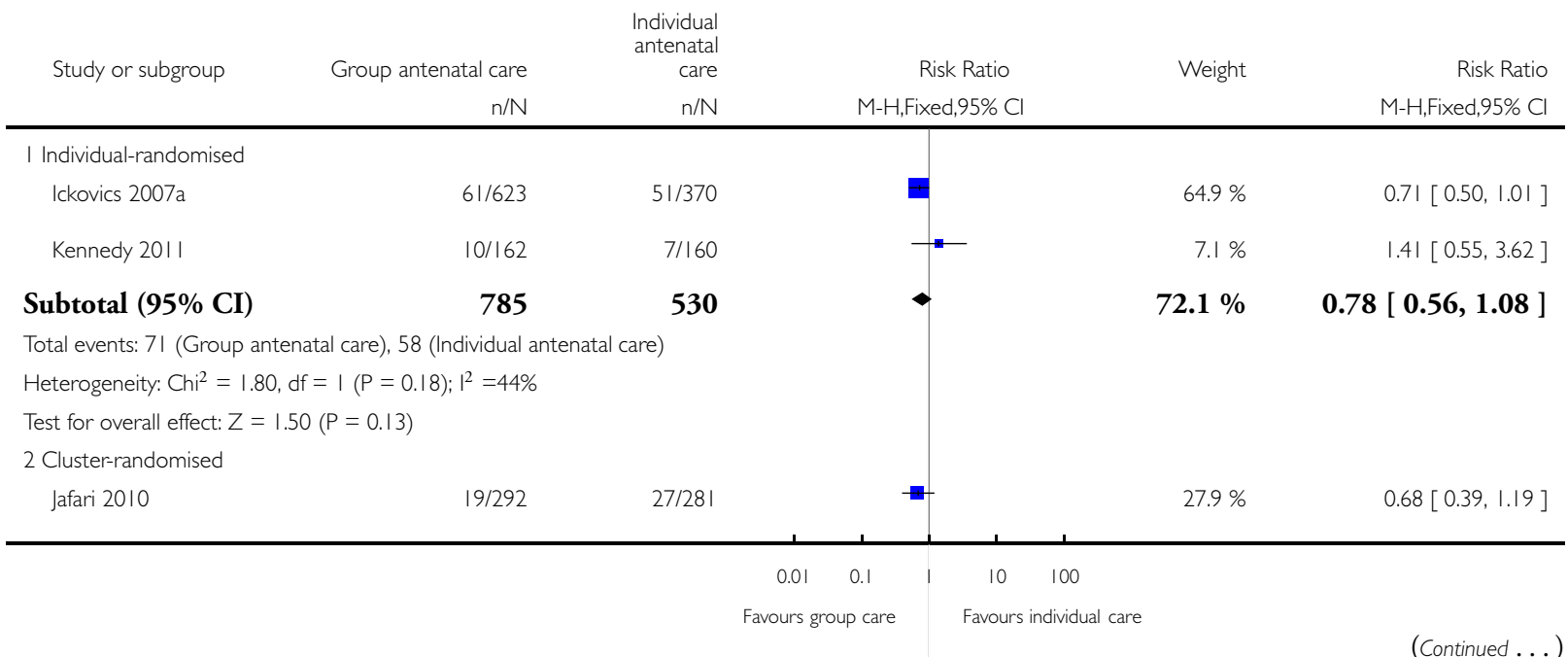

Group versus conventional antenatal care for women (Review) 


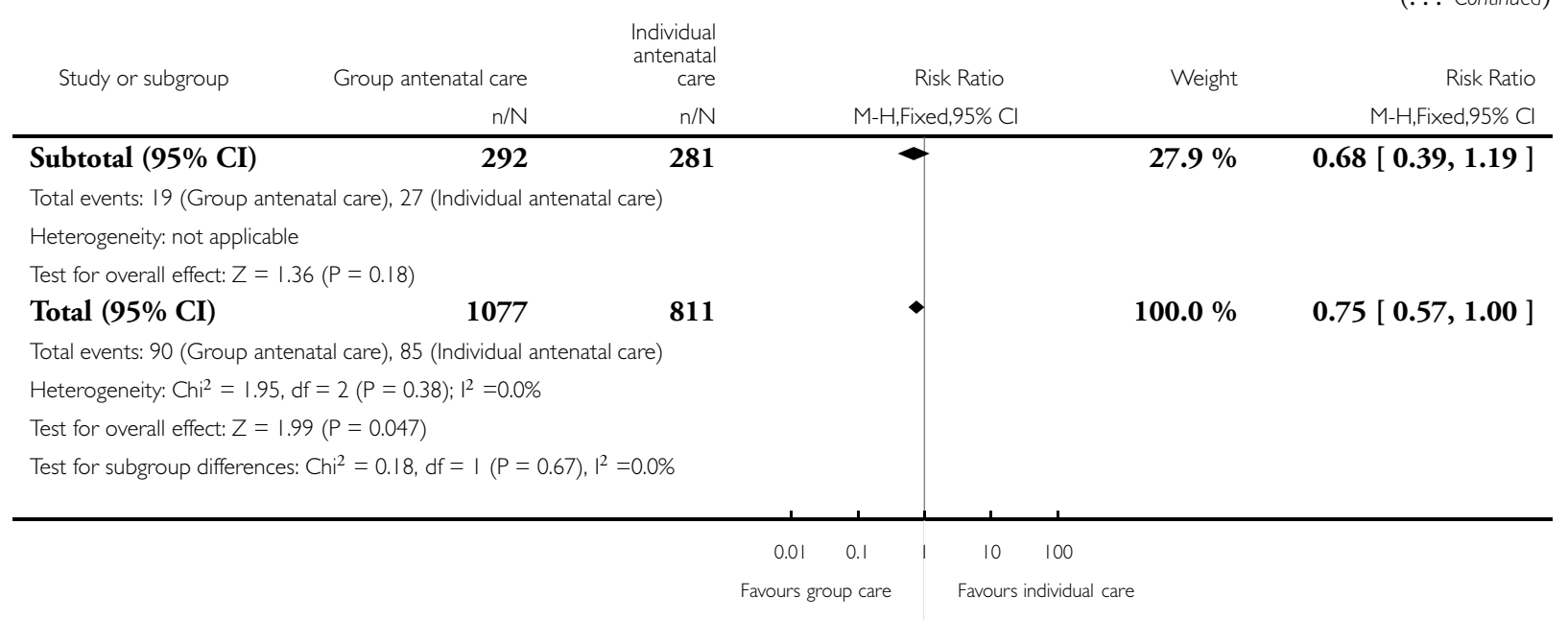

\section{Analysis I.2. Comparison I Group antenatal care versus individual antenatal care (adjusted data), Outcome 2 Gestational age.}

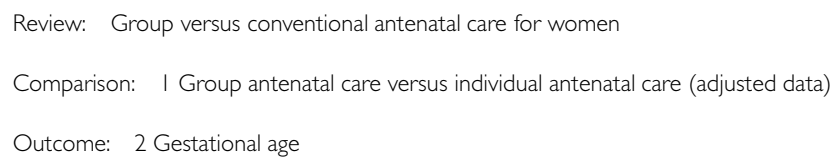

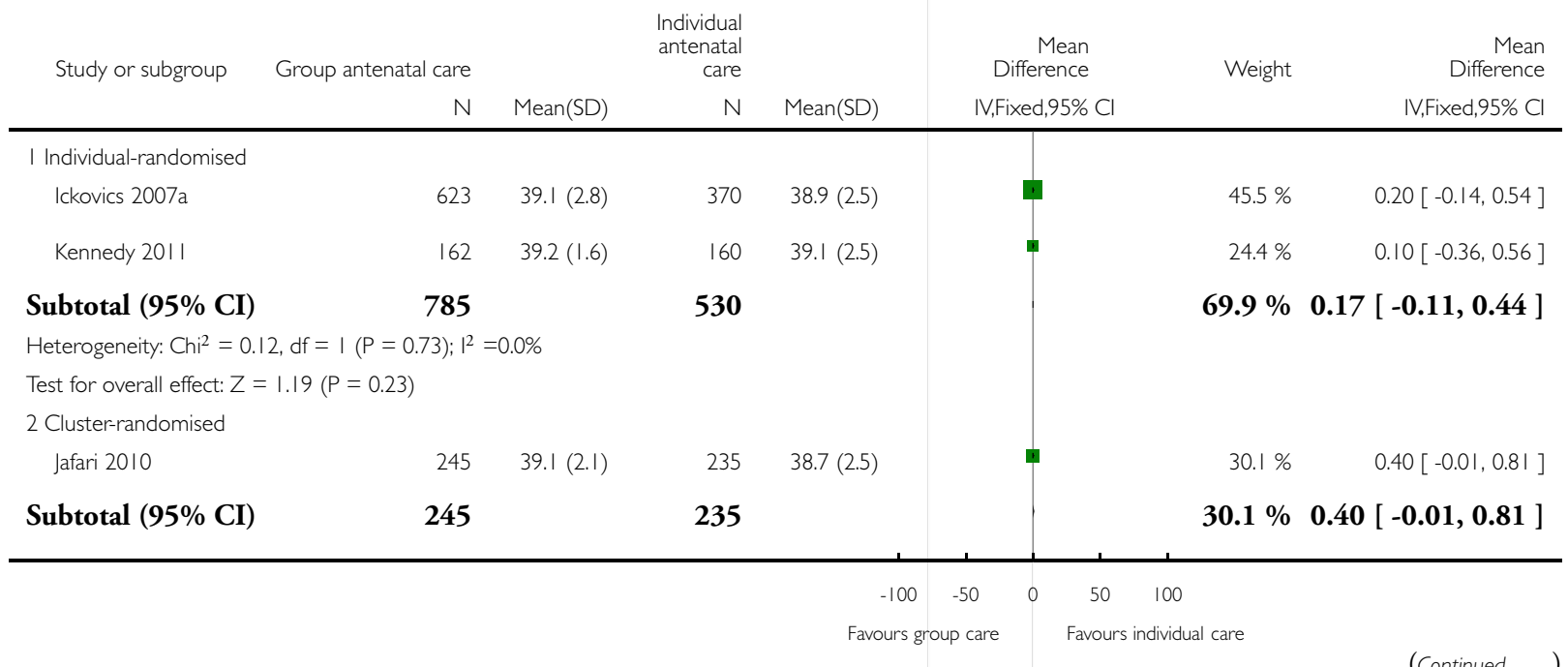




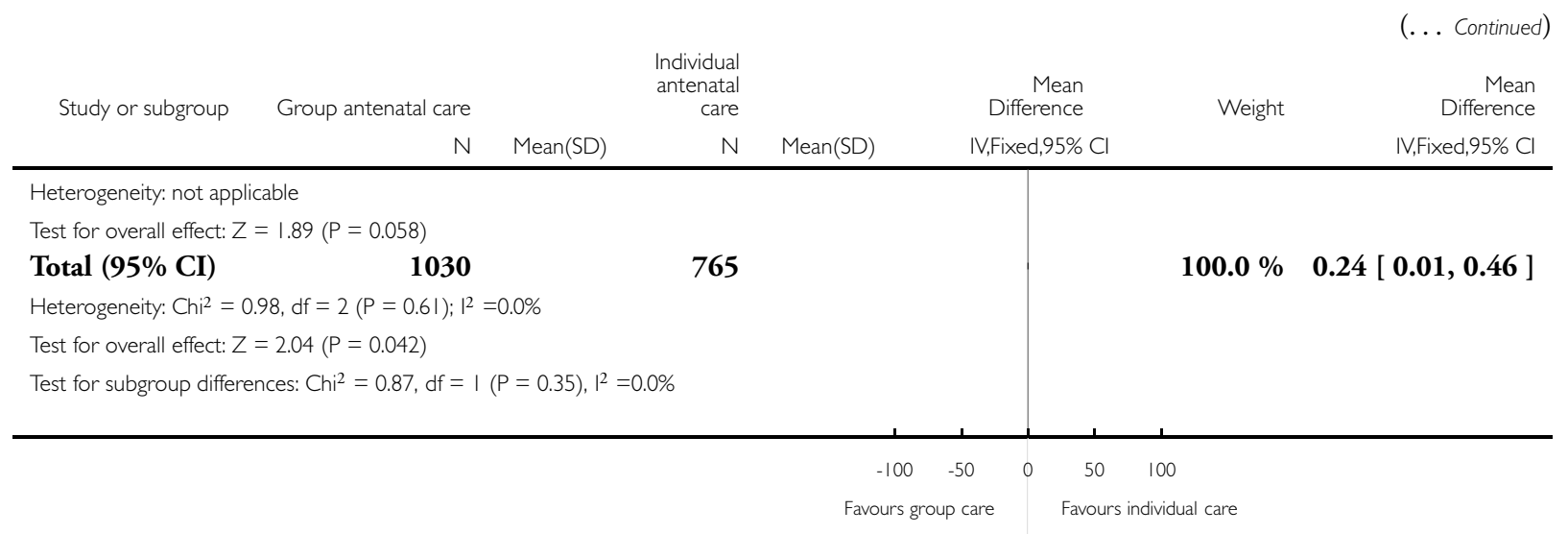

\section{Analysis I.3. Comparison I Group antenatal care versus individual antenatal care (adjusted data), Outcome} 3 Low birthweight.

Review: Group versus conventional antenatal care for women

Comparison: I Group antenatal care versus individual antenatal care (adjusted data)

Outcome: 3 Low birthweight

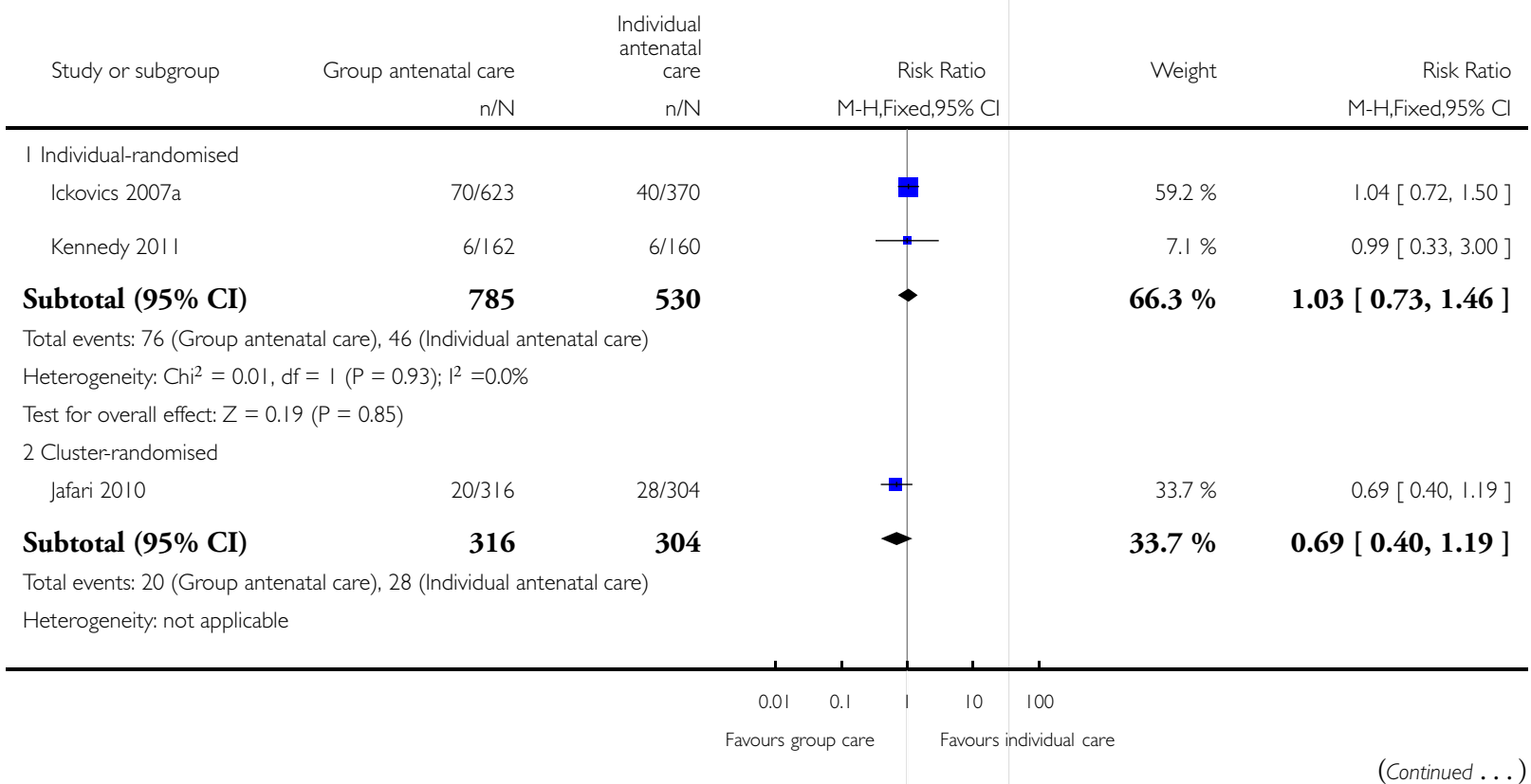

Group versus conventional antenatal care for women (Review) 


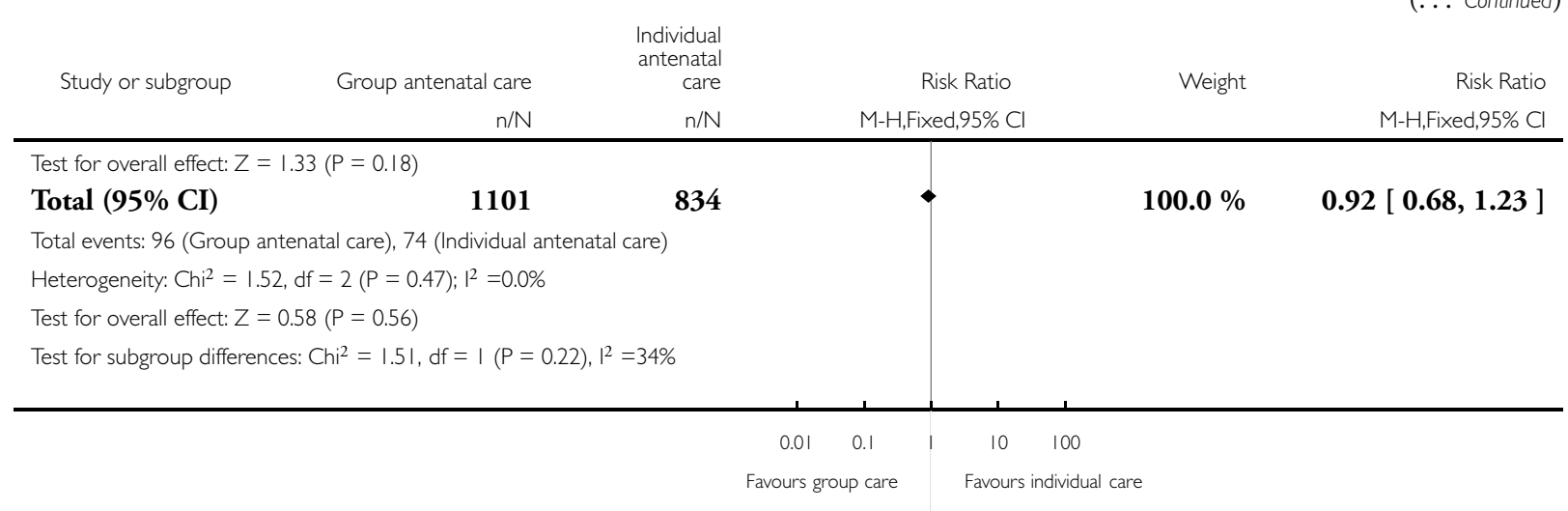

Analysis I.4. Comparison I Group antenatal care versus individual antenatal care (adjusted data), Outcome 4 Small-for-gestational age.

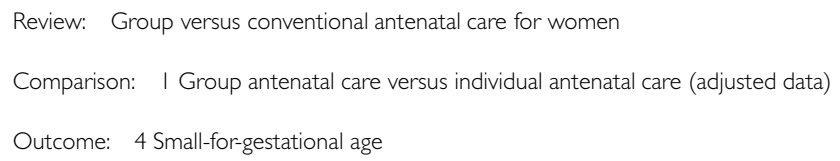




\begin{tabular}{|c|c|c|c|c|c|}
\hline Study or subgroup & Group antenatal care & $\begin{array}{c}\text { Individual } \\
\text { antenatal } \\
\text { care }\end{array}$ & Risk Ratio & Weight & Risk Ratio \\
\hline & $\mathrm{n} / \mathrm{N}$ & $n / N$ & M-H,Fixed,95\% Cl & & M-H,Fixed,95\% Cl \\
\hline
\end{tabular}

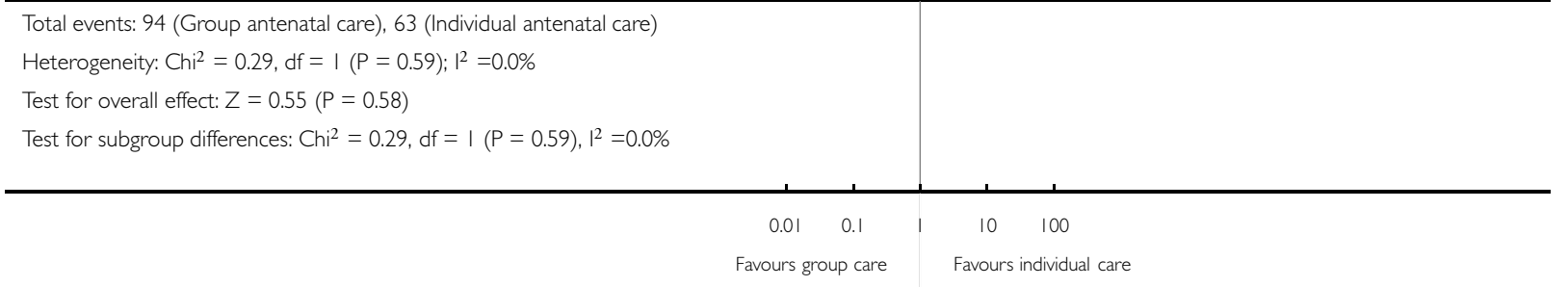

\section{Analysis I.5. Comparison I Group antenatal care versus individual antenatal care (adjusted data), Outcome 5 Perinatal mortality.}

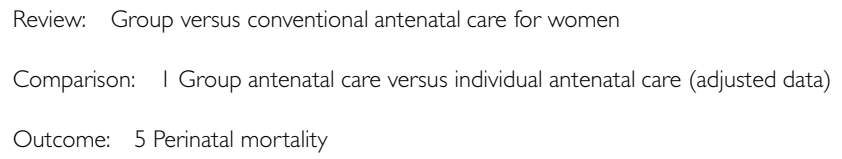

Subtotal $(\mathbf{9 5 \%}$ CI)

$785 \quad 530$

Total events: 8 (Group antenatal care), 8 (Individual antenatal care)

Heterogeneity: not applicable

Test for overall effect: $Z=1.05(P=0.29)$

2 Cluster-randomised

$\begin{array}{lll}\text { Jafari } 2010 & 7 / 320 & 10 / 308\end{array}$

Subtotal (95\% CI)

320

308

Total events: 7 (Group antenatal care), 10 (Individual antenatal care)

Heterogeneity: not applicable

Test for overall effect: $Z=0.81(P=0.42)$

Total (95\% CI)

1105

838

$50.4 \%$

$0.67[0.26,1.75]$

$49.6 \%$

$49.6 \%$

$50.4 \%$

$100.0 \%$

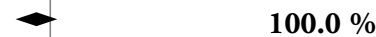

100

Favours group care

Favours individual care

(Continued...) 


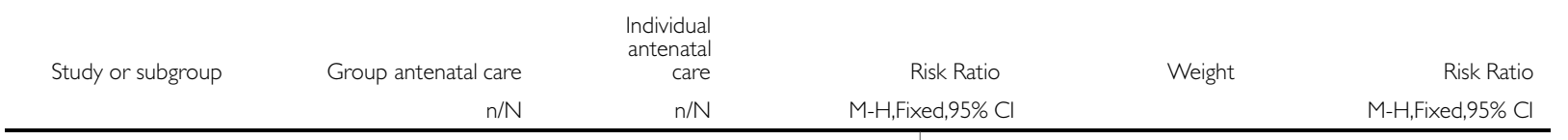

Total events: 15 (Group antenatal care), 18 (Individual antenatal care)

Heterogeneity: $\mathrm{Ch}^{2}=0.03, \mathrm{df}=\mathrm{I}(\mathrm{P}=0.86) ; \mathrm{I}^{2}=0.0 \%$

Test for overall effect: $Z=1.31(P=0.19)$

Test for subgroup differences: $\mathrm{Ch}^{2}=0.03, \mathrm{df}=\mathrm{I}(\mathrm{P}=0.86), \mathrm{I}^{2}=0.0 \%$

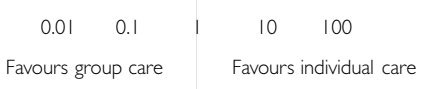

\section{Analysis I.6. Comparison I Group antenatal care versus individual antenatal care (adjusted data), Outcome 6 Birthweight.}
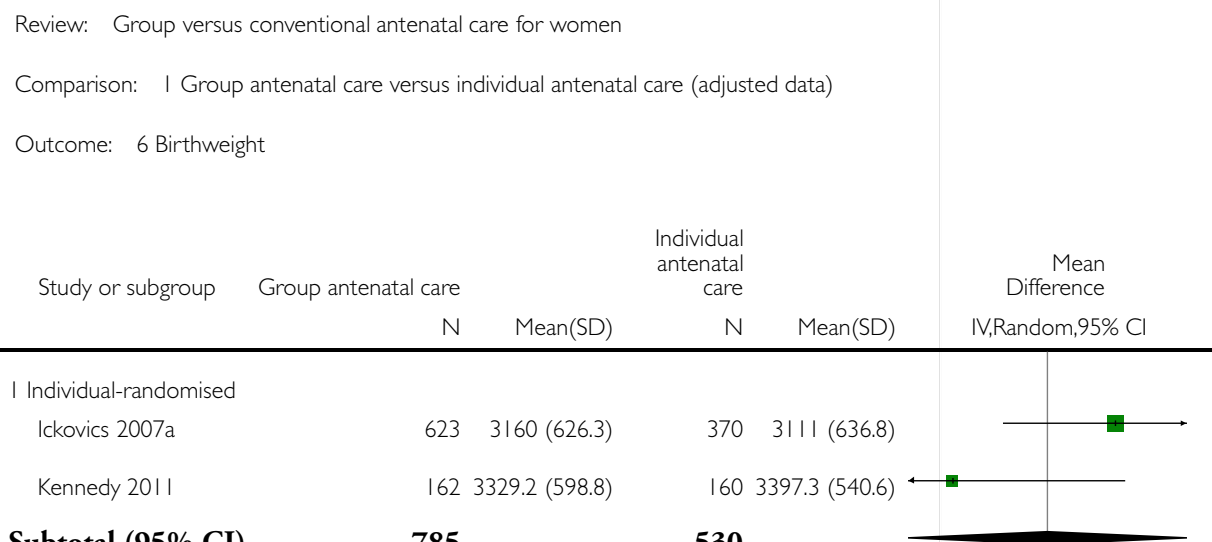

Subtotal (95\% CI)

Heterogeneity: $\mathrm{Tau}^{2}=3973.46 ; \mathrm{Chi}^{2}=2.38, \mathrm{df}=\mathrm{I}(\mathrm{P}=0.12) ; \mathbf{1}^{2}=58 \%$

Test for overall effect: $Z=0.01(P=1.0)$

2 Cluster-randomised

$$
\text { Jafari } 2010
$$

Subtotal (95\% CI)

Heterogeneity: not applicable

Test for overall effect: $Z=2.04(P=0.042)$

Total (95\% CI) 


\section{Analysis I.7. Comparison I Group antenatal care versus individual antenatal care (adjusted data), Outcome}

7 Inadequate antenatal care.

Review: Group versus conventional antenatal care for women

Comparison: I Group antenatal care versus individual antenatal care (adjusted data)

Outcome: 7 Inadequate antenatal care

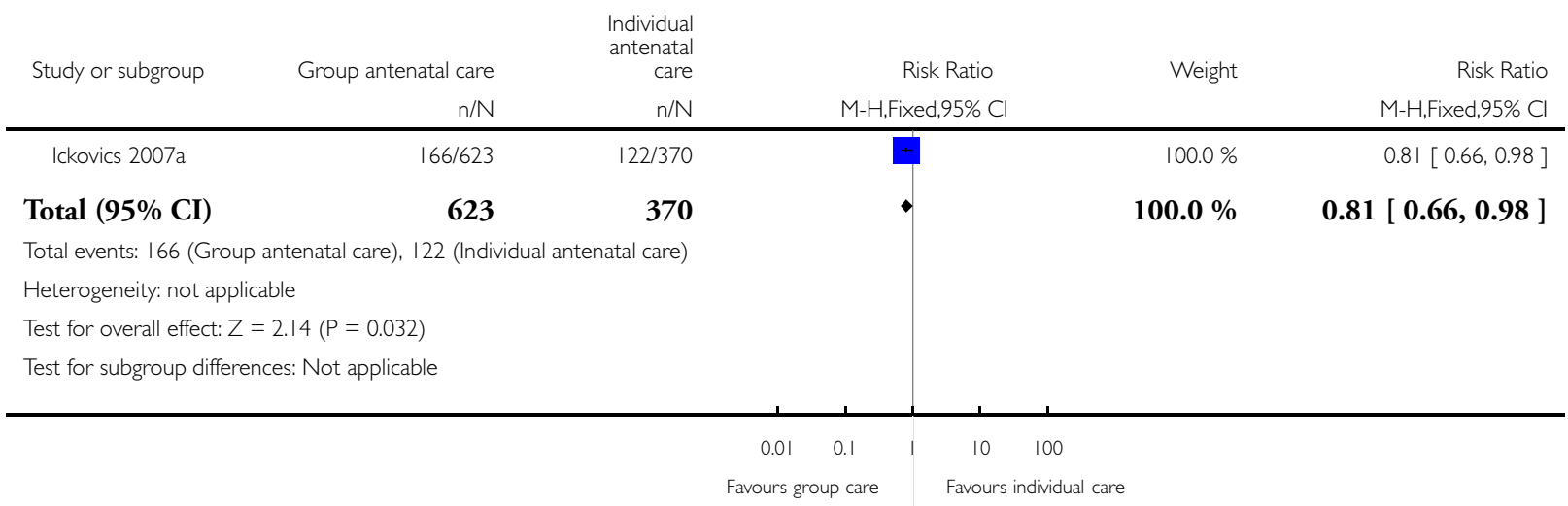


Analysis I.8. Comparison I Group antenatal care versus individual antenatal care (adjusted data), Outcome 8 Neonatal intensive care unit admission (not pre-specified).

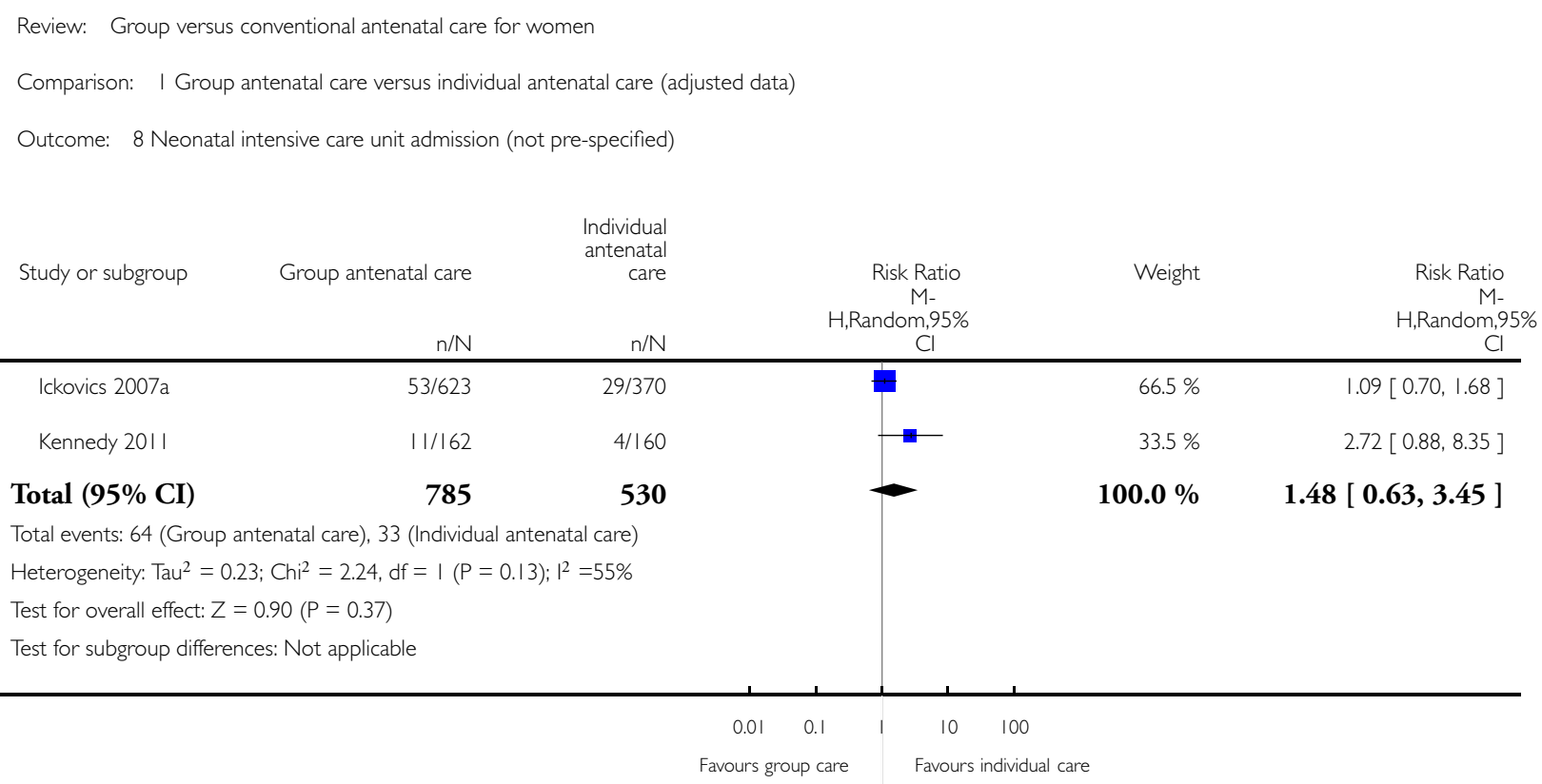


Analysis I.9. Comparison I Group antenatal care versus individual antenatal care (adjusted data), Outcome 9 Apgar at 5 minutes.

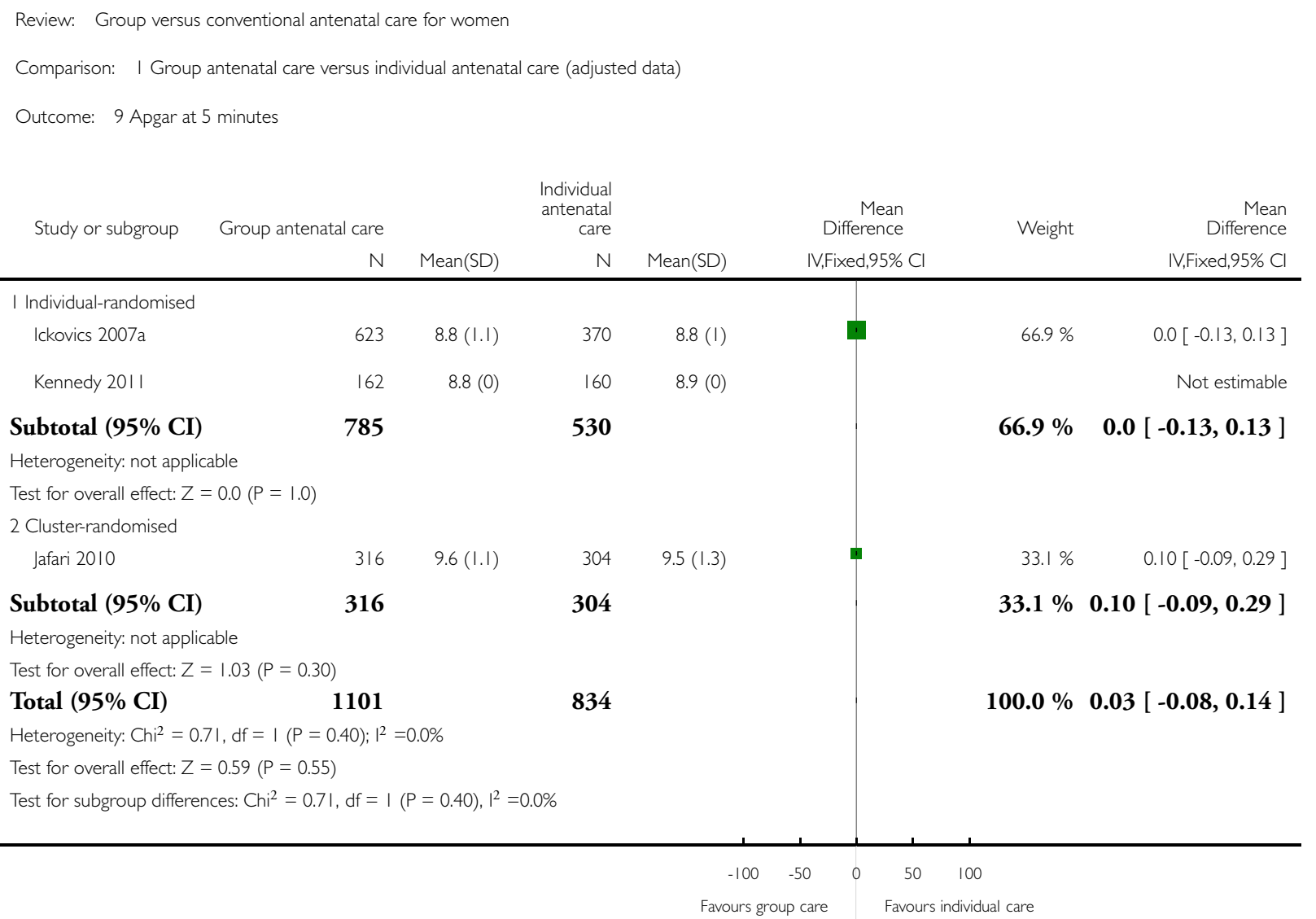


Analysis I.10. Comparison I Group antenatal care versus individual antenatal care (adjusted data), Outcome 10 Breastfeeding initiation.

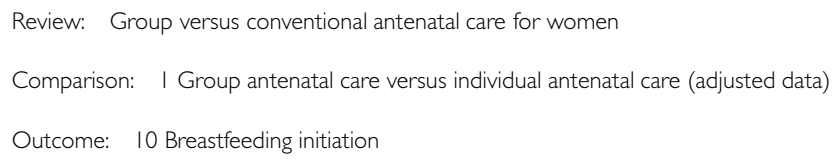

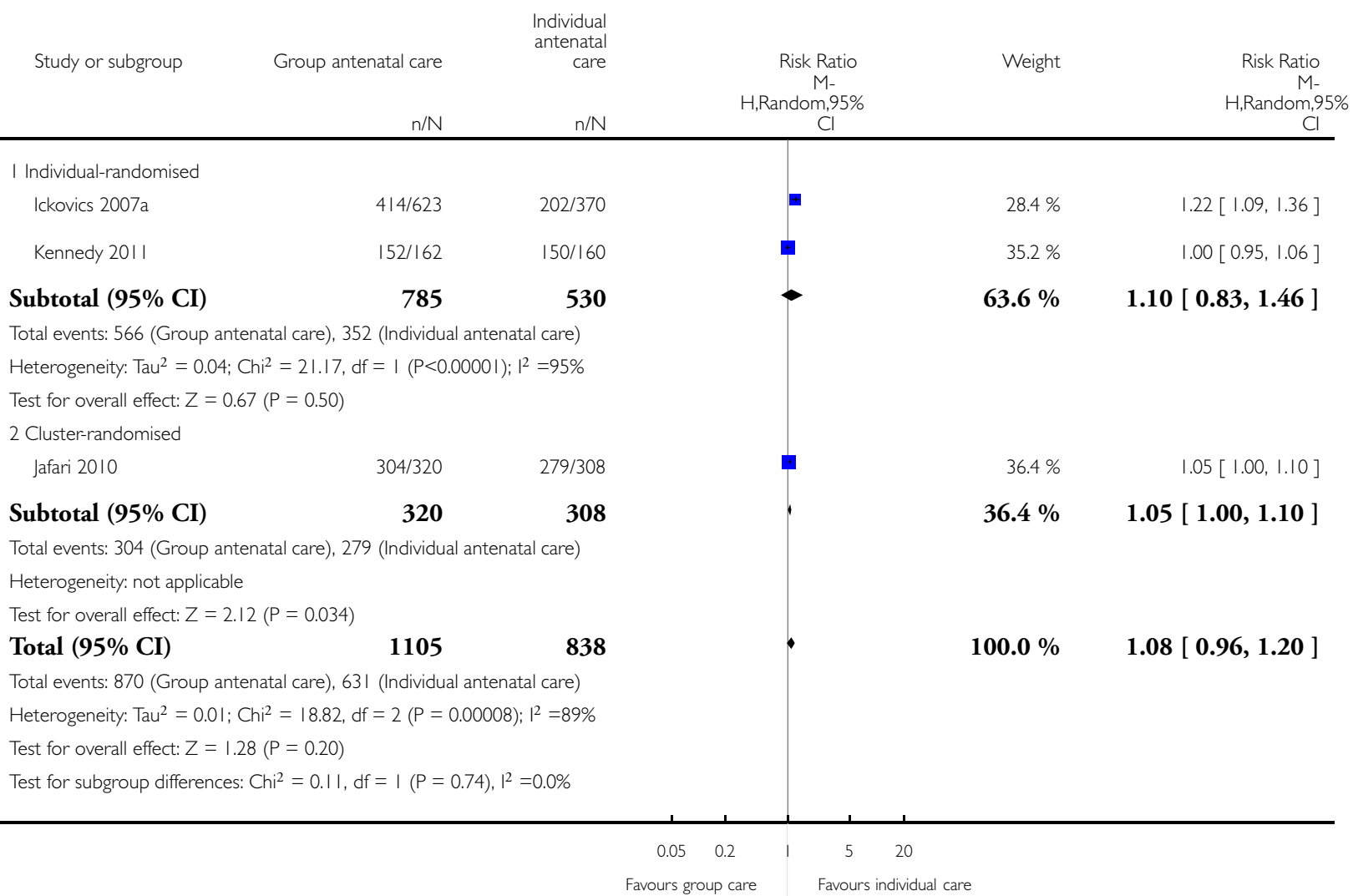


Analysis I.I I. Comparison I Group antenatal care versus individual antenatal care (adjusted data), Outcome I I Antenatal knowledge.

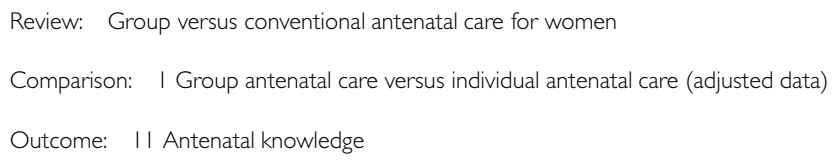

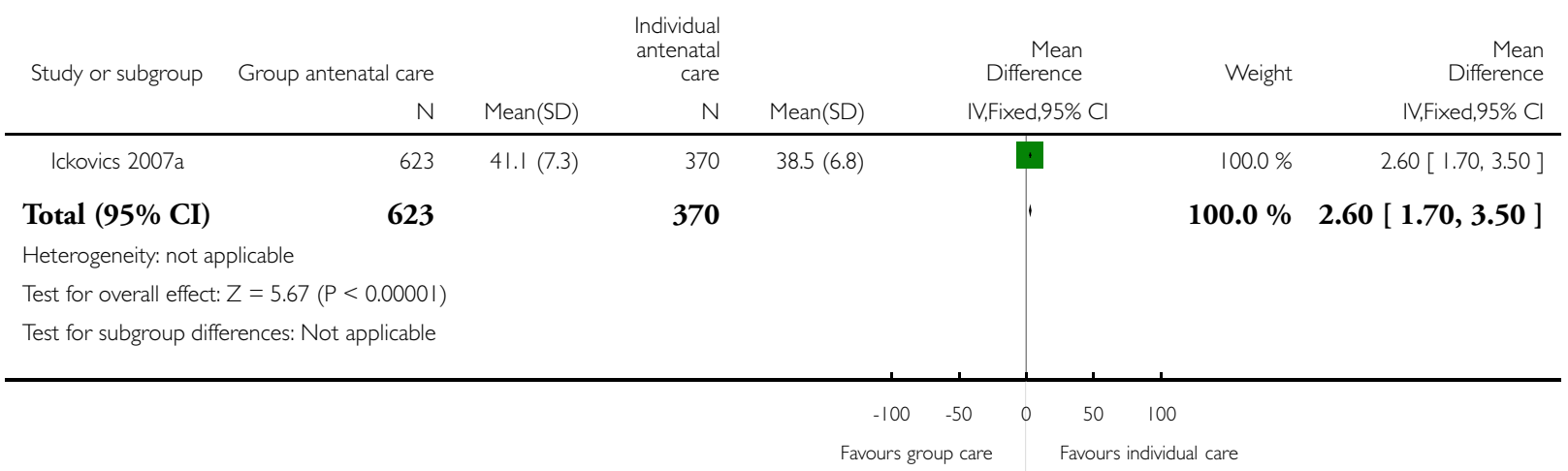

Analysis I.I2. Comparison I Group antenatal care versus individual antenatal care (adjusted data), Outcome 12 Antenatal distress.

Review: Group versus conventional antenatal care for women

Comparison: I Group antenatal care versus individual antenatal care (adjusted data)

Outcome: 12 Antenatal distress

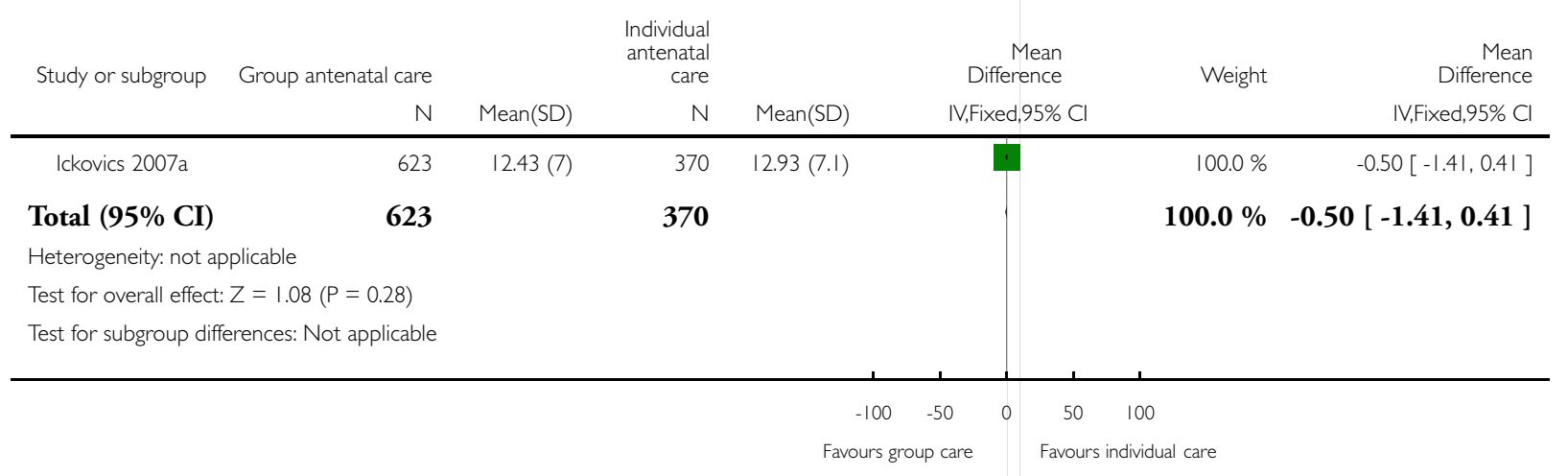


Analysis I.I3. Comparison I Group antenatal care versus individual antenatal care (adjusted data), Outcome 13 Readiness for labour and birth.

Review: Group versus conventional antenatal care for women

Comparison: I Group antenatal care versus individual antenatal care (adjusted data)

Outcome: 13 Readiness for labour and birth

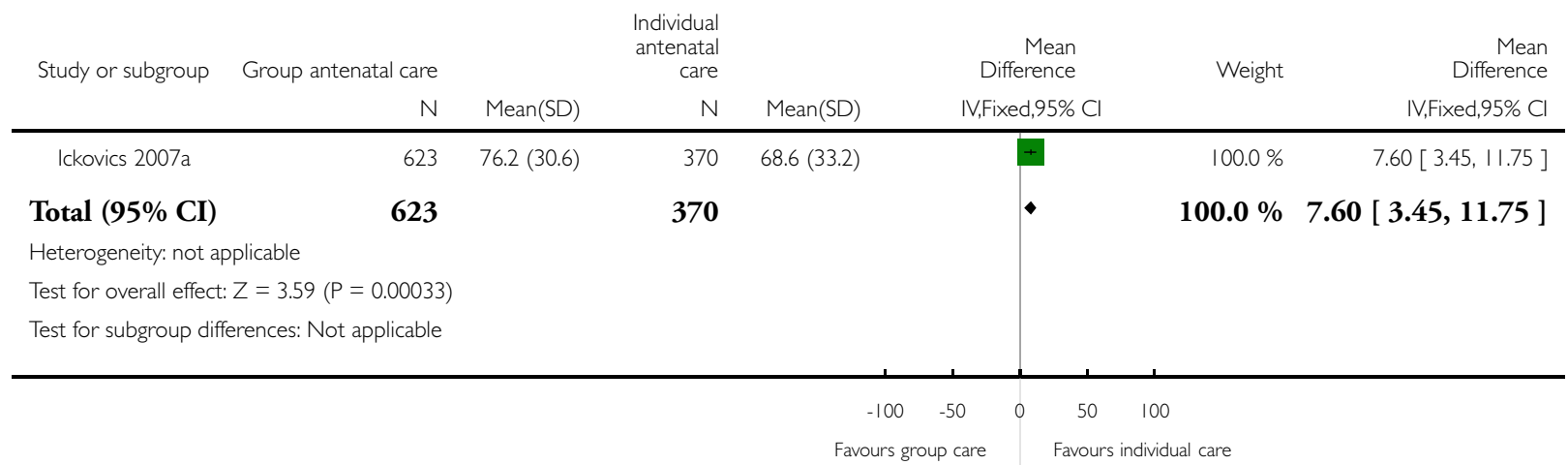

Analysis I.I4. Comparison I Group antenatal care versus individual antenatal care (adjusted data), Outcome 14 Readiness for infant care.

Review: Group versus conventional antenatal care for women

Comparison: I Group antenatal care versus individual antenatal care (adjusted data)

Outcome: 14 Readiness for infant care

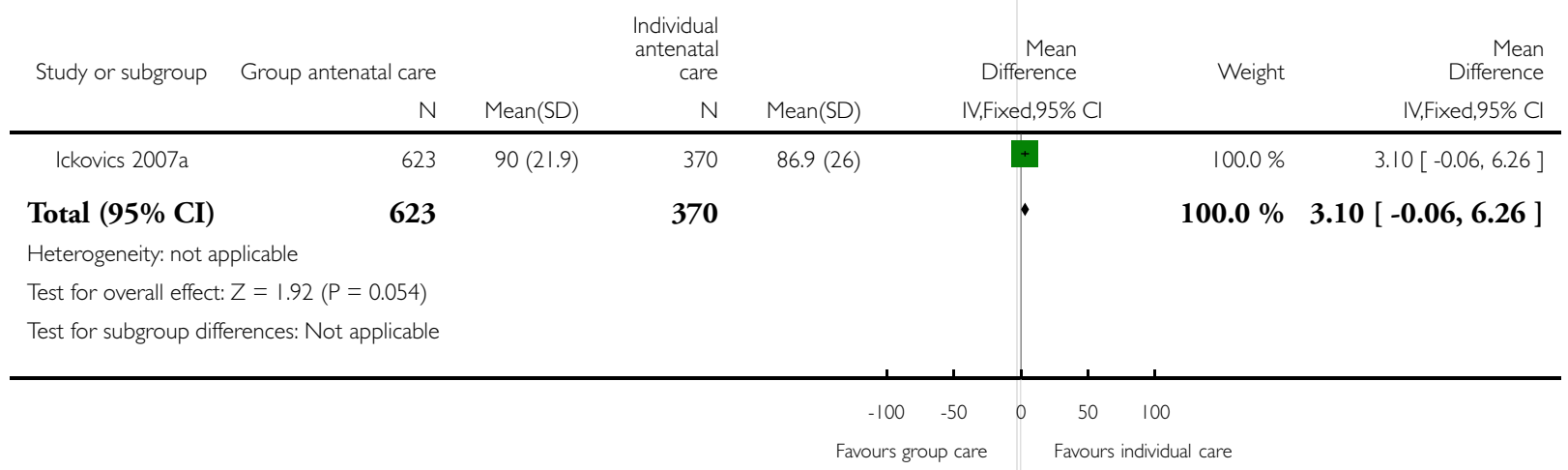


Analysis I.I5. Comparison I Group antenatal care versus individual antenatal care (adjusted data), Outcome I 5 Satisfaction with antenatal care.

Review: Group versus conventional antenatal care for women

Comparison: I Group antenatal care versus individual antenatal care (adjusted data)

Outcome: 15 Satisfaction with antenatal care

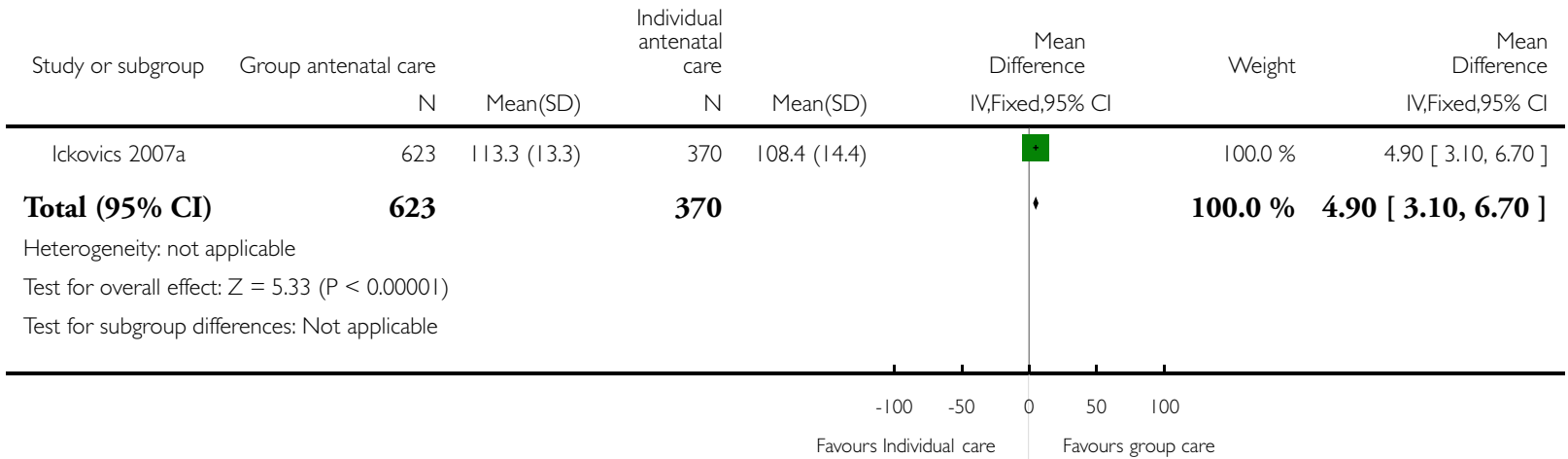

\section{Analysis I.16. Comparison I Group antenatal care versus individual antenatal care (adjusted data),} Outcome 16 Induction of labour.

Review: Group versus conventional antenatal care for women

Comparison: I Group antenatal care versus individual antenatal care (adjusted data)

Outcome: 16 Induction of labour

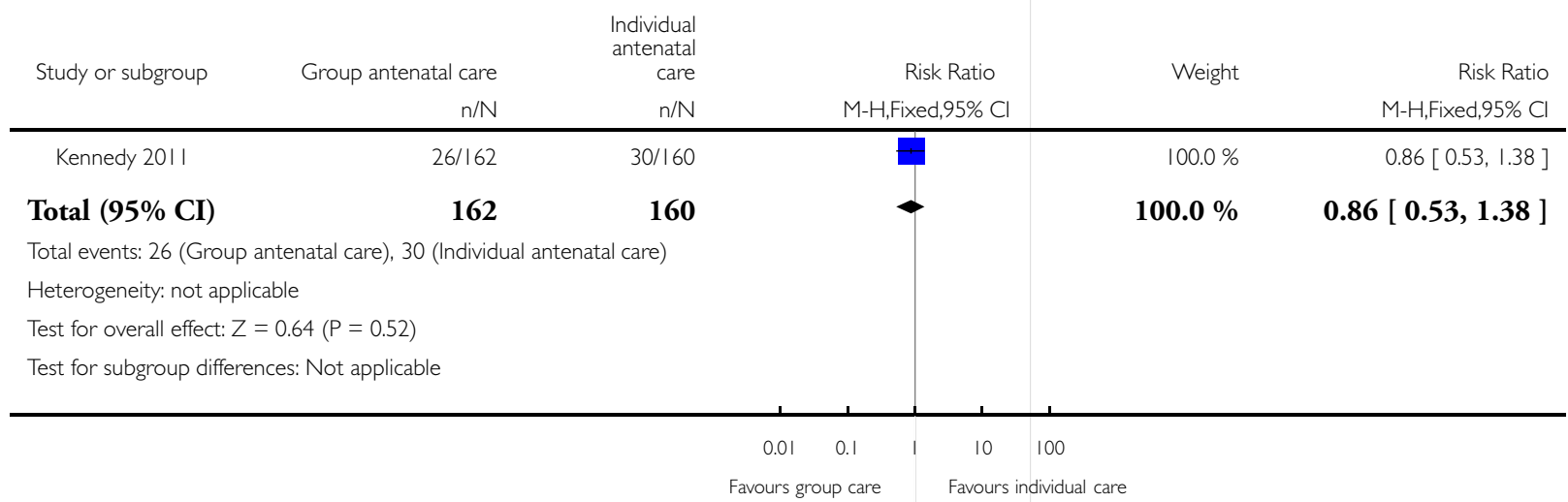


Analysis I.I7. Comparison I Group antenatal care versus individual antenatal care (adjusted data), Outcome 17 Augmentation using Syntocinon.

Review: Group versus conventional antenatal care for women

Comparison: I Group antenatal care versus individual antenatal care (adjusted data)

Outcome: 17 Augmentation using Syntocinon

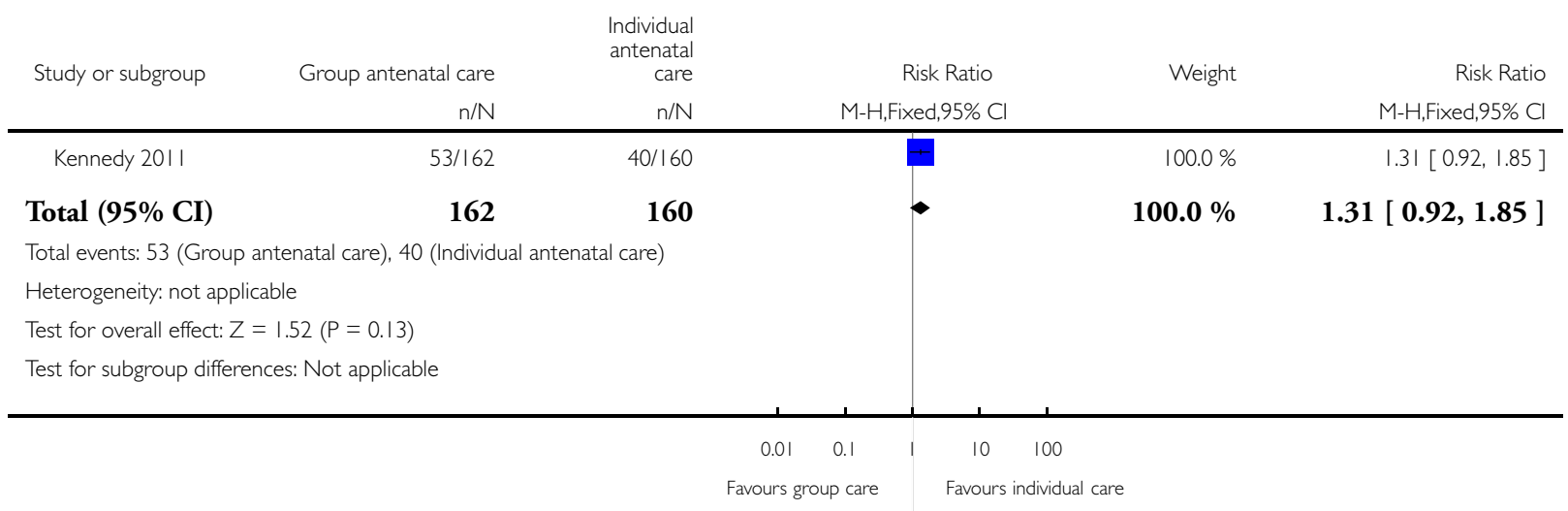

Analysis I.I8. Comparison I Group antenatal care versus individual antenatal care (adjusted data), Outcome 18 Other pain management.

Review: Group versus conventional antenatal care for women

Comparison: I Group antenatal care versus individual antenatal care (adjusted data)

Outcome: 18 Other pain management

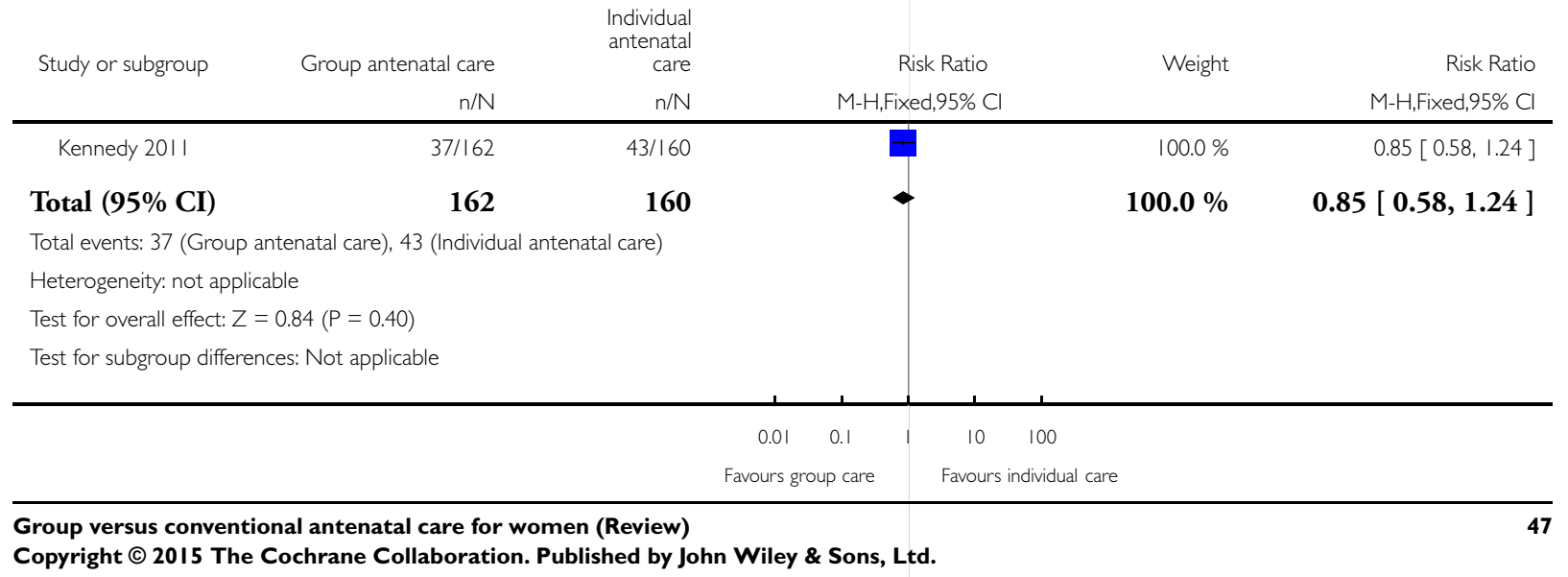


Analysis I.19. Comparison I Group antenatal care versus individual antenatal care (adjusted data), Outcome 19 Epidural.

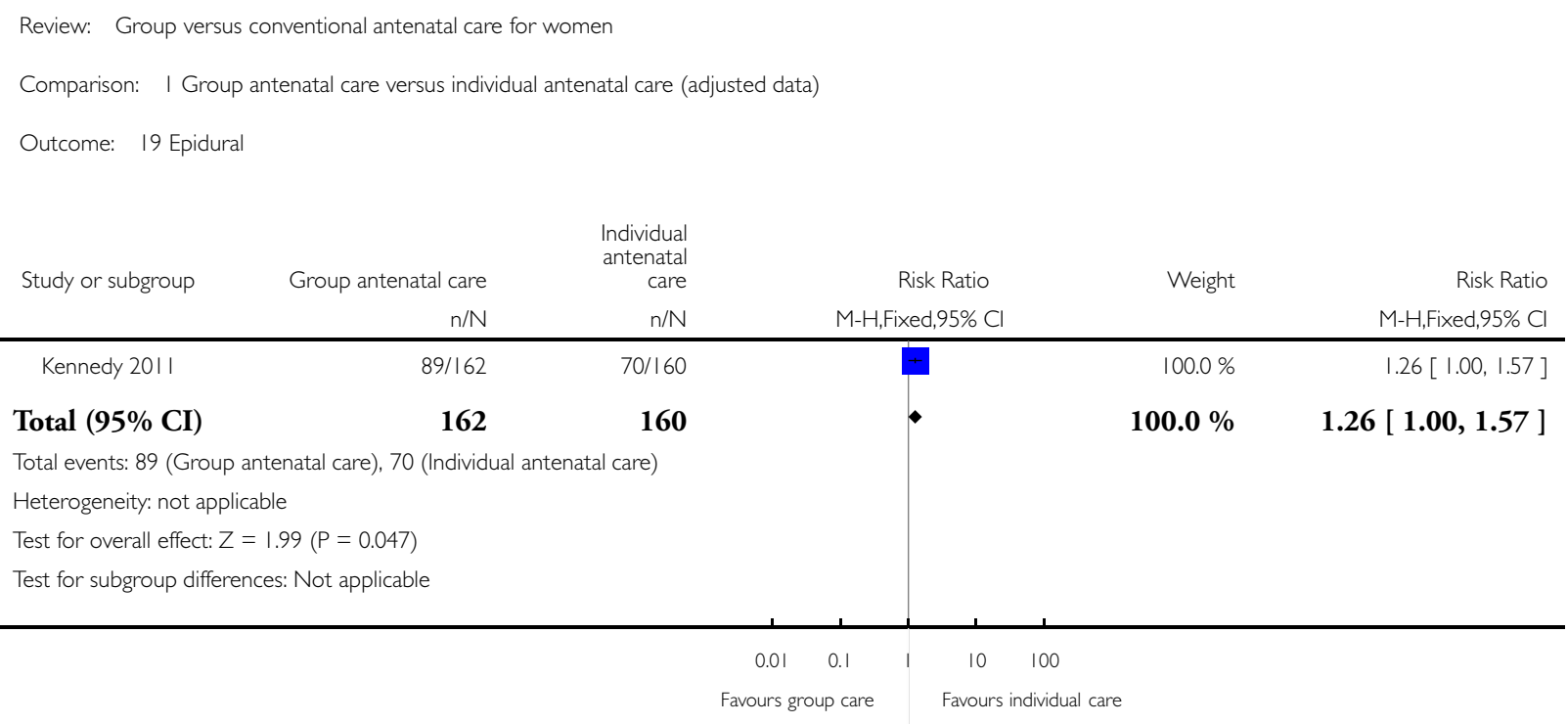


Analysis I.20. Comparison I Group antenatal care versus individual antenatal care (adjusted data), Outcome 20 Episiotomy.

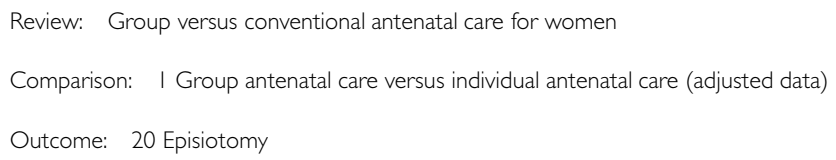

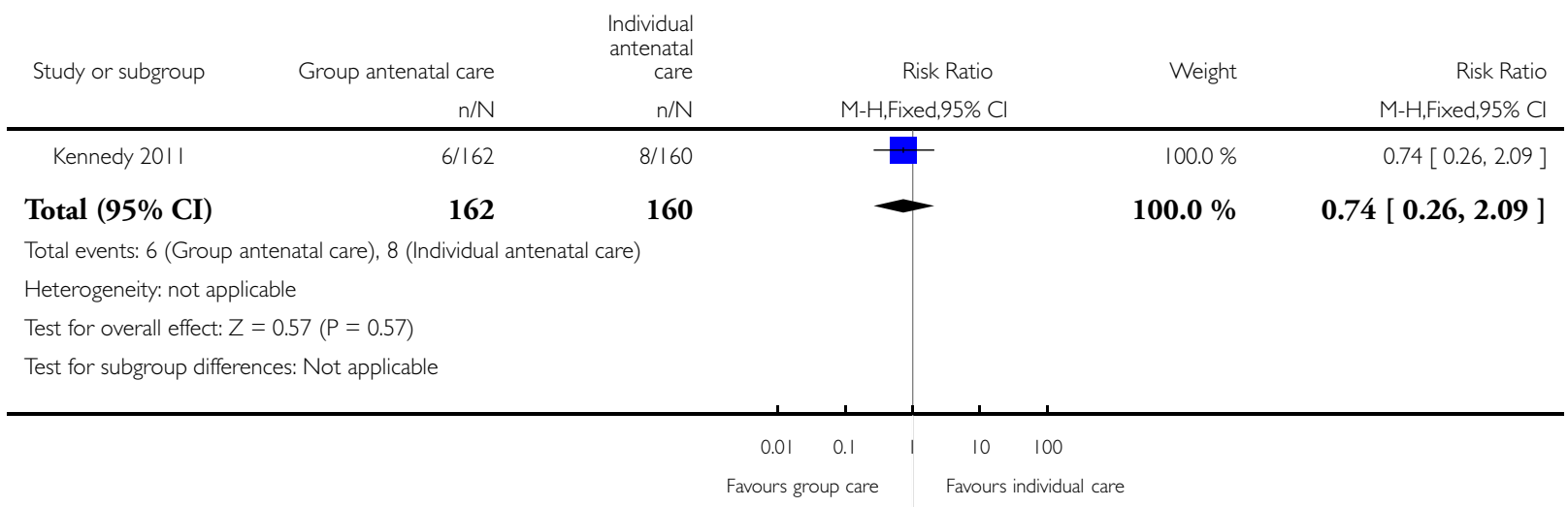

\section{Analysis I.2I. Comparison I Group antenatal care versus individual antenatal care (adjusted data),} Outcome 2I Spontaneous vaginal birth.

Review: Group versus conventional antenatal care for women

Comparison: I Group antenatal care versus individual antenatal care (adjusted data)

Outcome: 21 Spontaneous vaginal birth

\begin{tabular}{|c|c|c|c|c|c|c|c|}
\hline \multirow[t]{2}{*}{ Study or subgroup } & Group antenatal care & $\begin{array}{r}\text { Individual } \\
\text { antenatal } \\
\text { care }\end{array}$ & & & Risk Ratio & \multirow[t]{2}{*}{ Weight } & \multirow{2}{*}{$\begin{array}{r}\text { Risk Ratio } \\
\text { M-H,Fixed,95\% C }\end{array}$} \\
\hline & $\mathrm{n} / \mathrm{N}$ & $\mathrm{n} / \mathrm{N}$ & \multicolumn{3}{|c|}{ M-H,Fixed,95\% Cl } & & \\
\hline Kennedy 2011 & $94 / 162$ & $97 / 160$ & & & & $100.0 \%$ & $0.96[0.80,1.15]$ \\
\hline Total (95\% CI) & 162 & 160 & & & $\bullet$ & $100.0 \%$ & $0.96[0.80,1.15]$ \\
\hline \multicolumn{8}{|c|}{ Total events: 94 (Group antenatal care), 97 (Individual antenatal care) } \\
\hline \multicolumn{8}{|c|}{ Heterogeneity: not applicable } \\
\hline \multicolumn{8}{|c|}{ Test for overall effect: $Z=0.47(P=0.63)$} \\
\hline \multicolumn{8}{|c|}{ Test for subgroup differences: Not applicable } \\
\hline & & & 0.01 & 0.1 & 10 & 100 & \\
\hline \multicolumn{8}{|c|}{ Favours individual care } \\
\hline
\end{tabular}

Group versus conventional antenatal care for women (Review)

Copyright $\odot 2015$ The Cochrane Collaboration. Published by John Wiley \& Sons, Ltd. 


\section{Analysis I.22. Comparison I Group antenatal care versus individual antenatal care (adjusted data),} Outcome 22 Caesarean section.

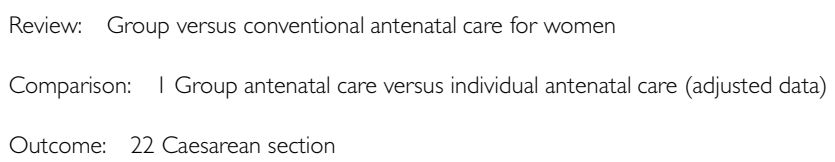

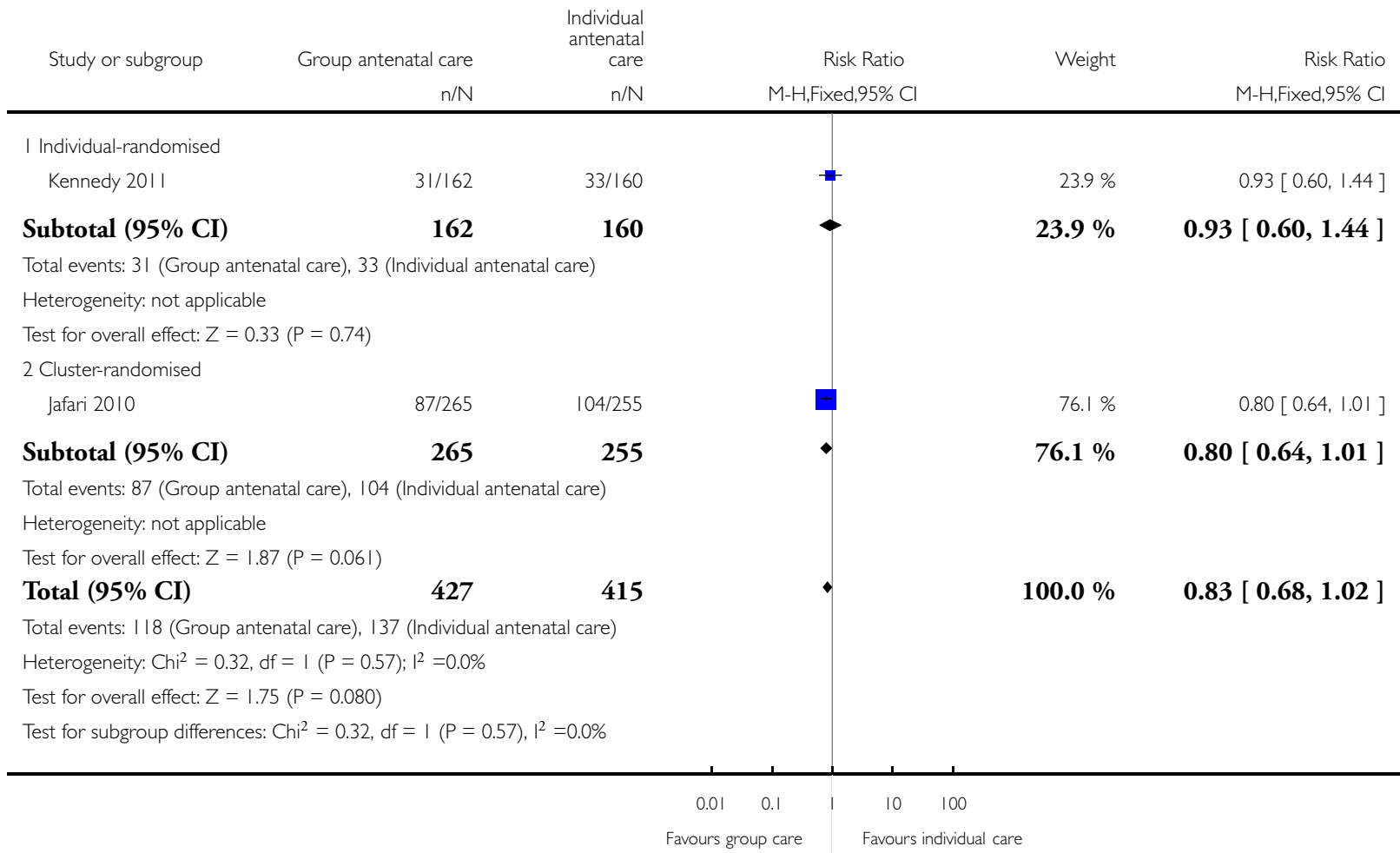


Analysis I.23. Comparison I Group antenatal care versus individual antenatal care (adjusted data), Outcome 23 Operative vaginal birth.

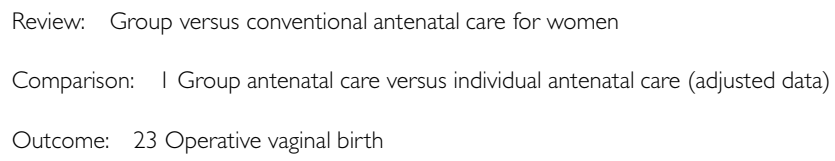

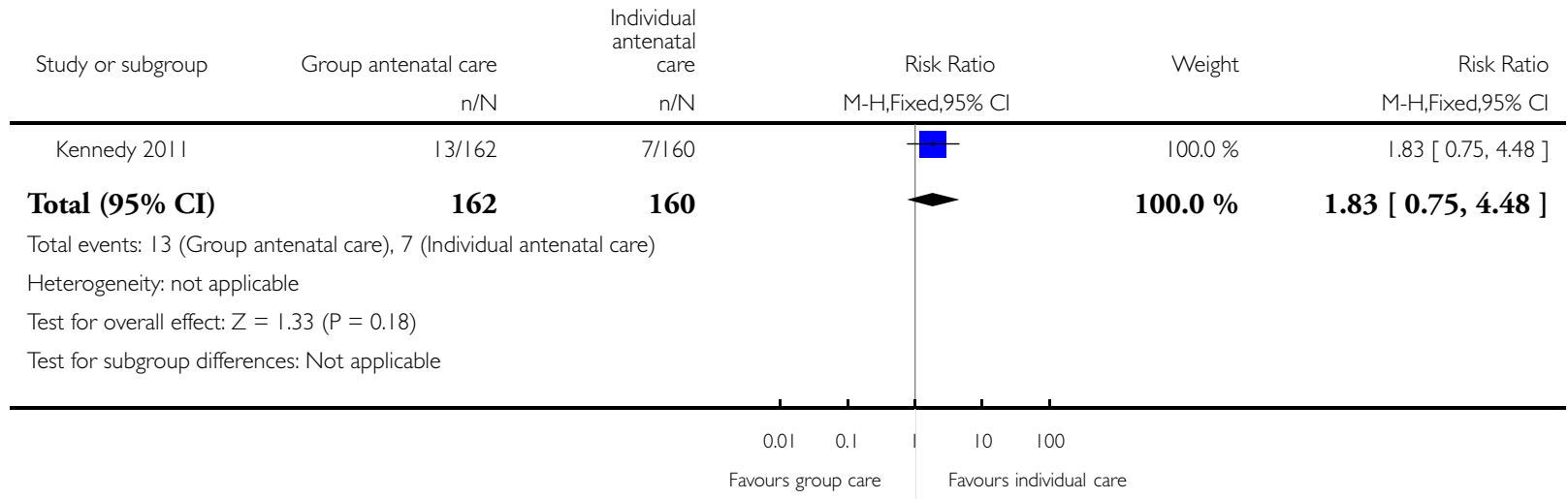

Analysis I.24. Comparison I Group antenatal care versus individual antenatal care (adjusted data), Outcome 24 Depression using component of CES-D instrument in third trimester.

Review: Group versus conventional antenatal care for women

Comparison: I Group antenatal care versus individual antenatal care (adjusted data)

Outcome: 24 Depression using component of CES-D instrument in third trimester

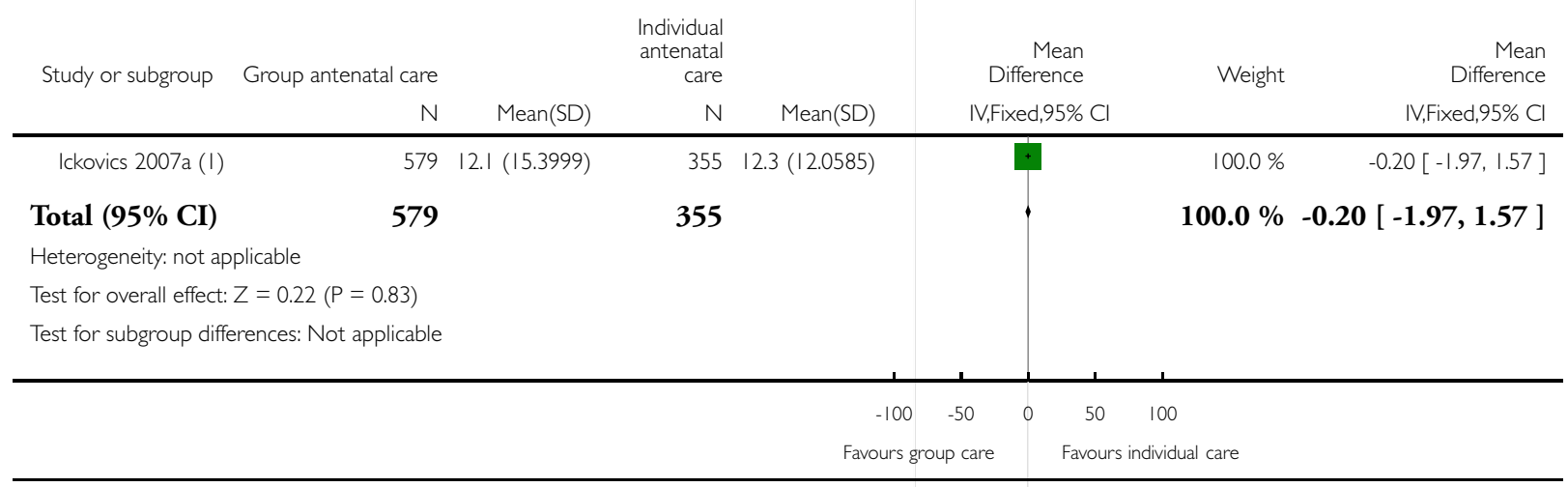


(I) Center for Epidemiologic Studies Depression Scale (CES-D)

Analysis I.25. Comparison I Group antenatal care versus individual antenatal care (adjusted data), Outcome 25 Depression using component of CES-D instrument 6 months' postpartum.

Review: Group versus conventional antenatal care for women

Comparison: I Group antenatal care versus individual antenatal care (adjusted data)

Outcome: 25 Depression using component of CES-D instrument 6 months' postpartum

\begin{tabular}{|c|c|c|c|c|c|c|c|}
\hline \multirow[t]{2}{*}{ Study or subgroup } & Group antenatal care & & $\begin{array}{r}\text { Individual } \\
\text { antenatal } \\
\text { care }\end{array}$ & & $\begin{array}{r}\text { Mean } \\
\text { Difference }\end{array}$ & \multirow[t]{2}{*}{ Weight } & \multirow{2}{*}{$\begin{array}{r}\text { Mean } \\
\text { Difference } \\
\text { IV,Fixed,95\% C }\end{array}$} \\
\hline & N & Mean(SD) & $N$ & Mean(SD) & IV,Fixed,95\% Cl & & \\
\hline Ickovics 2007a (I) & 491 & $9.73(14.403)$ & 296 & $9.8(11.011)$ & & $100.0 \%$ & $-0.07[-1.86,1.72]$ \\
\hline Total $(95 \% \mathrm{CI})$ & 491 & & 296 & & $\rightarrow$ & $100.0 \%$ & $-0.07[-1.86,1.72]$ \\
\hline \multicolumn{8}{|c|}{ Heterogeneity: not applicable } \\
\hline \multicolumn{8}{|c|}{ Test for overall effect: $Z=0.08(P=0.94)$} \\
\hline \multicolumn{8}{|c|}{ Test for subgroup differences: Not applicable } \\
\hline & & & & -20 & -10 & 20 & \\
\hline \multicolumn{8}{|c|}{ Favours group care $\quad$ Favours individual care } \\
\hline
\end{tabular}

(I) Center for Epidemiologic Studies Depression Scale (CES-D) 
Analysis I.26. Comparison I Group antenatal care versus individual antenatal care (adjusted data), Outcome 26 Depression using component of CES-D instrument 12 months' postpartum.

Review: Group versus conventional antenatal care for women

Comparison: I Group antenatal care versus individual antenatal care (adjusted data)

Outcome: 26 Depression using component of CES-D instrument 12 months' postpartum

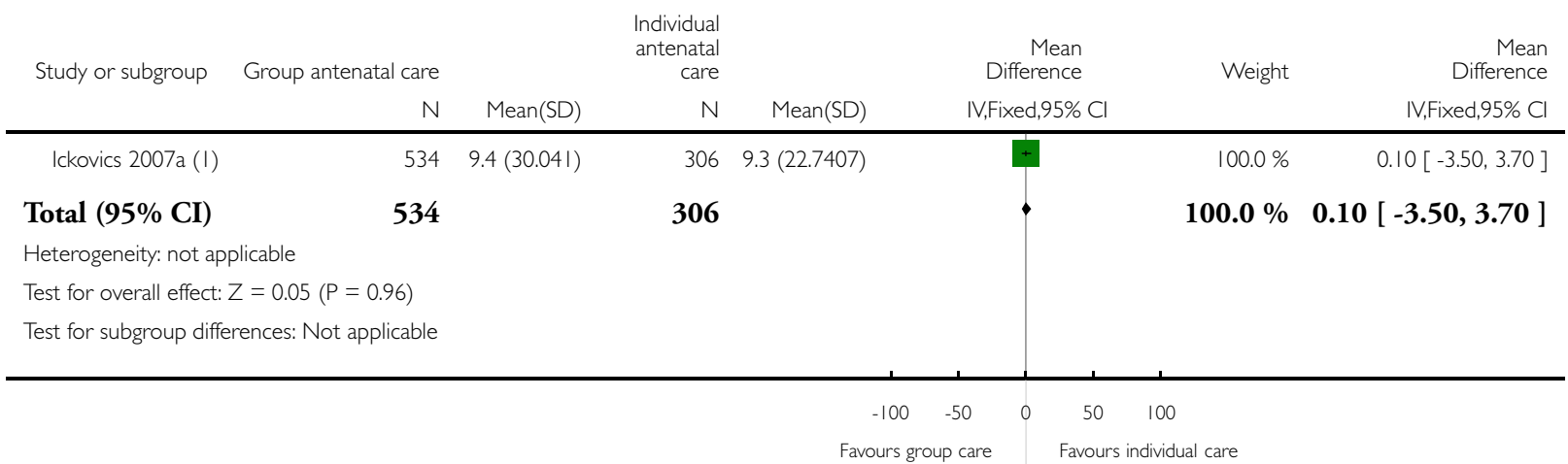

( I) Center for Epidemiologic Studies Depression Scale (CES-D)

Analysis I.27. Comparison I Group antenatal care versus individual antenatal care (adjusted data), Outcome 27 Stress using PSS at 6 months' postpartum.

Review: Group versus conventional antenatal care for women

Comparison: I Group antenatal care versus individual antenatal care (adjusted data)

Outcome: 27 Stress using PSS at 6 months' postpartum

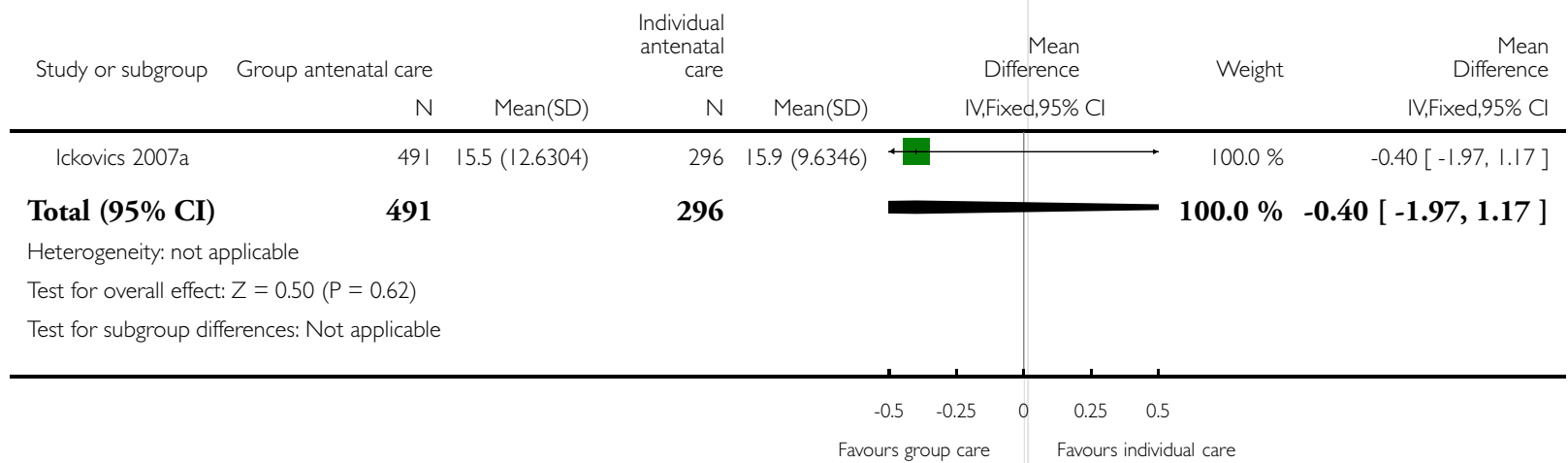


Analysis I.28. Comparison I Group antenatal care versus individual antenatal care (adjusted data), Outcome 28 Stress using PSS at 12 months' postpartum.

Review: Group versus conventional antenatal care for women

Comparison: I Group antenatal care versus individual antenatal care (adjusted data)

Outcome: 28 Stress using PSS at 12 months' postpartum

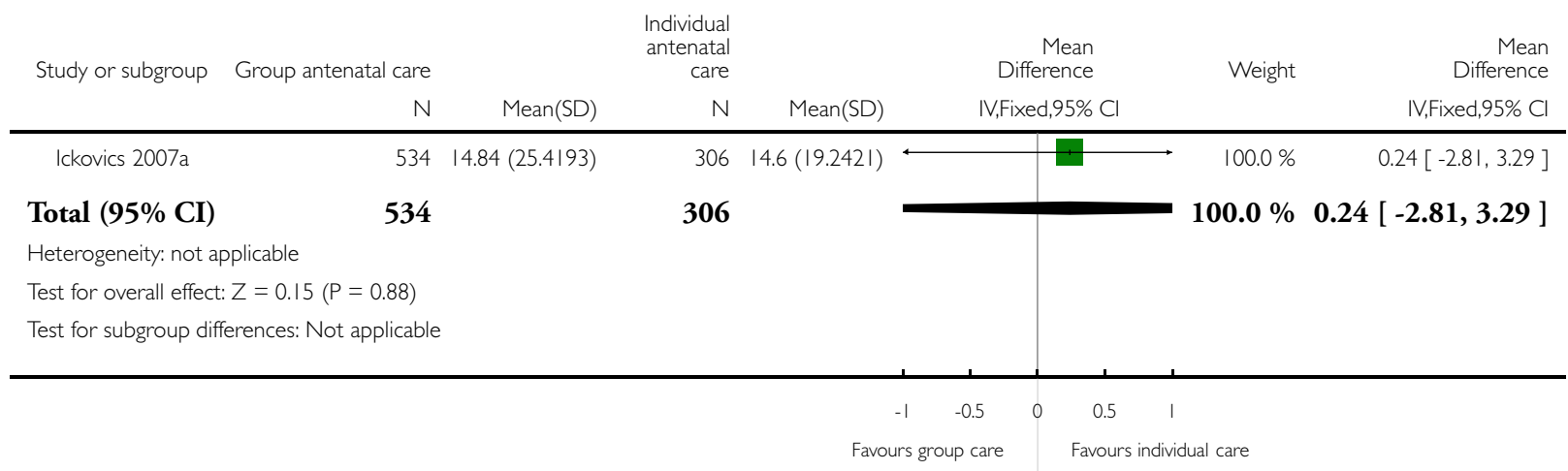

Analysis I.30. Comparison I Group antenatal care versus individual antenatal care (adjusted data), Outcome 30 Attendance at antenatal care (number of sessions).

Review: Group versus conventional antenatal care for women

Comparison: I Group antenatal care versus individual antenatal care (adjusted data)

Outcome: 30 Attendance at antenatal care (number of sessions)

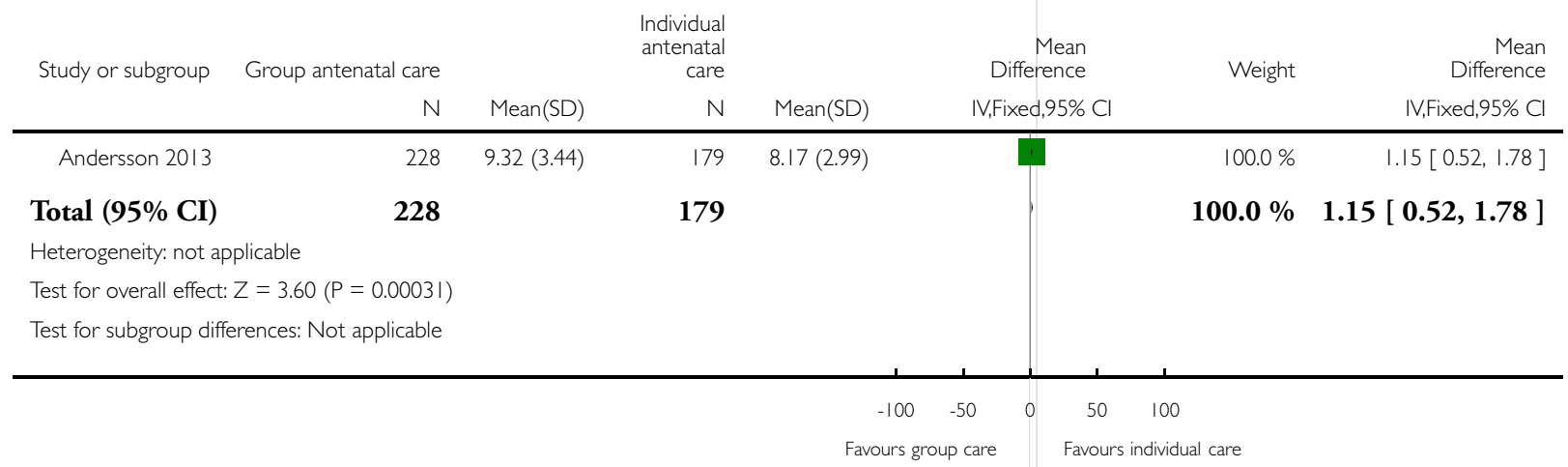


ADDITIONAL TABLES

Table 1. Adjustment of outcome data for effects of cluster randomisation

\begin{tabular}{|c|c|c|c|}
\hline Outcome & Cluster size and ICC & Original data: group care & Original data: conventional care \\
\hline Preterm birth & 47.43 cluster size. ICC 0.002 & $21 / 320$ & $30 / 308$ \\
\hline Gestational age & $\begin{array}{l}47.43 \text { cluster size. ICC } 0.0065 \text {. } \\
\text { No ICC was provided for gesta- } \\
\text { tional age; data were adjusted us- } \\
\text { ing the ICC for small-for-gesta- } \\
\text { tional age. Only the sample size } \\
\text { was adjusted }\end{array}$ & 320 & 308 \\
\hline Small-for-gestational age & 47.43 cluster size. ICC 0.0065 & $7 / 320$ & $9 / 308$ \\
\hline Birthweight & $\begin{array}{l}47.43 \text { cluster size. ICC } 0.0003 \text {. } \\
\text { No ICC was provided for birth- } \\
\text { weight; data were adjusted us- } \\
\text { ing the ICC for low birthweight. } \\
\text { Only the sample size was adjusted }\end{array}$ & 320 & 308 \\
\hline Low birthweight & 47.43 cluster size. ICC 0.0003 & $20 / 320$ & $28 / 308$ \\
\hline Apgar at 5 minutes & $\begin{array}{l}47.43 \text { cluster size. ICC } 0.0003 \text {. } \\
\text { No ICC was provided for Ap- } \\
\text { gar at } 5 \text { minutes; data were ad- } \\
\text { justed using the ICC for Apgar at } \\
1 \text { minute. Only the sample size } \\
\text { was adjusted }\end{array}$ & 320 & 308 \\
\hline Breastfeeding Initiation & $\begin{array}{l}\text { No relevant ICC was available; } \\
\text { data were not adjusted }\end{array}$ & $\mathrm{n} / \mathrm{a}$ & $\mathrm{n} / \mathrm{a}$ \\
\hline Caesarean section & $\begin{array}{l}47.43 \text { cluster size. ICC } 0.0044 \text {. } \\
\text { No ICC was provided for CS; } \\
\text { data were adjusted using the ICC } \\
\text { for elective CS }\end{array}$ & $105 / 320$ & $126 / 308$ \\
\hline Perinatal mortality & $\begin{array}{l}47.43 \text { cluster size. ICC }-0.00006 \text {. } \\
\text { Effect of the adjustment was zero }\end{array}$ & $7 / 320$ & $10 / 308$ \\
\hline
\end{tabular}




\section{WHAT'S NEW}

Last assessed as up-to-date: 31 October 2014.

\begin{tabular}{lll}
\hline Date & Event & Description \\
\hline 18 July 2014 & New citation required but conclusions have not changed & Review updated. \\
\hline 18 July 2014 & New search has been performed & $\begin{array}{l}\text { The search was updated and 2 new trials were in- } \\
\text { cluded (Andersson 2013; Jafari 2010). Four new trials } \\
\text { were excluded (Ford 2001; Koushede 2013; Leung 2012; } \\
\text { Salmela-Aro 2012). Methods were updated and a 'Sum- } \\
\text { mary of findings' table was added }\end{array}$ \\
\hline
\end{tabular}

\section{CONTRIBUTIONSOFAUTHORS}

For the 2014 review update, Christine Catling is the contact person. She is the guarantor and takes primary responsibility for the conduct of the review. She assisted in assessing papers for inclusion/exclusion, ensuring methodological quality and writing the results and discussion.

Nancy Medley adjusted and entered the cluster-randomised trial data, edited the text and prepared the 'Summary of findings' table.

Maralyn Foureur had a primary role in assessing papers for inclusion/exclusion and commented on drafts of the protocol and the review. Clare Ryan had a primary role in writing the protocol and in updating the literature review.

Alison Teate provided a clinical and practical perspective to the protocol development, and had a primary role in assessing papers for inclusion/exclusion.

Nicky Leap conceived of the review with Caroline Homer and provided a clinical and practical perspective.

Caroline Homer is responsible for conceiving of the review and designing and coordinating the protocol and the first published version of this review (Homer 2012).

\section{DECLARATIONSOF INTEREST}

A Teate, N Leap and CSE Homer have undertaken a pilot study of group antenatal care using CenteringPregnancy principles (Teate 2011). This was done in collaboration with Professor Schindler-Rising, the founder of Centering Pregnancy in the USA, and a coauthor and advisor for both trials in this review. Professor Schindler-Rising was not involved in this review, and her assistance did not influence the methodology or findings. Professor Foureur is also a co-author in ongoing research on group antenatal care for women with obesity (Davis 2012). 


\section{SOURCES OF SUPPORT}

\section{Internal sources}

- Faculty of Nursing, Midwifery and Health, UTS, Australia.

In-kind support to undertake the review

\section{External sources}

- UNDP-UNFPA-UNICEF-WHO-World Bank Special Programme of Research, Development and Research Training in Human Reproduction (HRP), Department of Reproductive Health and Research (RHR), World Health Organization, Switzerland.

\section{DIFFERENCES BETWEEN PROTOCOLANDREVIEW}

Primary and secondary outcomes were predetermined as described. Neonatal intensive care unit (NICU) admission was added as an outcome to the review.

\section{NDEX TERMS}

\section{Medical Subject Headings (MeSH)}

Infant, Low Birth Weight; Peer Group; Premature Birth [epidemiology]; Prenatal Care [*methods]; Randomized Controlled Trials as Topic

\section{MeSH check words}

Female; Humans; Infant, Newborn; Pregnancy 